UNIVERSIDADE FEDERAL DO RIO GRANDE DO NORTE

CENTRO DE CIÊNCIAS EXATAS E DA TERRA

PROGRAMA DE PÓS-GRADUAÇÃO EM GEODINÂMICA E GEOFÍSICA

\author{
DISSERTAÇÃO DE MESTRADO
}

\title{
PARÂMETROS DE FONTE DE MICROTERREMOTOS EM CASCAVEL - CE
}

Autor:

\section{IRENALDO PESSOA CÂNDIDO JÚNIOR}

\author{
Orientador: \\ Prof. Dr. Aderson Farias do Nascimento \\ DGEF / PPGG / UFRN \\ Co-Orientador: \\ Prof. Dr. Joaquim Mendes Ferreira \\ DGEF / PPGG / UFRN
}

Dissertação n ${ }^{\circ}$ 75/PPGG

Natal - RN, Abril de 2009 


\title{
PARÂMETROS DE FONTE DE MICROTERREMOTOS EM CASCAVEL - CE
}

Autor:

\section{IRENALDO PESSOA CÂNDIDO JÚNIOR}

\author{
Dissertação de Mestrado apresentada \\ em 17 de abril de 2009, para a \\ obtenção do título de Mestre em \\ Ciências da Terra, com área de \\ concentração em Geofísica, pelo \\ Programa de Pós-Graduação em \\ Geodinâmica e Geofísica da UFRN.
}

\section{Comissão Examinadora}

PROF. DR. ADERSON FARIAS DO NASCIMENTO (ORIENTADOR - DGEF / PPGG / UFRN) PROF. DR. WALTER EUGÊNIO DE MEDEIROS (DGEF / PPGG / UFRN)

PROF. DR. ANDRÉS REINALDO RODRIGUEZ PAPA (ON / MCT) 
Dedico este trabalho aos meus pais Maria Irene e Irenaldo Pessoa pela confiança e por me mostrarem todos os valores da vida. E aos meus irmãos: Ana Cristina,Moisés Firmino e Maria Aparecida. 


\section{AGRADECIMENTOS}

É muito difícil enumerar todos aqueles que, direta ou indiretamente, contribuíram para a realização deste trabalho. Porém, há pessoas e instituições que não podem deixar de serem citadas neste agradecimento.

Ao professor Dr. Aderson Farias do Nascimento, orientador, por ter acreditado em mim, pelo acompanhamento prestado no decorrer da elaboração desta dissertação e pelo seu companheirismo.

Ao professor Dr. Joaquim Mendes Ferreira, co-orientador, por sua contribuição e ajuda no decorrer deste trabalho.

Aos professores Dr. George Sand Leão Araújo de França e Dr. Carlos da Silva Vilar, pela amizade e, principalmente, pela paciência em responder minhas dúvidas.

Ao professor Dr. Walter Eugênio de Medeiros, pelas sugestões dadas no seminário de pesquisa I.

Ao professor Dr. Gilvan Luiz Borba, por ter me ajudado e orientado durante meu estágio docência.

Aos meus amigos, Paulo, Moacir, Leonardo, Daniel, Thiago, Gisele, Jéferson e Sânzia, pela amizade e por tornarem a graduação em Física mais descontraída.

Aos professores do DFTE, em especial, Rui Tertuliano, Claudionor Bezerra, Carlos Chesman e Osman, por terem contribuído na minha formação acadêmica.

Aos funcionários do DFTE, DGEF, DG e PPGG. 
Aos técnicos do Laboratório Sismológico da UFRN Carlos dos Anjos, Eduardo Alexandre e Regina Spineli, pela receptividade, amizade e por estarem sempre dispostos a ajudar.

Aos colegas de sala do PPGG, Flávio Lemos, Sandro Gomes, Maria Fernanda, Heleno Carlos, Francisco Eduardo, Bonnie Ives, Paulo Henrique, Aline Gomes e Rosana Nascimento, pelo companheirismo e momentos de descontração.

Ao Laboratório Sismológico, pelos dados cedidos para a realização deste trabalho.

Ao PPGG, pelos recursos materiais.

À Capes, pelo apoio financeiro, através da concessão de bolsa de mestrado.

Ao CNPq, FINEP e ao convênio Capes/Conselho Britânico pelos recursos que possibilitaram a aquisição dos dados utilizados. 


\section{RESUMO}

Nesta dissertação foi estudada a característica de ruptura dos sismos da cidade de Cascavel - CE, Nordeste Brasileiro. Localizada na borda da Bacia Potiguar, a cidade de Cascavel é uma das áreas intraplaca mais sismicamente ativa do Brasil. Neste município, no dia 20 de novembro de 1980, ocorreu o maior sismo de que se tem notícia no Nordeste, com magnitude igual 5,2m . A partir de 1989, essa região tem sido estudada instrumentalmente, sendo realizadas diversas campanhas com redes sismográficas. Desde o início do monitoramento até abril de 2008, foram registrados mais de 55.000 eventos.

Com os dados coletados por uma rede de seis estações digitais triaxiais em uma campanha realizada entre 29 de setembro de 1997 e 05 de março de 1998, foi realizado um estudo para determinar os parâmetros de fonte, ajustando-se os espectros de deslocamento de cada sismo no domínio da frequência.

A partir dos ajustes dos espectros de deslocamento, foi possível obter os valores da frequência de corte $\left(f_{c}\right)$ e da amplitude de longo período $\left(\Omega_{0}\right)$. Os parâmetros foram determinados a partir dos modelos de fonte propostos por Brune (1970) e Madariaga (1976) para 21 sismos $\left(0,7 \leq m_{b} \leq 2,1\right)$, obtendo-se as estimativas do raio da fonte $(r)$, momento sísmico $\left(M_{0}\right)$, stress drop estático $(\Delta \sigma)$, stress aparente $\left(\sigma_{a}\right)$, energia sísmica irradiada $\left(E_{S}\right)$ e magnitude momento $\left(M_{W}\right)$ de cada evento.

Foi observado que o stress drop e a razão entre a energia irradiada e o momento sísmico (stress aparente) aumentam com o incremento do momento e, consequentemente, com o valor da magnitude para a escala investigada. Assim como sugerido por Abercrombie (1995), neste trabalho também parece haver um quebra na relação de escala para sismos com magnitudes menores que três $\left(M_{W}<3,0\right)$, o que implica em um processo de ruptura diferente para terremotos grandes e pequenos.

Caso esta hipótese seja válida, os sismos analisados neste trabalho não são autosimilares. Assim, os eventos maiores tendem a irradiar mais energia por unidade de área que os menores.

Palavras-chave: sismicidade em Cascavel - CE, espectro de deslocamento, parâmetros de fonte, sismicidade intraplaca, relação de escala, auto-similaridade. 


\section{ABSTRACT}

In this dissertation it was studied the rupture characteristic of earthquakes of the Town of Cascavel - CE, Northeastern Brazil. Located on the border of the Potiguar Basin, the Town of Cascavel is one of the most seismically active intraplate areas in the country. In this town, on November $20^{\text {th }}, 1980$ a $5,2 m_{b}$ earthquake occurred. This was the largest earthquake ever reported in Northeast Brazil. Studies of this region using instruments were possible after 1989, with several campaigns being done using seismographic networks. From the beginning of the monitoring to April 2008 more than 55,000 events were recorded.

With the data collected by a network with six 3-components digital seismographic stations during the campaigns done from September $29^{\text {th }}, 1997$ to March $5^{\text {th }}, 1998$, estimates of source parameters were found fitting the displacement spectra in the frequency domain for each event.

From the fitting of the displacement spectra it was possible to obtain the corner frequency $\left(f_{c}\right)$ and long period amplitude $\left(\Omega_{0}\right)$. Source parameters were determined following Brune (1970) and Madariaga (1976) models. Twenty-one seismic events were analyzed $\left(0.7 \leq m_{b} \leq 2.1\right)$ in order to estimate the source dimension $(r)$, seismic moment $\left(M_{0}\right)$, static stress drop $(\Delta \sigma)$, apparent stress $\left(\sigma_{a}\right)$, seismic energy $\left(E_{S}\right)$ and moment magnitude $\left(M_{W}\right)$ for each of the events.

It was observed that the ratio between radiated seismic energy and moment seismic (apparent stress) increases with increasing moment and hence magnitude at the observed range. As suggested by Abercrombie (1995), also in this work there is a breakdown in the scaling for earthquakes with magnitudes smaller than three $\left(M_{W}<3.0\right)$, so that the rupture physics is different for larger events.

If this assumption is valid, the earthquakes analyzed in this work are not selfsimilar. Thus, larger events tend to radiated more energy per unit area than smaller ones.

Key Word: sismicity in Cascavel - CE, displacement spectra, source parameters, intraplate sismicity, scaling, self-similarity. 


\section{ÍNDICE}

AGRADECIMENTOS ..ii

RESUMO .iv

ABSTRACT ...v

ÍNDICE

LISTA DE FIGURAS ......................................................................................viii

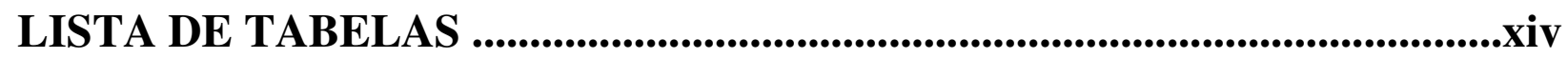

CAPÍTULO 1 -INTRODUÇÃO............................................................................ 1

1.1 Sismicidade na Borda da Bacia Potiguar ................................................ 1

1.2 Sismicidade em Cascavel - CE ................................................................. 5

1.3 Resumo da Geologia da Área ........................................................... 14

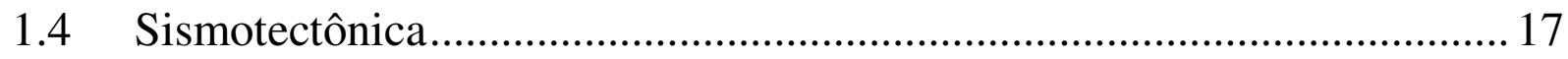

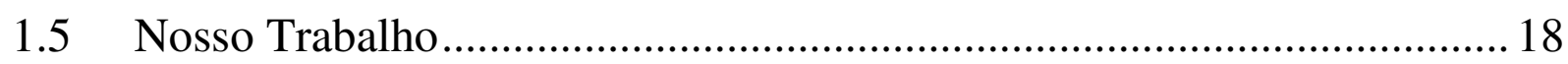

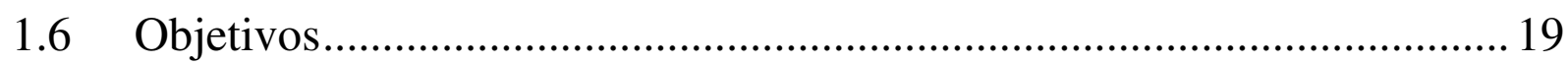

CAPÍTULO 2 -FONTE SÍSMICA ...................................................................... 21

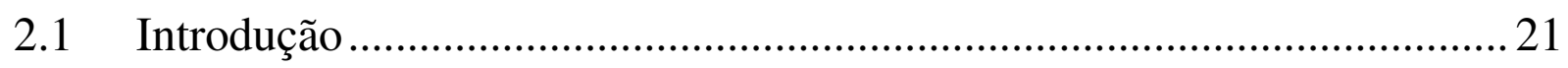

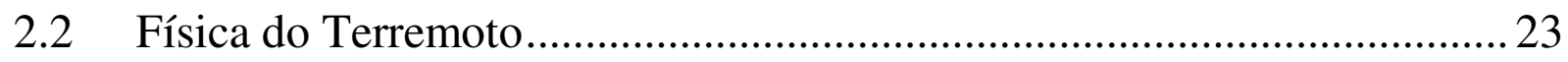

2.2.1 Parâmetros Estáticos e Dinâmicos do Terremoto.................................... 25

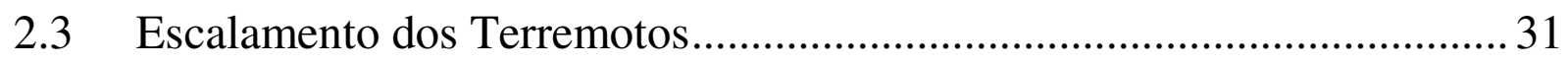

2.4 Como Estimar os Parâmetros de Fonte? ......................................................... 36

CAPÍTULO 3 -DADOS SISMOLOGICOS......................................................40

3.1 Aquisição e Seleção dos Dados ................................................................... 40

3.2 Remoção da Resposta do Equipamento .................................................... 44

CAPÍTULO 4 -METODOLOGIA........................................................................46

4.1 Análise Espectral ................................................................................... 46

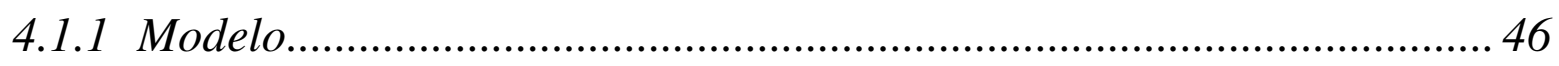


4.1.2 Análise Padrão no Domínio da Frequência ........................................... 47

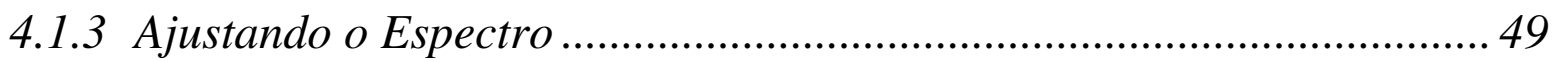

4.2 Energia Sísmica e Magnitude Momento MW ............................................ 51

CAPÍTULO 5 -RESULTADOS DOS PARÂMETROS DE FONTE.................55

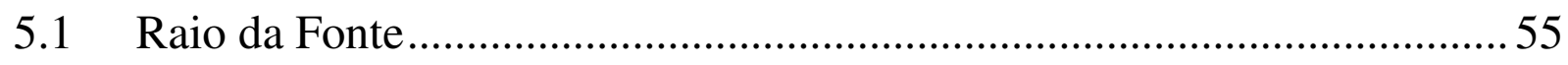

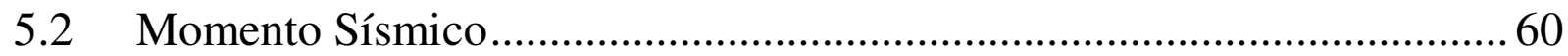

5.3 Momento Sísmico e Frequência de Corte .................................................66

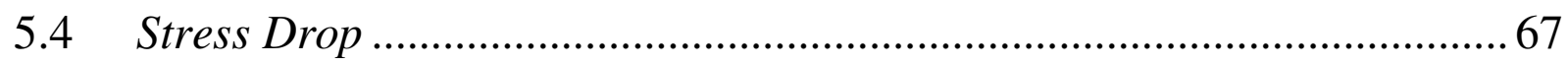

5.5 Energia Sísmica e Magnitude Momento MW ............................................ 71

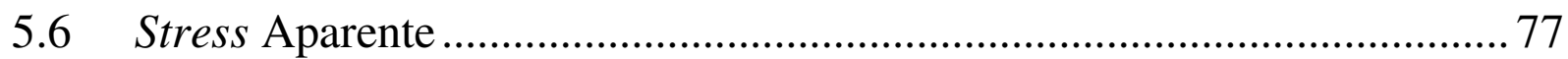

CAPÍTULO 6 -CONCLUSÕES E PERSPECTIVAS.......................................81

REFERÊNCIAS BIBLIOGRÁFICAS.............................................................84

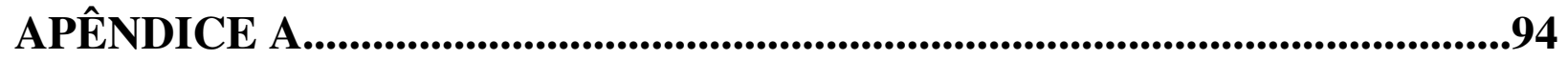

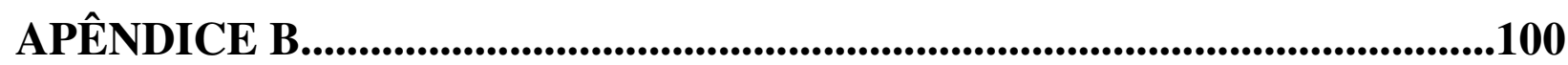

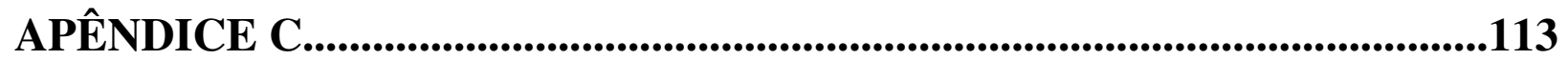




\section{LISTA DE FIGURAS}

Figura 1.1: Distribuição dos sismos com magnitude $\geq 2,0 m_{b}$ no Nordeste Brasileiro, as bolas cinzas indicam os epicentros dos sismos com o tamanho variando de acordo com a magnitude (Vilar et al., 2005).

Figura 1.2: Estrutura da Bacia Potiguar, principais reservatórios e alguns mecanismos focais determinados. Exceto para a Barragem do Açu, todos os outros círculos representam os epicentros de sismos naturais com magnitude $\geq 2,0 m_{b}$. As bolas de praia (beach balls) indicam os mecanismos focais: a) João Câmara (1987); b) Barragem do Açu (1995); c) Palhano (1998); d) Cascavel-Pacajus (1985) (Ferreira et al., 2008).

Figura 1.3: Nordeste Brasileiro: em cinza escuro está representado o contorno das principais bacias do nordeste, em azul estão os principais rios e o círculo branco destaca a região de estudo (modificado de Gomes, 2007).

Figura 1.4: Atividade sísmica na região de Cascavel - Pacajus no Ceará. Os quadrados azuis indicam as principais cidades. Os triângulos verdes denotam as estações usadas na campanha de 1989. Na campanha de 1993/1994 foram usadas as mesmas estações de 1989 mais as cinco estações indicadas pelos triângulos vermelhos, porém, no máximo operaram seis estações simultaneamente. A linha preta representa o canal de água e a área cinza representa as coberturas sedimentares da Bacia Potiguar (DNPM, 1984). A cruz marca o epicentro do evento de 1980, o qual foi obtido por registros históricos (modificado de Ferreira et al., 1998).

Figura 1.5: Distribuição do número de eventos sísmicos registrados pela estação CH8A, desde 16 de dezembro de 1993 até 12 de abril de 2008. Este histograma representa um total de 55.990 sismos.

Figura 1.6: Campanha 1996/1997: Os triângulos vermelhos representam as estações digitais. A estação analógica referida no texto, operou no mesmo lugar que a estação CH08 (modificado de Vilar, 2000). 
Figura 1.7: Campanha 1997/1998: os triângulos vermelhos representam as estações sismográficas, os quadrados azuis as principais cidades, a região cinza claro a Bacia Potiguar e a região branca o embasamento cristalino. $\mathrm{O}$ canal de água está representado pela linha preta.

Figura 1.8: Distribuição do número de eventos sísmicos registrados diariamente pela estação CH8A entre 29 de setembro de 1997 e 05 de março de 1998. O histograma foi construído com 4.536 sismos.

Figura 1.9: Mapa geológico simplificado da Província Borborema, o quadrado mostra a área de estudo (Modificado de Jardim de Sá, 1994).

Figura 1.10: Mapa geológico simplificado da área de estudo. Fonte: CPRMmapeamento geológico, Integrações Geológicas Regionais, escala 1:500.000 (2006).

Figura 2.1: Tipos de ondas sísmicas. As ondas $\mathrm{P}$ (a) e $\mathrm{S}$ (b), longitudinais e transversais, respectivamente, são os dois tipos mais importantes de propagação das ondas sísmicas. Junto à superfície da Terra, propagamse também as ondas superficiais: Rayleigh (c) e Love (d) (modificado de Texeira et al.,.2008).

Figura 2.2: Classificação esquemática dos vários tipos de eventos que podem gerar ondas sísmicas (modificado de Bormann et al., 2002).

Figura 2.3: Representação de uma fonte sísmica com simetria esférica, em que a energia acumulada em um ponto é irradiada em todas as direções (modificado de Lay \& Wallace, 1995).

Figura 2.4: Esquema do processo de ruptura quando ocorre um terremoto (modificado de Lay e Wallace, 1995).

Figura 2.5: A figura representa um par de forças e um duplo-binário. O par de forças são pontos de forças opostas separadas por uma pequena distância. Um duplo-binário é um conjunto de pares de forças complementares, de forma que nenhum torque resultante seja produzido (modificado de Shearer, 1999)

Figura 2.6: Relação entre o deslocamento e a velocidade do campo-próximo (a), campo-distante (b) e o correspondente espectro de amplitude (c). O momento sísmico $M_{0}$ é proporcional à área achurada sob a curva de 
deslocamento do campo-distante. A figura (c) representa o espectro de amplitude (modificado de Prieto, 2007).

Figura 2.7: Variação do esforço em um ponto na falha como função do deslize, baseado no modelo de enfraquecimento do deslize. Este modelo explica a partição da energia durante a ruptura e a relação entre a energia irradiada $\mathrm{E}_{\mathrm{S}}$ e o stress drop $\Delta \sigma$. O esforço friccional $\sigma_{f}(\mathrm{~s})$ está representado pela curva espessa. Esta figura representa uma unidade da falha, o comportamento do esforço pode ser diferente em várias regiões da falha (modificado de Prieto, 2007).

Figura 2.8: Comparação entre os parâmetros estático e dinâmicos da fonte. Por simplicidade, foi considerado $\sigma_{\mathrm{p}}=\sigma_{0}$. Note que enquanto o stress drop depende apenas do esforço inicial e final, a energia sísmica irradiada $E_{S}$ é uma função do esforço friccional $\sigma_{f}(\mathrm{~s})$ (curva mais espessa) durante o processo de ruptura (modificado de Prieto, 2007).

Figura 2.9: Relação do stress aparente com a magnitude e o momento sísmico para alguns estudos (Prieto, 2007).

Figura 2.10: Auto-similaridade. A figura superior mostra dos terremotos que diferem na área por um fator $b$. No meio estão alguns parâmetros que dependem da dimensão $\mathrm{L}$ e como eles escalam com b para os terremotos que possuem a mesma física de ruptura. A figura inferior mostra o pulso deslocamento do campo-distante, em que a largura é aumenta por um fator $b$ e altura por $b^{2}$, de forma que a energia é aumentada por $b^{3}$. Observe que a razão energia/momento permanece constante (modificado de Walter et al., 2006).

Figura 2.11: Modelos de ruptura para terremotos grandes e pequenos. Por simplicidade foi considerado $\sigma_{\mathrm{p}}=\sigma_{0}$. A linha espessa representa o esforço friccional $\sigma_{\mathrm{f}}$. Devido à ruptura, o esforço inicial $\sigma_{0}$ decai até o esforço final $\sigma_{1}$ com o aumento do deslize D. a) No modelo da autosimilaridade, a energia irradiada $\mathrm{E}_{\mathrm{S}}$ aumenta como função do deslize $\mathrm{D}$; b) neste caso, a energia de fratura varia com o deslize $\mathrm{D}$ assim, $\mathrm{E}_{\mathrm{S}}$ não escala proporcionalmente como uma função de $\mathrm{D}$, o que implica numa 
dependência do stress aparente $\sigma_{\mathrm{a}}$ com a magnitude; c) no modelo de lubrificação da falha de Kanamori \& Heaton (2000) o esforço friccional decresce como no modelo da auto-similaridade até um certa distância quando, então, decresce ainda mais, gerando um alto stress drop e irradiando muito mais energia (modificado de Prieto, 2007).

Figura 2.12: Um sismograma pode ser representado pela convolução do sinal emitido pela fonte com os operadores que representam os efeitos da estrutura da Terra e do instrumento.

Figura 3.1: O mapa representa a Bacia Potiguar e o embasamento cristalino. Os quadrados azuis denotam as principais cidades e os triângulos vermelhos são as estações usadas neste estudo. Os círculos brancos representam os epicentros dos sismos usados para obter os parâmetros de fonte.

Figura 3.2: a) Registro do sismo65 na estação $\mathrm{CH} 08$ (canal Norte). b) O mesmo sismo após a resposta do equipamento ter sido removida e realizada a integração no tempo.

Figura 4.1: Representação do espectro de deslocamento de um sismo plotado num gráfico log-log. A reta vertical representa a frequência de corte, a qual separa o espectro em duas regiões conhecidas como assintota de baixas e altas frequências.

Figura 4.2: Dado antes do ajuste. a) $\mathrm{O}$ intervalo da onda $\mathrm{S}$ utilizado para determinar os parâmetros de fonte está representado pela linha vermelha. b) Intervalo anterior após ter a resposta do equipamento removida e ser integrado no tempo. c) Espectro de deslocamento do intervalo da onda $\mathrm{S}$ após aplicar a Transformada de Fourier.

Figura 4.3: a) $\mathrm{O}$ intervalo da onda $\mathrm{S}$ utilizado para determinar os parâmetros de fonte está representado pela linha vermelha. b) Intervalo anterior após ter a resposta do equipamento removida e ser integrado no tempo. c) Espectro de deslocamento do intervalo da onda S (linha azul) após aplicar a Transformada de Fourier e ajustar o espectro (linha vermelha) através da equação (4.1), obtendo a frequência de corte.

Figura 4.4: Ilustração da relação entre o espectro da fonte (após corrigir todos os efeitos de propagação e outros efeitos da fonte) e os parâmetros estáticos 
e dinâmicos. O momento sísmico $\mathbf{M}_{0}$ e a frequêcia de corte $f_{\mathrm{c}}$ podem ser relacionados ao espectro de deslocamento (esquerda). A energia sísmica está relacionada à área sob o espectro da velocidade quadrática (direita) (Modificado de Prieto, 2007).

Figura 4.5: Espectro de velocidade quadrática do sismo65, componente Norte. A energia sísmica é obtida integrando este espectro.

Figura 5.1: Variação nos valores dos raios da fonte dos 21 sismos utilizados neste trabalho. Os raios foram obtidos a partir da equação (4.3) usando o Modelo de Brune. A maior variação ocorreu no sismo69, com uma diferença de 46 m entre o valor máximo (CH13) e o mínimo (CH11).

Figura 5.2: Variação nos valores dos raios da fonte dos 21 sismos utilizados neste trabalho. Os raios foram obtidos a partir da equação (4.3) usando o Modelo de Madariaga. A maior variação ocorreu no sismo69, com uma diferença de $26 \mathrm{~m}$ entre o valor máximo e o mínimo.

Figura 5.3: Momento Sísmico versu Raio da Fonte para diversos trabalhos, os números $(107,38,98,109,123,143)$ denotam os sismos usados por Tomic (2004) para obter os parâmetros de fonte (modificado de Tomic, 2004)

Figura 5.4: Momento Sísmico versus Raio da Fonte (Modelo de Brune). O momento sísmico foi obtido da equação (4.2) e o raio da fonte da equação (4.3). Os símbolos coloridos representam os resultados de cada estação. As linhas transversais são valores de stress drop constante.

Figura 5.5: Momento Sísmico versus Raio da Fonte (Modelo de Madariaga). O momento sísmico foi obtido da equação (4.2) e o raio da fonte da equação (4.3). Os símbolos coloridos representam os resultados de cada estação. As linhas transversais são valores de stress drop constante.

Figura 5.6: Momento Sísmico Médio versus Raio Médio. As linhas transversais representam valores de stress drop constante.

Figura 5.7: Relação entre o momento sísmico e a frequência de corte. Aqui foi encontrado que $M_{0} \propto f_{c}^{-2,5}$ representada pela linha vermelha. A linha azul representa a relação $M_{0} \propto f_{c}^{-3,0}$ 
Figura 5.8: Stress Drop Médio versus Momento Sísmico Médio. A figura mostra um aumento no valor do stress drop com o aumento do momento sísmico, assim há uma quebra na relação de escala. .70

Figura 5.9: Energia Sísmica versus Momento Sísmico. A energia foi estimada a partir da equação (4.5), é possível perceber a dependência deste parâmetro com o momento sísmico e, conseqüentemente, com a magnitude.

Figura 5.10: Energia Sísmica Média versus Momento Sísmico Médio. A energia aumenta com o incremento do momento sísmico.

Figura 5.11: Comparação entre a magnitude $m_{b}$ e a magnitude momento $M_{W}$ estimada a partir do momento sísmico. É possível observar uma boa correlação entre as duas escalas.

Figura 5.12: Stress Aparente versus Momento Sísmico. A figura mostra um aumento no valor do stress aparente com o aumento do momento sísmico. Assim há uma quebra na relação de escala.

Figura 5.13: Stress Aparente Médio versus Momento Sísmico Médio. A figura mostra um aumento no valor do stress aparente com o aumento do momento sísmico 


\section{LISTA DE TABELAS}

Tabela 1.1: Principais sismos com magnitudes $\geq 4,0 m_{b}$ e intensidade (MM) $\geq$ VI ocorridos na borda da Bacia Potiguar desde 1968 segundo Ferreira (1997). RBGf denota o Boletim Sísmico da Revista Brasileira de Geofísica.

Tabela 1.2: Eventos ocorridos na região de Cascavel - CE, com magnitude $\geq 3,0 m_{b}$. Obtidos tanto historicamente como instrumentalmente. Fonte: Boletim Sísmico Brasileiro.

Tabela 3.1: Coordenadas das estações sismográficas obtidas pelo GPS.

Tabela 3.2: Localização dos 21 sismos usados neste trabalho. Também está incluída a magnitude de cada evento, bem como o dia em cada um aconteceu.

Tabela 5.1: Raio da fonte obtido através da equação (4.3) utilizando o modelo de fonte proposto por Brune (1970). Na tabela acima não foi obtido nenhum valor para a estação CH09, pois não foi possível ajustar os seus espectros de deslocamento.

Tabela 5.2: Raio da fonte obtido através da equação (4.3) utilizando o modelo de fonte proposto por Madariaga (1976). Na tabela acima não foi obtido nenhum valor para a estação CH09, pois não foi possível ajustar os seus espectros de deslocamento.

Tabela 5.3: Momento sísmico obtido através da equação (4.2). Na tabela acima não foi obtido nenhum valor para a estação $\mathrm{CH09}$, pois não foi possível ajustar os seus espectros.

Tabela 5.4: Stress drop obtido através da equação (2.5) utilizando o modelo de fonte proposto por Brune (1970). Na tabela acima não foi obtido nenhum valor para a estação $\mathrm{CH} 09$, pois não foi possível ajustar os seus espectros.

Tabela 5.5: Stress drop obtido através da equação (2.5) utilizando o modelo de fonte proposto por Madariaga (1976). Na tabela acima não foi obtido nenhum valor para a estação $\mathrm{CH} 09$, pois não foi possível ajustar os seus espectros. 
Tabela 5.7: Os valores de $M_{W}$ foram obtidos pela média dos valores de cada estação calculados através da equação (4.6). Os valores de $m_{b}$ foram obtidos pela duração do evento, através das equações (3.1) e (3.2).

Tabela 5.8: Stress aparente obtido através da equação (2.8) utilizando as estimativas da energia sísmica e do momento sísmico. 


\section{CAPÍTULO 1 - INTRODUÇÃO}

Este capítulo traz uma abordagem sobre a sismicidade na borda da Bacia Potiguar e sobre a sismicidade e a geologia região de estudo. Também é feita uma introdução sobre o tipo de trabalho desenvolvido e seus objetivos.

\subsection{Sismicidade na Borda da Bacia Potiguar}

A atividade sísmica no Nordeste se destaca em relação ao restante do Brasil. Isto se deve ao fato dos sismos ocorrerem com certa frequência e de já terem sido registrados alguns com magnitude $>5,0 m_{b}$. A maioria destes eventos está localizada em áreas habitadas, principalmente nos estados do Ceará e Rio Grande do Norte. Segundo alguns autores (Berrocal et al., 1984; Assumpção, 1992 e 1998), o Nordeste Brasileiro é considerado uma das regiões de maior atividade sísmica intraplaca do País.

A maioria dos eventos registrados nesta região encontra-se em torno da Bacia Potiguar (Ferreira et al., 1998). O primeiro sismo de que se tem conhecimento, a partir de dados históricos, aconteceu em 1808 próximo à cidade de Açu, com magnitude em torno de 4,8 $m_{b}$ (como nesta época ainda não havia monitoramento com estações sísmicas, a magnitude foi estimada pelos relatos do que havia sido sentido na área; Ferreira \& Assumpção, 1983) e intensidade VI (escala MM - Escala de Mercalli Modificada).

Desde 1968 têm ocorrido vários enxames de sismos com magnitude acima de 4,0 $m_{b}$ (Tabela 1.1), muitos deles com intensidades acima de VII MM (Ferreira \& Assumpção, 1983). Destes enxames, destacam-se três sismos com magnitude maior que ou igual a 5,0 $m_{b}$ : Pacajus (1980; 5,2 $m_{b}$ ) e João Câmara (1986 e 1989; 5,1 e 5,0 $m_{b}$, respectivamente), sendo o primeiro, o maior sismo já registrado no Nordeste (Ferreira \& Assumpção, 1983). A Figura 1.1 mostra a distribuição dos sismos com magnitude $\geq 2,0$ $m_{b}$ (magnitude de ondas de corpo) no Nordeste do Brasil.

A sismicidade em torno da Bacia Potiguar tem duas características importantes: (1) sismicidade tipo enxame de longa duração, até mesmo para sismos com magnitudes 
menores ou igual a 2,0 $m_{b}$, que estende-se de vários meses, a muitos anos, tal como os enxames de João Câmara (Oliveira et al., 1989 e 1994) e (2) sismos rasos com profundidades menores que $12 \mathrm{~km}$ (Assumpção et al., 1989; Takeya, 1992; Ferreira et al., 1995).

Devido ao grande número de afloramentos graníticos/gnáissicos do escudo PréCambriano (Almeida et al., 1981) nesta área, e à ocorrência de enxames de sismos, é possível manter estações sismográficas portáteis por um longo período, com registros de boa qualidade (chegadas das ondas $\mathrm{P}$ e $\mathrm{S}$ bastante claras), já que se tem uma ótima relação sinal-ruído. Mesmo com o pequeno número de estações e registros analógicos, foi possível determinar hipocentros precisos e mecanismos focais compostos, utilizando modelos simples de velocidade (Ferreira et al., 1987, 1995; Assumpção et al., 1989).

\begin{tabular}{lcccl}
\hline \multicolumn{1}{c}{ Localidade } & Data & $m_{b}$ & I (MM) & \multicolumn{1}{c}{ Referência: } \\
\hline Dr. Severiano (RN) & $15 / 02 / 68$ & 4,1 & VI-VII & Ferreira e Assumpção (1983) \\
& $23 / 07 / 68$ & 4,6 & VII & Ferreira e Assumpção (1983) \\
Parazinho (RN) & $22 / 07 / 73$ & 4,3 & VII & Ferreira e Assumpção (1983) \\
Pacajus (CE) & $20 / 11 / 86$ & 5,2 & VII & Ferreira e Assumpção (1983) \\
João Câmara (RN) & $21 / 08 / 86$ & 4,2 & VI-VII & Ferreira et al. (1987); RBGf \\
& $30 / 11 / 86$ & 5,1 & VII & Takeya et al. (1989); RBGf \\
& $10 / 03 / 89$ & 5,0 & VII & Costa et al. (1989); RBGf \\
& $18 / 10 / 88$ & 4,2 & VI & Assumpção et al. (1989); RBGf \\
Palhano (CE) & $26 / 03 / 89$ & 4,5 & VII & RBGF \\
\hline
\end{tabular}

Tabela 1.1: Principais sismos com magnitudes $\geq 4,0 m_{b}$ e intensidade (MM) $\geq$ VI ocorridos na borda da Bacia Potiguar desde 1968 segundo Ferreira (1997). RBGf denota o Boletim Sísmico da Revista Brasileira de Geofísica.

Apesar da sismicidade na borda da Bacia Potiguar já ser conhecida desde o século XIX, apenas a partir de 1986 foi possível estudar esta atividade sísmica utilizando-se estações portáteis (analógicas e digitais). A primeira rede sismográfica foi montada na cidade de João Câmara (Ferreira et al., 1987). Depois foram montadas redes em outras cidades (Ferreira et al., 1998). Na maioria dos casos foi possível determinar o mecanismo focal e identificar os planos de falha, como mostrado na Figura 1.2. 


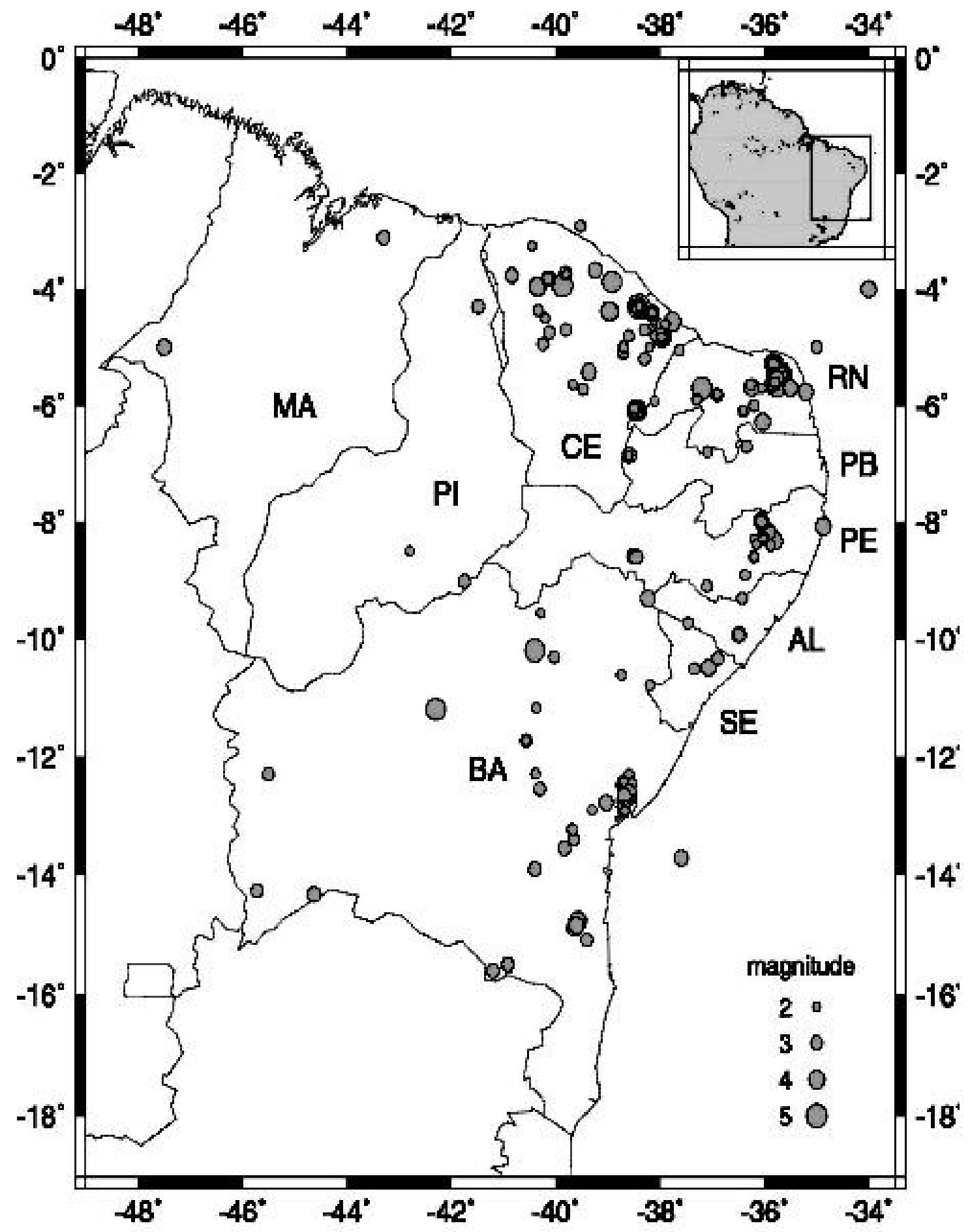

Figura 1.1: Distribuição dos sismos com magnitude $\geq 2,0 m_{b}$ no Nordeste Brasileiro, as bolas cinzas indicam os epicentros dos sismos com o tamanho variando de acordo com a magnitude (Vilar et al., 2005). 


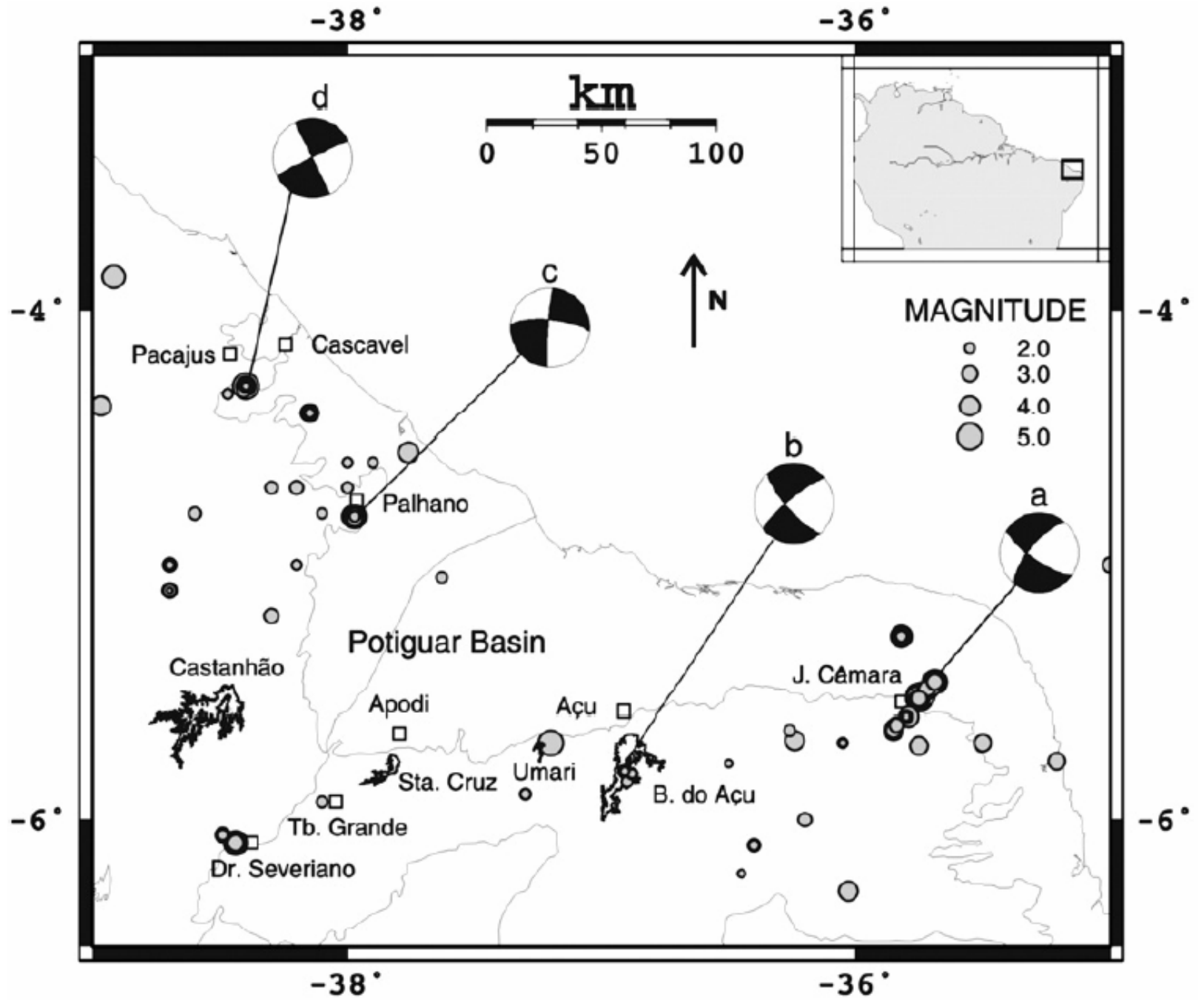

Figura 1.2: Estrutura da Bacia Potiguar, principais reservatórios e alguns mecanismos focais determinados. Exceto para a Barragem do Açu, todos os outros círculos representam os epicentros de sismos naturais com magnitude $\geq 2,0$ $m_{b}$. As bolas de praia (beach balls) indicam os mecanismos focais: a) João Câmara (1987); b) Barragem do Açu (1995); c) Palhano (1998); d) Cascavel-Pacajus (1985) (Ferreira et al., 2008). 


\subsection{Sismicidade em Cascavel - CE}

Desde 1980, quando a 20 de novembro, ocorreu um sismo de magnitude 5,0 $m_{b}$, o maior tremor de terra já registrado no Nordeste Brasileiro, a sismicidade na região de Cascavel - CE (Figura 1.3) vem sendo estudada pela UFRN. Este evento (com intensidade VII MM) provocou o colapso de várias casas na área epicentral e foi sentido por até $600 \mathrm{~km}$ de distância (Ferreira et al., 1998). Apesar deste sismo ter ocorrido dentro dos limites do município de Cascavel, ele ficou conhecido como o tremor de Pacajus, nome da maior cidade próxima à área epicentral (Ferreira \& Assumpção, 1983). A estação de Itataia, localizada $150 \mathrm{~km}$ à Oeste da cidade de Pacajus, registrou réplicas do evento de 1980 por mais de dois anos (Berrocal et al. 1984).

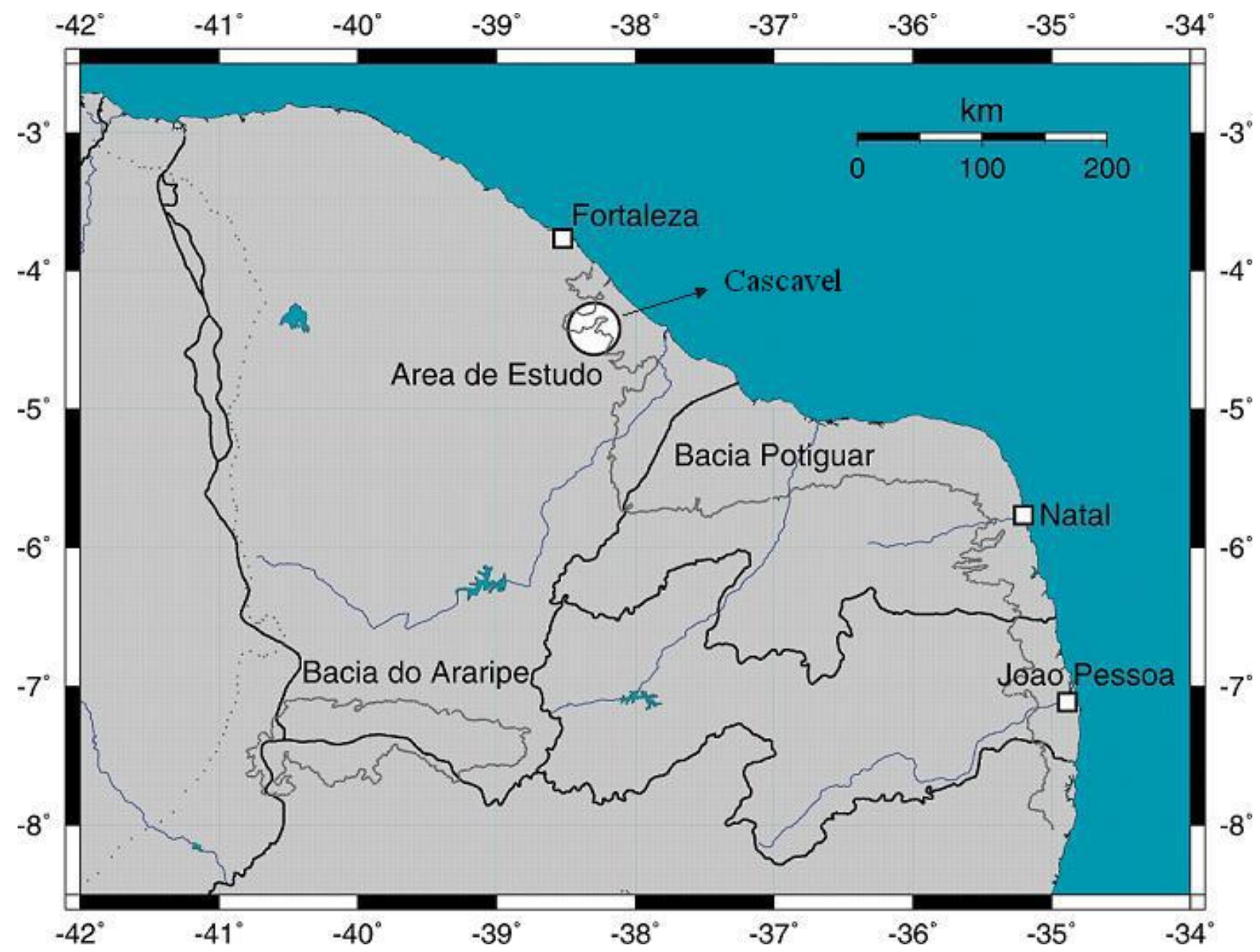

Figura 1.3: Nordeste Brasileiro: em cinza escuro está representado o contorno das principais bacias do nordeste, em azul estão os principais rios e o círculo branco destaca a região de estudo (modificado de Gomes, 2007). 
Devido aos constantes tremores ocorridos no estado do Ceará, diversas campanhas já foram realizadas nesta região com o objetivo de determinar os hipocentros, os mecanismos focais e a relação dos sismos com a geologia da área (Ferreira et al., 1998).

A seguir, são apresentadas, as campanhas realizadas utilizando estações portáteis de período curto.

\section{Campanha de 1989}

A primeira campanha foi realizada em 1989 (Ferreira et al., 1998), ano no qual foi possível estudar a região instrumentalmente utilizando redes sismográficas. A partir deste momento, quase sempre, pelo menos uma estação analógica permaneceu operando na região. Durante a campanha de 1989, a UFRN, instalou três estações analógicas (CH01, CH03 e CH04), representadas pelos triângulos verdes na Figura 1.4. A estação local $\mathrm{CH} 01$, instalada próximo à cidade de Chorozinho - CE (Figura 1.4), registrou um total de 749 eventos, na forma de microtremores, entre julho de 1989 e fevereiro de 1991 . Na Figura 1.4 também estão representados os epicentros dos sismos (triângulos pequenos) registrados nessa campanha.

De acordo com Ferreira et al. (1998), o período compreendido entre julho de 1989 e dezembro de 1993 teve uma atividade sísmica relativamente baixa, quase sempre abaixo de 100 sismos por mês. A partir de junho de 1994 a atividade sísmica voltou a aumentar (Figura 1.5), e no dia 11 de agosto daquele ano, foi registrado um sismo com magnitude 3,5 $m_{b}$. Na Tabela 1.2 estão apresentados os eventos ocorridos na região de Cascavel com magnitude $\geq 3,0 \quad m_{b}$, obtidos tanto instrumentalmente como historicamente.

\section{Campanha de 1993/1994}

Devido à ocorrência de uma série de sismos com magnitude acima de 2,0 $m_{R}$ (entre outubro e dezembro de 1993), que causaram danos ao canal de água (Figura 1.4) (construído emergencialmente para abastecer a cidade de Fortaleza, capital do estado do Ceará), foi realizada uma segunda campanha (Ferreira et al., 1998). Esses sismos 


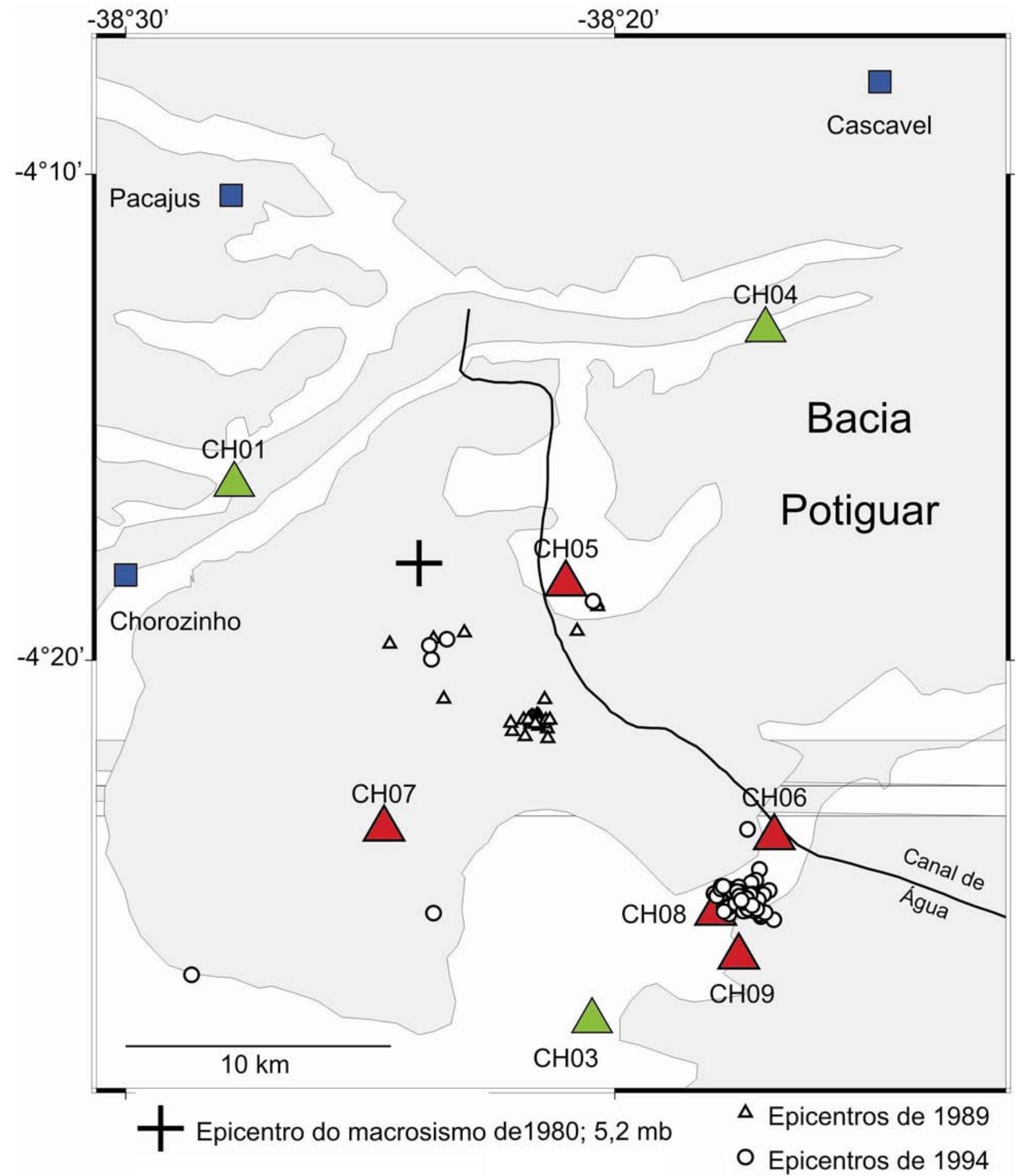

Figura 1.4: Atividade sísmica na região de Cascavel - Pacajus no Ceará. Os quadrados azuis indicam as principais cidades. Os triângulos verdes denotam as estações usadas na campanha de 1989. Na campanha de 1993/1994 foram usadas as mesmas estações de 1989 mais as cinco estações indicadas pelos triângulos vermelhos, porém, no máximo operaram seis estações simultaneamente. A linha preta representa o canal de água e a área cinza representa as coberturas sedimentares da Bacia Potiguar (DNPM, 1984). A cruz marca o epicentro do evento de 1980, o qual foi obtido por registros históricos (modificado de Ferreira et al., 1998). 
ocorreram próximos à estação $\mathrm{CH06}$, onde o canal corre sobre solo arenoso e inconsolidado. Entre 17 de dezembro de 1993 e 19 de janeiro de 1994, uma rede de quatro estações sismográficas analógicas operou no local. A partir de 20 de janeiro 1994, a rede passou a ter seis estações, que ficaram operando até 01 de março daquele ano. Durante essa campanha, foram usadas as mesmas estações da campanha de 1989 mais cinco estações (Figura 1.4), porém apenas seis estações operaram simultaneamente.

\begin{tabular}{|c|c|c|}
\hline Data & Magnitude $\left(m_{b}\right)$ & Referência: \\
\hline $20 / 11 / 1980$ & 5,2 & Ferreira \& Assumpção (1983) \\
\hline $02 / 01 / 1981$ & 3,6 & Boletim Sísmico \\
\hline $12 / 01 / 1981$ & 3,8 & Boletim Sísmico \\
\hline $11 / 08 / 1994$ & 3,5 & Boletim Sísmico \\
\hline $22 / 04 / 1995$ & 3,5 & Boletim Sísmico \\
\hline $19 / 09 / 1997$ & 3,6 & Boletim Sísmico \\
\hline $21 / 09 / 1997$ & 3,3 & Boletim Sísmico \\
\hline $22 / 09 / 1997$ & 3,3 & Boletim Sísmico \\
\hline $16 / 12 / 1997$ & 3,1 & Boletim Sísmico \\
\hline $04 / 06 / 1998$ & 4,0 & Boletim Sísmico \\
\hline $06 / 06 / 1998$ & 3,4 & Boletim Sísmico \\
\hline $22 / 01 / 2000$ & 3,3 & Boletim Sísmico \\
\hline $23 / 01 / 2000$ & 3,1 & Boletim Sísmico \\
\hline $23 / 01 / 2000$ & 3,0 & Boletim Sísmico \\
\hline $29 / 06 / 2000$ & 3,5 & Boletim Sísmico \\
\hline $04 / 07 / 2000$ & 4,1 & Boletim Sísmico \\
\hline $23 / 09 / 2000$ & 3,1 & Boletim Sísmico \\
\hline $10 / 11 / 2000$ & 3,0 & Boletim Sísmico \\
\hline $26 / 02 / 2001$ & 3,7 & Boletim Sísmico \\
\hline $24 / 08 / 2004$ & 3,0 & Boletim Sísmico \\
\hline $28 / 06 / 2006$ & 3,1 & Boletim Sísmico \\
\hline
\end{tabular}

Tabela 1.2: Eventos ocorridos na região de Cascavel $-\mathrm{CE}$, com magnitude $\geq 3,0 m_{b}$. Obtidos tanto historicamente como instrumentalmente. Fonte: Boletim Sísmico Brasileiro. 


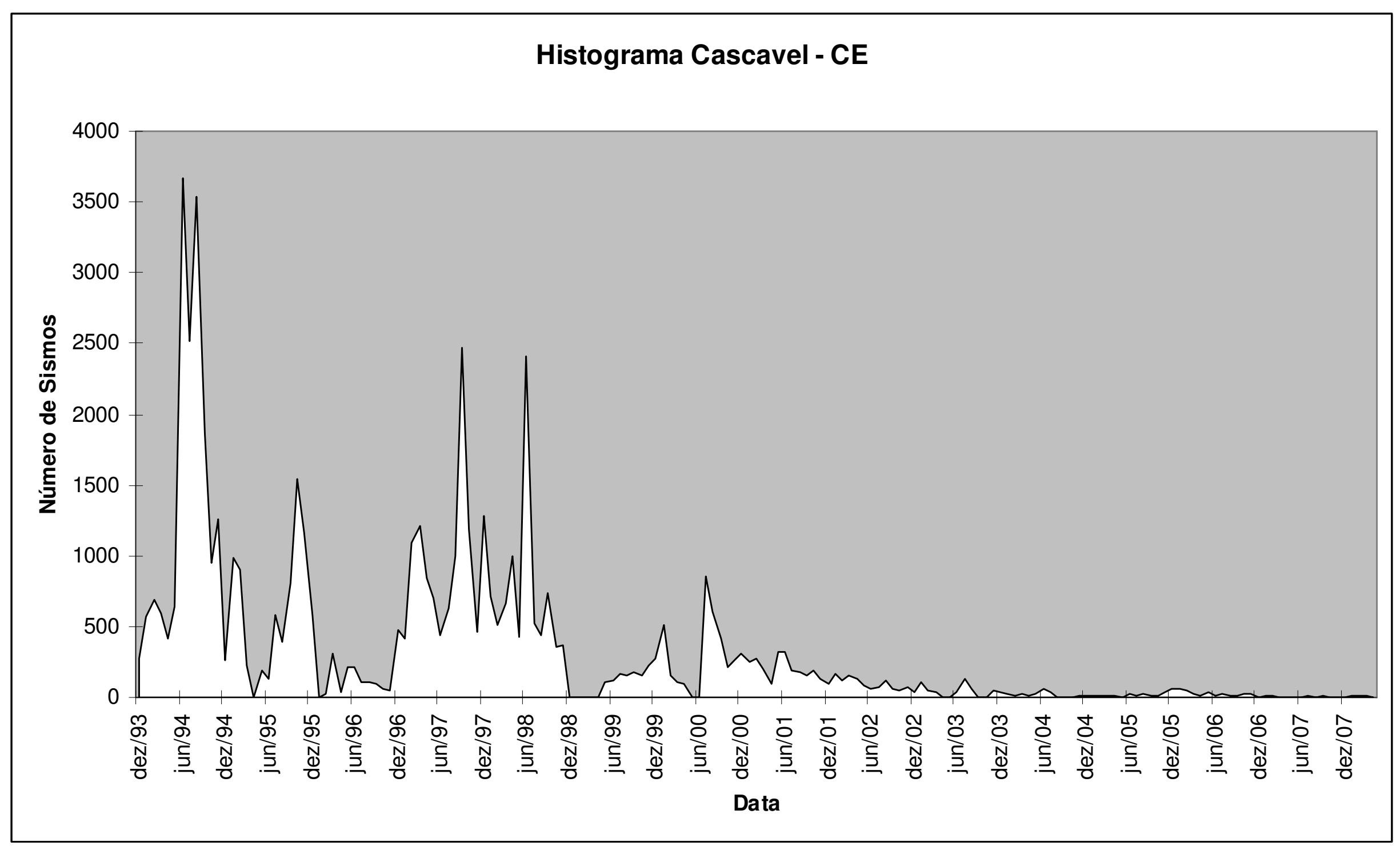

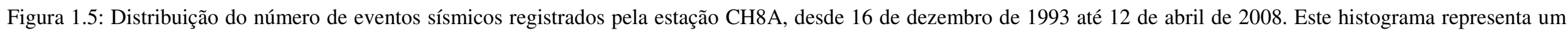
total de 55.990 sismos. 


\section{Campanha de 1996/1997}

Em 1995 (Figura 1.5) a atividade sísmica foi moderada, porém no dia 22 de abril daquele ano ocorreu um sismo de magnitude 3,5 $m_{b}$ (Tabela 1.2). Como pode ser observada na Figura 1.5, no ano de 1996, a sismicidade na região diminuiu consideravelmente, mas no final do ano houve um aumento significativo, e em 16 de dezembro começaram a operar as estações digitais, sendo instaladas oito estações triaxiais (Vilar, 2000). Estas estações estão representadas na Figura 1.6.

Durante o período em que operou esta rede sismográfica, entre 16 de dezembro de 1996 e 02 de abril de 1997, foram registrados 3.153 sismos pela estação analógica CH8A. $\mathrm{Na}$ realização desta campanha houve uma intensa atividade sísmica (Figura 1.5). Com os dados coletados pelas estações digitais, Vilar (2000) localizou os epicentros e determinou o mecanismo focal dos eventos.

\section{Campanha de 1997/1998}

Esta dissertação utiliza dados adquiridos por uma rede sismográfica digital triaxial (Figura 1.7), composta por seis estações localizadas no município de Cascavel - CE, a qual operou entre 29 de setembro de 1997 e 05 de março de 1998. Na Figura 1.7, além das estações sismográficas digitais, também estão mostradas as principais cidades da região e o contato entre o embasamento cristalino do Pré-Cambriano e a Bacia Potiguar.

Durante esse período a estação analógica (CH8A) registrou um total de 4.536 eventos (Figura 1.8). Na Figura 1.8 é possível observar que, por algumas vezes, a atividade diária passou dos 100 sismos. O dia de maior atividade desse período ocorreu em 09 de setembro de 1997, com um total de 149 registros.

Esta intensa atividade prolongou-se até o início de dezembro de 1998, porém, antes disso, no dia 04 de junho ocorreu a maior atividade sísmica diária, sendo registrado um total de 656 eventos, o maior número de registros em um dia desde o início do monitoramento em 1989. Entre 03 de dezembro de 1998 e 14 de maio de 1999, a estação CH8A ficou desativada. Após seu reinicio, notou-se que houve uma atividade sísmica relativamente baixa com uma média diária de 50 sismos. 


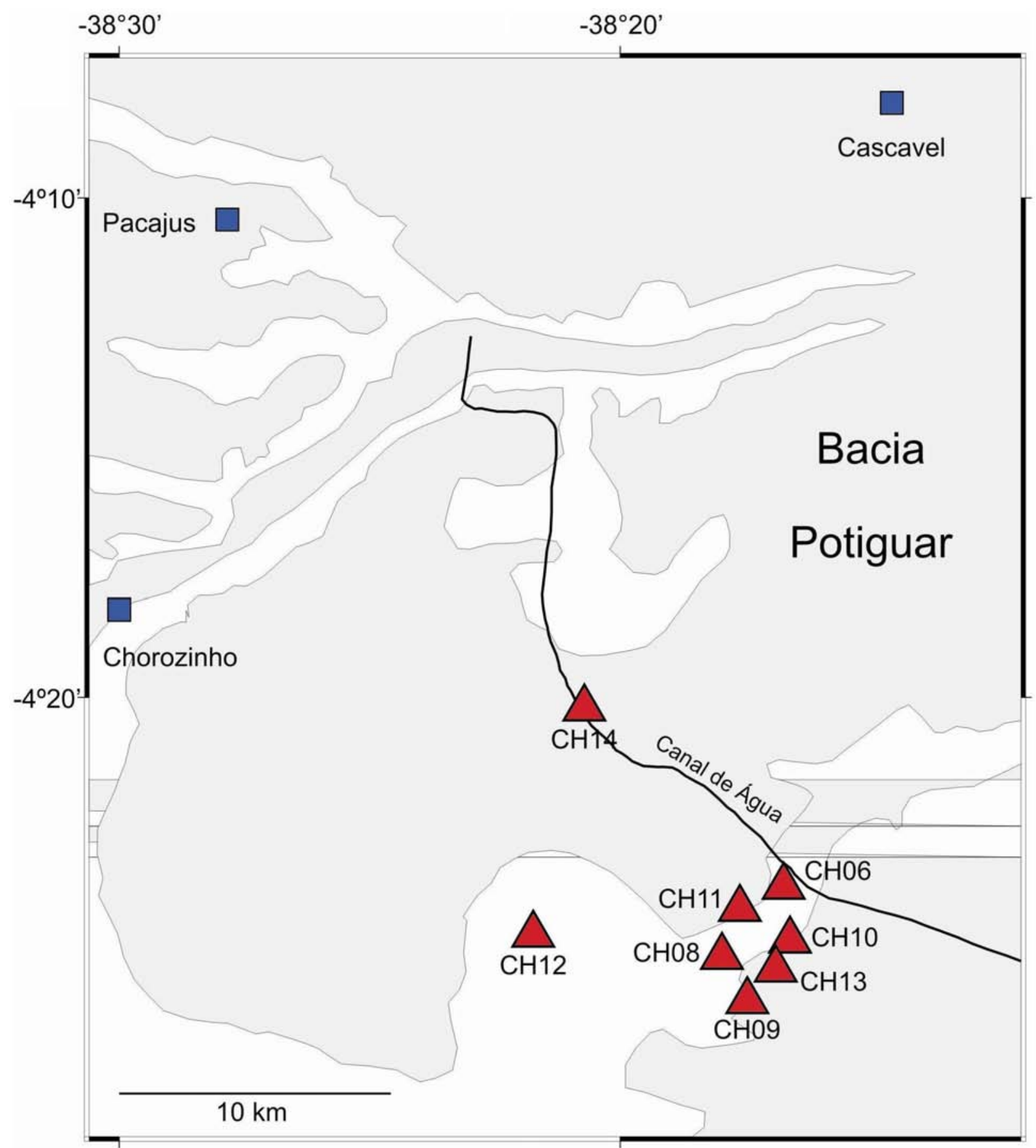

Figura 1.6: Campanha 1996/1997: Os triângulos vermelhos representam as estações digitais. A estação analógica referida no texto, operou no mesmo lugar que a estação CH08 (modificado de Vilar, 2000). 


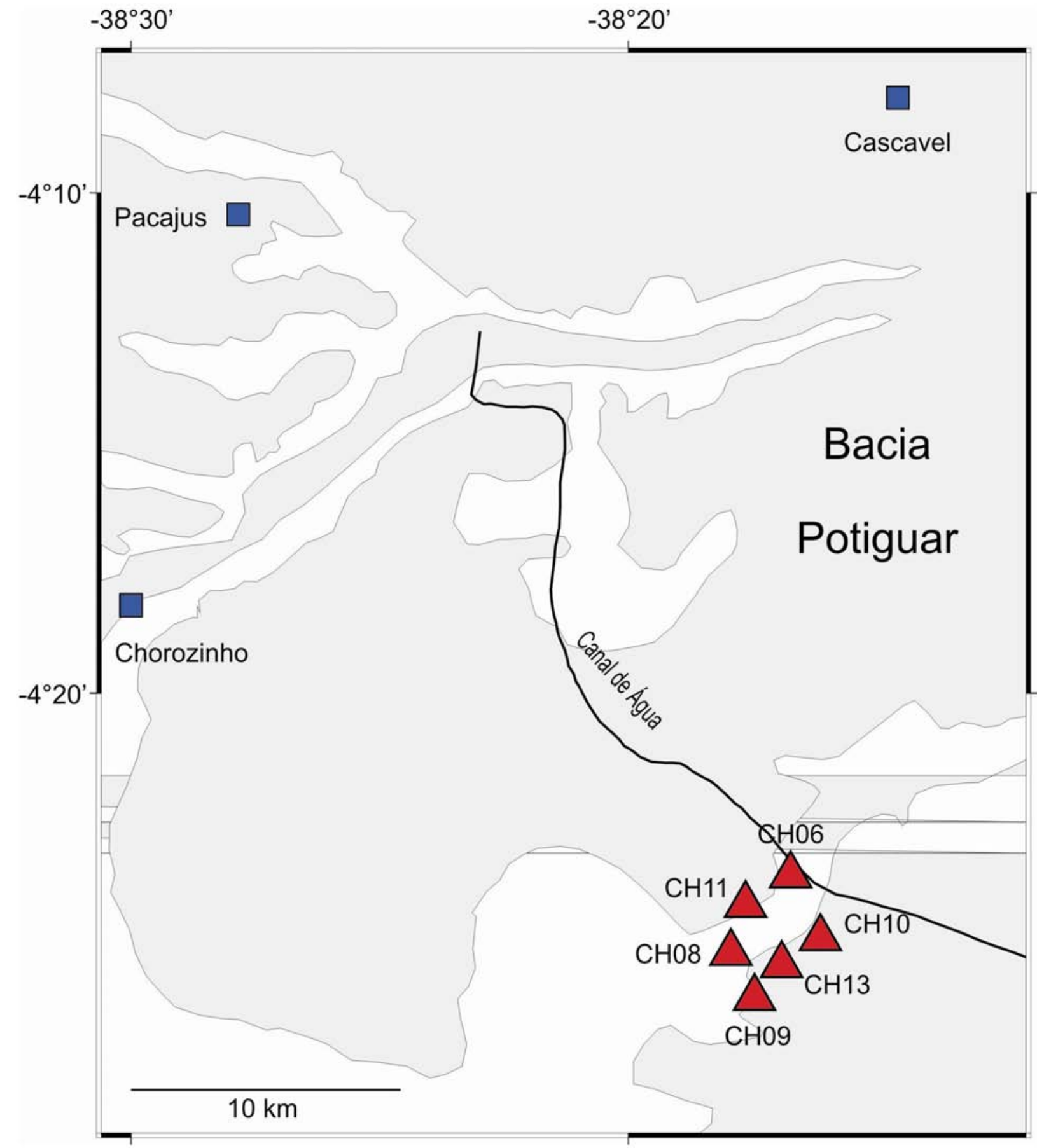

Figura 1.7: Campanha 1997/1998: os triângulos vermelhos representam as estações sismográficas, os quadrados azuis as principais cidades, a região cinza claro a Bacia Potiguar e a região branca o embasamento cristalino. $\mathrm{O}$ canal de água está representado pela linha preta. 


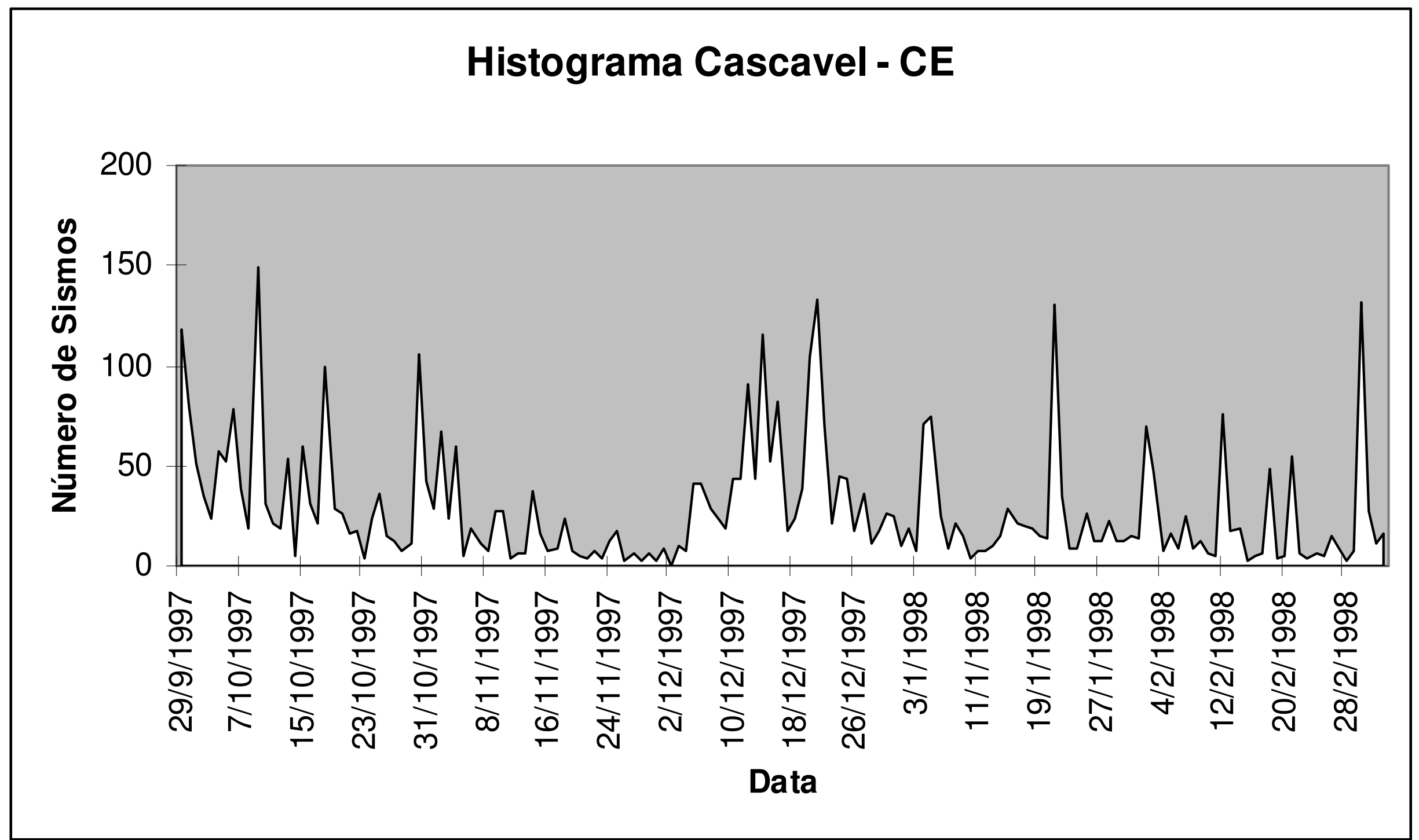

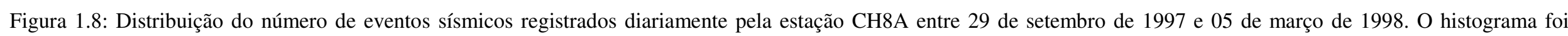
construído com 4.536 sismos. 
A estação CH8A ainda esteve desativada por mais dois períodos, de 25 de abril a 05 de junho de 2000 e do dia 16 de agosto ao dia 20 de outubro de 2003, sendo que ela operou pela última vez no dia 12 de abril de 2008. De dezembro de 1993 a abril de 2008 foram registrados mais de 55.000 eventos sísmicos na região de Cascavel, o que a torna uma das regiões de maior sismicidade intraplaca do Brasil.

\subsection{Resumo da Geologia da Área}

O propósito desta seção é apresentar, sucintamente, a contextualização geológica da área de estudo, de modo a justificar a utilização de alguns valores de propriedades físicas das rochas da região estudada, como por exemplo, o fator de qualidade Q.

Segundo a divisão proposta por Almeida et al. $(1977,1984)$ no Nordeste brasileiro, as rochas Pré-Cambrianas ao norte do Craton São Francisco compõem a Província Borborema (Figura 1.9), enquanto as rochas sedimentares do Fanerozóico ocorrem na Província Costeira e Margem Continental.

A Província Borborema representa o segmento crustal de uma extensa faixa, que foi afetada pela Orogênese Brasiliana $(600 \pm 100 M a)$, denominada Faixa Trans-Saara. Essa faixa foi originada pela colisão entre os Crátons do Oeste Africano/São Luís e São Francisco/Congo-Kasai, que constituíram massas continentais consolidadas de tempos brasilianos (Jardim de Sá, 1994). A Província Borborema delimita-se à Norte e Leste com a Margem Continental Atlântica, onde está recoberta pelos sedimentos costeiros mesocenozóicos, a Sul com o Cráton São Francisco e a Oeste com rochas sedimentares paleozóicas da Bacia do Parnaíba (Cavalcante, 2006), conforme mostrado na Figura 1.9.

A área de estudo deste trabalho está inserida no Domínio tectônico Setentrional da Província Borborema, de idade Pré-Cambriana (Almeida et al., 2000). Na área sísmica, destacam-se a existência de embasamentos Pré-Cambrianos e a presença de sedimentos fanerozóicos da Bacia Potiguar.

De acordo com Matos (1992), a Bacia Potiguar é uma bacia do tipo rift e sua evolução está dividida em duas partes: A primeira fase (rifteamento) foi marcada por esforços distensivos WNW-ESSE, formando o graben. Esse período foi marcado pelo preenchimento de grande parte da bacia. Durante a segunda fase, os esforços distensivos 


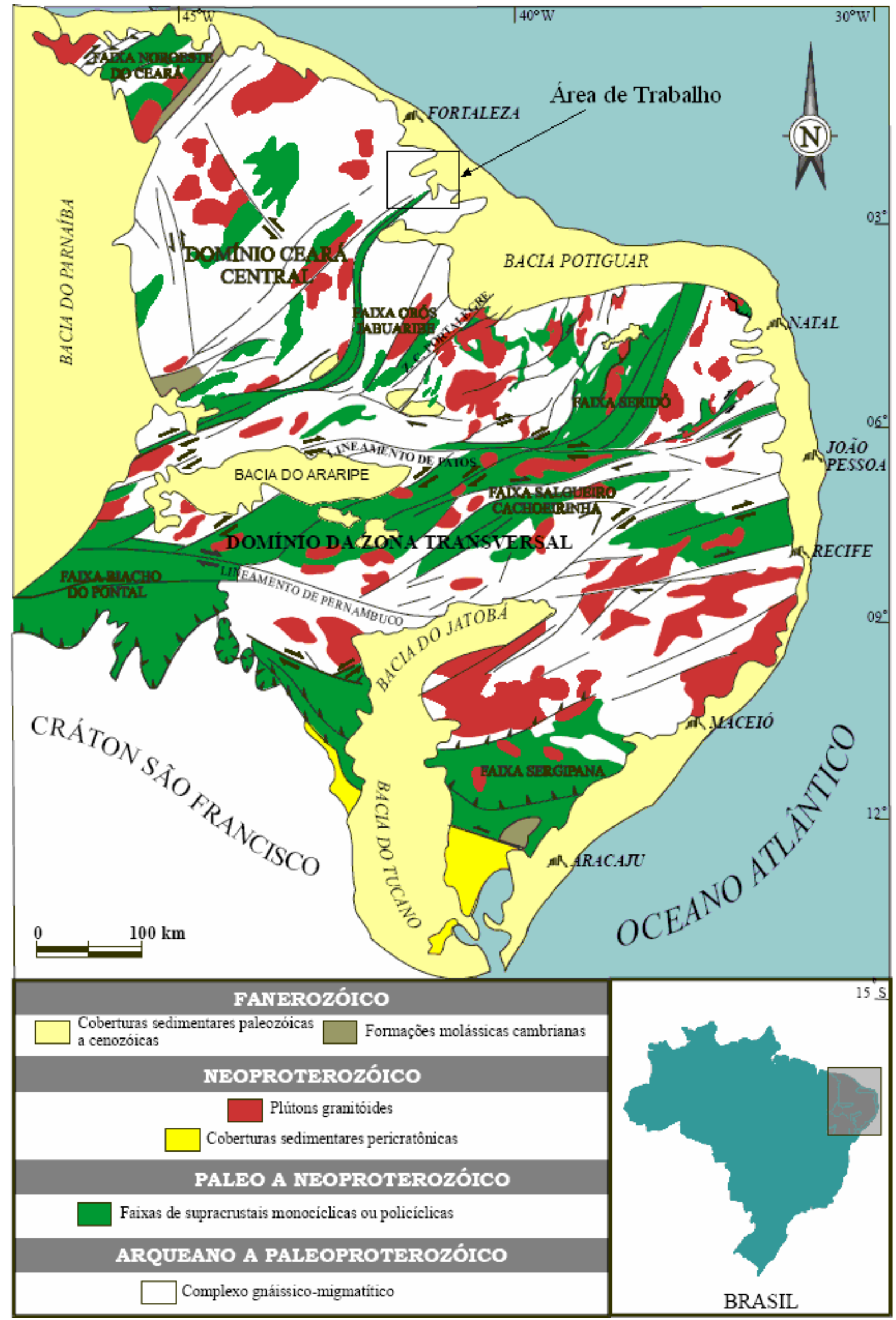

Figura 1.9: Mapa geológico simplificado da Província Borborema, o quadrado mostra a área de estudo (Modificado de Jardim de Sá, 1994). 
máximos atuantes assumiram, aproximadamente, a direção E-W, sendo estes responsáveis pelas rupturas na porção imersa.

A região de estudo é formada por rochas cristalinas e sedimentares. As rochas cristalinas englobam o Complexo Ceará, Jaguaretama e Orós (calcários, quartzitos, xistos, gnaisses), além de rochas granitóides. Estas rochas ocorrem predominantemente nos lados Leste e Sul da área de trabalho. Este conjunto de rochas cristalinas está deformado pela Orogênese Brasiliana, que imprimiu nestas unidades foliações e zonas de cisalhamento dúcteis, todas com direção NE. Uma das mais importantes estruturas da área é a Zona de Cisalhamento Senador Pompeu (ZCSP). Na área de estudo, esta zona é marcada pelo alinhamento de uma unidade de quartzitos (cor laranja, localizado no canto centro sul da área) (Figura 1.10).

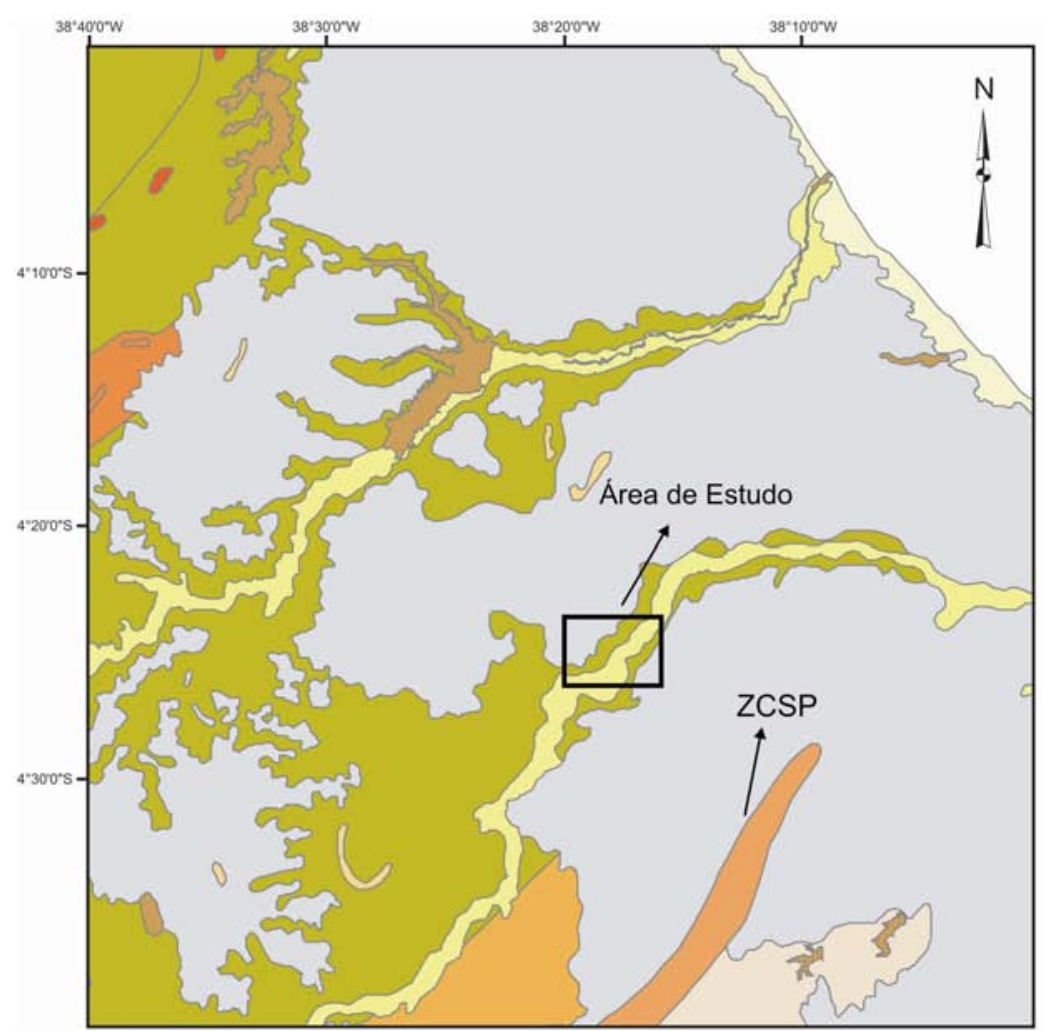

UNIDADES LITOESTRATIGRÁFICAS

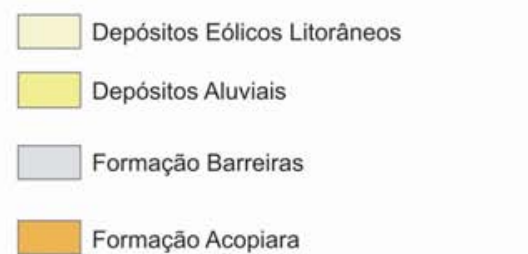

Complexo Ceará - Unidade Canindé

Complexo Ceará - Unidade Independência

$\square$ Formação Jaguaretama

Formação Santarém

Granitóides diversos

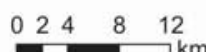

Figura 1.10: Mapa geológico simplificado da área de estudo. Fonte: CPRM-mapeamento geológico, Integrações Geológicas Regionais, escala 1:500.000 (2006).

A ZCSP apresenta-se regionalmente retilínea, com trend NE, apresentando cerca de $350 \mathrm{~km}$ de comprimento e $10 \mathrm{~km}$ de largura. No sentido NE, esta zona converge para o cinturão Orós, cujo trend rotaciona de $\mathrm{N}$ para NE, estendendo-se sob os depósitos da 
planície costeira. No sentido SW, esta zona converge para a Zona de Cisalhamento Tauá (ZCT) (Cavalcante, 2006).

As rochas e sedimentos englobam a Formação Barreiras e Acopiara (arenitos, conglomerados, siltitos e folhelhos), além de depósitos aluviais e eólicos (areias e argilas). Estas rochas representam a maior parte da área e recobrem o embasamento cristalino. As rochas sedimentares formam coberturas extensas (Formação Barreiras), que ocorrem na forma de vales (depósitos aluviais) ou ao longo da costa (depósitos litorâneos). As coberturas sedimentares são pouco espessas e geralmente não ultrapassam $50 \mathrm{~m}$.

\subsection{Sismotectônica}

Esta seção traz um breve resumo sobre sismotectônica, com o objetivo de mostrar que a maioria dos sismos está localizada no limite de placas e que, no caso da sismicidade intraplaca, eles estão localizados em zonas de fraqueza.

Há muito tempo é conhecido o fato de aproximadamente $90 \%$ da atividade sísmica global se encontrar nas regiões de limites de placas litosféricas (Sykes \& Sbar, 1973), tendo, inclusive, a quantidade de sismos, assim como a magnitude e energia dissipada, servido como orientação na delimitação das placas.

Embora a sismicidade intraplaca seja responsável por somente uma pequena fração da energia liberada (10\% p. ex., Jonhston, 1989), os danos podem ser relativamente importantes devido à baixa atenuação da litosfera nas regiões da crosta continental estável.

Segundo Sykes (1978), nos continentes, os sismos intraplaca tendem a se concentrar ao longo de zonas de fraqueza pré-existentes, dentro das áreas afetadas pela orogênese maior e mais recente que precedeu à abertura dos atuais oceanos. A sismicidade da Bacia Potiguar está distribuída numa faixa de aproximadamente $100 \mathrm{~km}$ em torno da margem emersa (Ferreira \& Assumpção, 1983).

A Bacia Potiguar é uma bacia mesozóica marginal, e sua borda está marcada por intensa atividade sísmica (Figura 1.2). Segundo Assumpção (1992), essa bacia tem um papel fundamental na sismicidade da região, e fatores como o contraste de densidade 
lateral e a carga sedimentar na plataforma continental são as causas que geram esforços distensionais na parte superior da crosta continental, próximo aos limites desta bacia.

\subsection{Nosso Trabalho}

A UFRN desenvolve há mais de 20 anos estudos de sismicidade na região Nordeste. Ao longo desse período foram instaladas várias redes locais para estudar a atividade sísmica. Tais estudos compreenderam, na sua grande maioria, determinação hipocentral, mecanismo focal e evolução espaço-temporal das atividades sísmicas (Ferreira et al., 1998).

Com o uso cada vez mais comum de estações sismográficas digitais, pode-se realizar outros tipos de estudos, tais como anisotropia sísmica e mecanismos de migração espaço-temporal da sismicidade induzida (do Nascimento et al., 2002, 2004). Contudo, outros estudos também podem ser realizados, tal como o de determinação de parâmetros de fonte sísmica (estáticos e dinâmicos), os quais podem fornecer informações importantes sobre a natureza do falhamento (Tomic et al., 2008).

Por estar localizado no embasamento cristalino, o Nordeste Brasileiro presta-se muito bem à investigação da dinâmica de ruptura de rochas através da inversão de parâmetros de fonte pois, devido à baixa atenuação do embasamento cristalino, é possível obter uma ótima relação sinal-ruído.

Neste trabalho, com os dados sísmicos disponíveis, foi possível determinar parâmetros de fonte tais como, momento sísmico, stress drop*, stress aparente, dimensão da fonte e energia sísmica irradiada de alguns sismos registrados durante a campanha realizada entre 1997 e 1998.

A obtenção de parâmetros de fonte é de fundamental importância, não apenas para entender os terremotos de um modo geral, mas também em muitas aplicações práticas da sismologia moderna, particularmente no estudo de risco sísmico, parâmetro importante a ser utilizado em projetos de engenharia. Porém, isto não é tão facilmente obtido; um dos principais problemas enfrentados pelos sismólogos é o de como distinguir entre a fonte e os efeitos de propagação no sismograma. Este problema é ainda pior no estudo de

\footnotetext{
* O termo stress drop é conhecido em português como queda de esforço, porém neste trabalho será usada a palavra em inglês.
} 
pequenos terremotos, pois as altas frequências necessárias para definir as pequenas fontes são mais afetadas pela atenuação ao longo da trajetória e pelos efeitos do meio geológico próximo à superfície (Abercrombie, 1995).

Neste trabalho, para obter os parâmetros de fonte, será usado o método que consiste em ajustar o espectro de deslocamento de cada sismo, tendo como base os modelos de fontes circulares propostos por Brune (1970) e Madariaga (1976).

O modelo de Brune assume uma falha circular de raio $\mathrm{r}$ em que a ruptura ocorre instantaneamente no meio, assim, a fonte é idealizada como um único evento de deslize dinâmico.

No modelo de Madariaga a ruptura inicia em um ponto e propaga-se radialmente para fora com velocidade de ruptura $v_{r}=0,9 \beta$, em que $\beta$ é a velocidade da onda $\mathrm{S}$, atingindo um certo diâmetro quando então a propagação pára.

A dimensão da fonte (neste caso raio da fonte, já que é suposta uma falha circular) e o stress drop estão condicionados ao modelo utilizado. A estimativa do raio da fonte utilizando o modelo de Brune é aproximadamente 1,8 vezes maior que as do modelo de Madariaga, enquanto que o stress drop é cerca de 5,5 vezes menor. Desta forma, a estimativa desses dois parâmetros está fortemente relacionada com o modelo utilizado.

\subsection{Objetivos}

No período compreendido entre 29 de setembro de 1997 e 05 de março de 1998, o Laboratório de Sismologia da UFRN, realizou uma campanha com uma rede sismográfica digital composta por seis estações triaxiais, instaladas na região de Cascavel - CE. Esta dissertação de mestrado é o resultado da análise de 21 sismos com magnitude $\left(0,7 \leq m_{b} \leq 2,1\right)$ registrados neste período.

Os objetivos aqui são:

- Analisar os dados digitais que foram registrados durante esta campanha; 
- Ajustar o espectro de deslocamento das ondas S, para obter os parâmetros de fonte (raio da fonte, momento sísmico, stress drop, energia sísmica irradiada, stress aparente e magnitude momento);

- Discussão dos resultados obtidos, com vista a investigar a física da ruptura de microtremores nesta área. 


\section{CAPÍTULO 2 - FONTE SÍSMICA}

Este capítulo revisa o modelo de fonte circular utilizado neste trabalho, bem como as características do processo de ruptura, os tipos de informações que se pode retirar da fonte (parâmetros de fonte), além de explicar, de forma sucinta, como obter tais parâmetros.

\subsection{Introdução}

Os terremotos tectônicos são causados quando a parte frágil da crosta da Terra está sujeita a um esforço que excede a sua tensão de rompimento (Bormann et al., 2002). A ruptura ocorrerá, principalmente, ao longo de uma falha pré-existente ou, às vezes, ao longo de uma nova falha. Quando ocorre um terremoto, são geradas ondas sísmicas que se propagam através do interior da Terra, podendo ser registradas por estações sismográficas espalhadas em diversas regiões.

As ondas sísmicas são classificadas em ondas de corpo e ondas de superfície. As primeiras são divididas em dois tipos: ondas $\mathrm{P}$ (onda compressional), a qual vibra paralelamente à direção de propagação, e ondas $\mathrm{S}$ (onda de cisalhamento), ao contrário da anterior, esta onda vibra perpendicularmente à direção de propagação. Já as ondas de superfície (Rayleigh e Love) resultam das interações das ondas P e S com a interface em que se propagam. A Figura 2.1 mostra os quatro tipos de ondas sísmicas.

O terremoto é um dos desastres naturais mais danosos, por isso é essencial entender os processos físicos que levam a sua ocorrência, bem como fazer uma profunda compreensão do processo de ruptura. Assim, é necessário entender a fonte sísmica, quantificando alguns parâmetros sísmicos que descrevem tal processo. Desta forma, a sismologia (área que estuda o interior da Terra e a física dos terremotos), tem papel fundamental na investigação dos terremotos que periodicamente atingem nosso planeta, tentando alertar a sociedade sobre possíveis riscos.

Existem dois tipos de fontes (Figura 2.2): as naturais e as artificiais, estas últimas sendo aquelas causadas pelo homem, entre as quais, como representação mais 
importante, destacam-se às explosões. Neste trabalho será realizado um estudo acerca dos sismos tectônicos, isto é, do primeiro tipo citado acima.
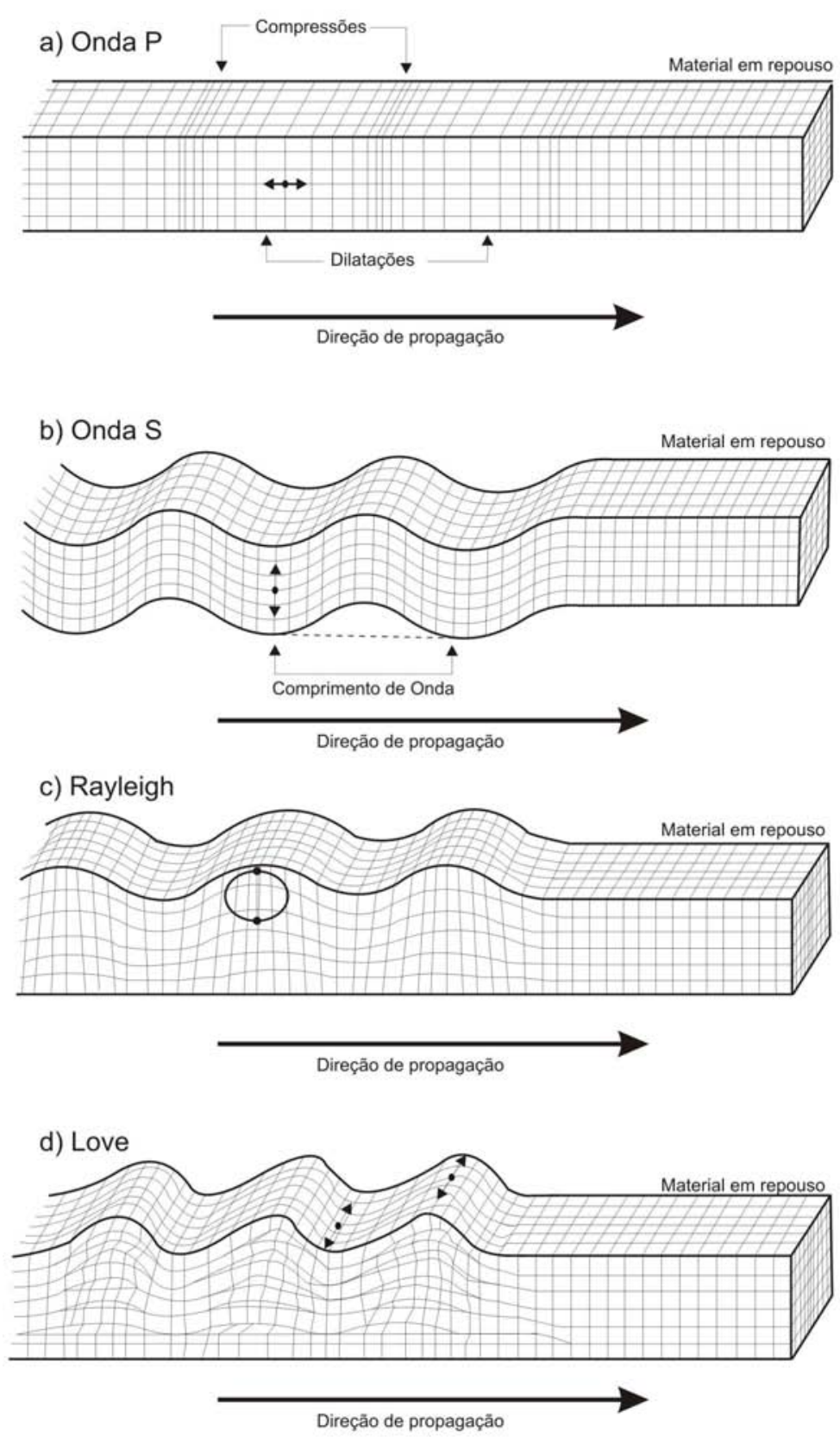

Figura 2.1: Tipos de ondas sísmicas. As ondas P (a) e S (b), longitudinais e transversais, respectivamente, são os dois tipos mais importantes de propagação das ondas sísmicas. Junto à superfície da Terra, propagam-se também as ondas superficiais: Rayleigh (c) e Love (d) (modificado de Texeira et al.,.2008)

A Figura 2.3 representa uma fonte sísmica, de forma esquemática. Para efeito de simplificação foi considerada uma fonte com simetria esférica, em que a energia acumulada em um ponto é irradiada em todas as direções. Assim, não foi considerada a directividade. Na prática, isso não é verdade, pois o falhamento envolve movimento de 
cisalhamento, o qual possui baixa simetria (Lay \& Wallace, 1995). A energia, no modelo da Figura 2.3, é liberada na forma de um pulso $F(t)$, o qual pode ter várias formas.

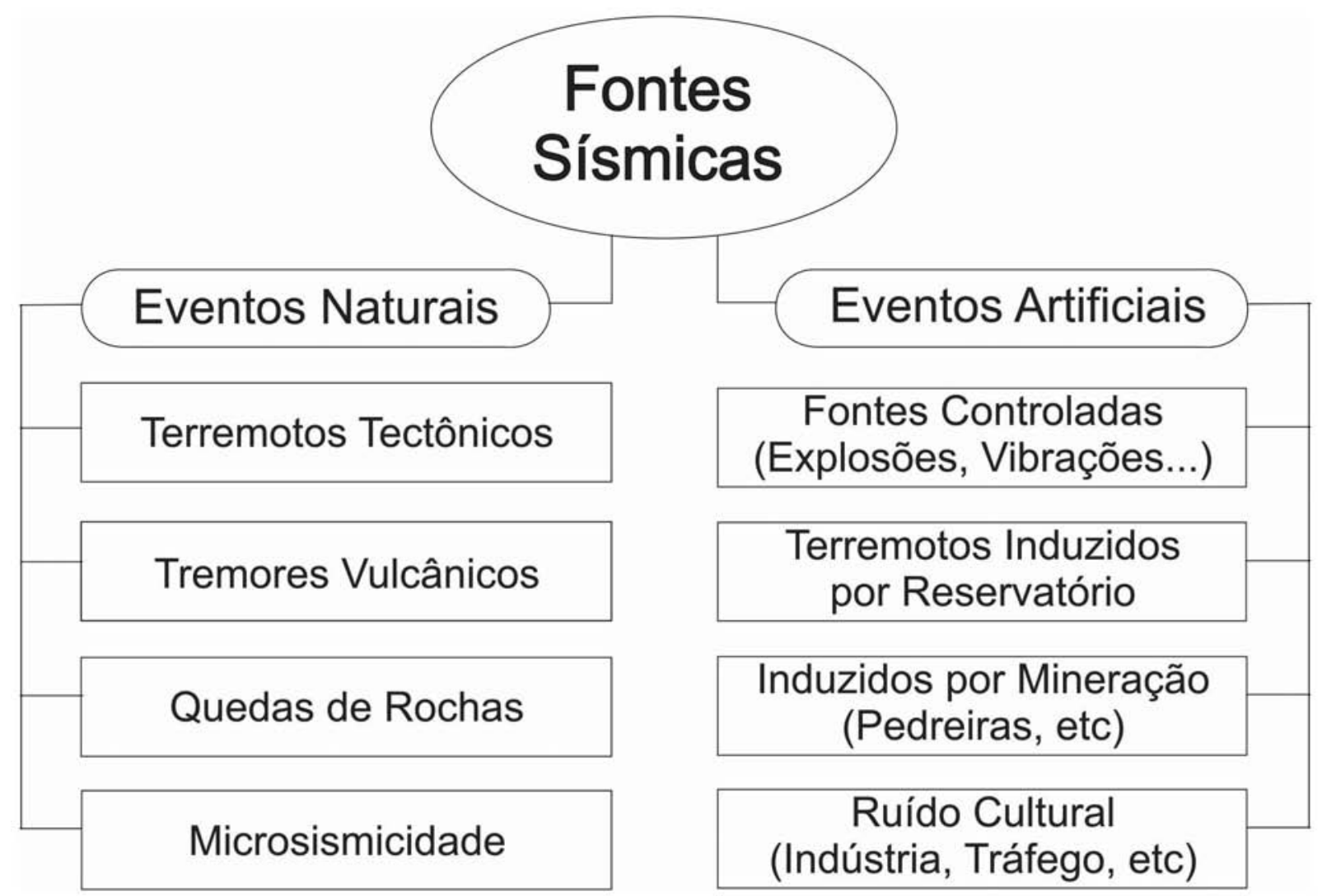

Figura 2.2: Classificação esquemática dos vários tipos de eventos que podem gerar ondas sísmicas (modificado de Bormann et al., 2002).

\subsection{Física do Terremoto}

As placas tectônicas da Terra deslizam umas sobre as outras, em alguns casos acomodando-se pelo deslizamento gradual, em outros casos por uma ruptura que acomoda este movimento pelo súbito deslize sobre um plano de falha (Prieto, 2007). A Figura 2.4 mostra um esquema do processo de ruptura, o qual se inicia no hipocentro (origem ou foco do evento) e propaga-se sobre o plano de falha como uma frente de ruptura, separando regiões que estão deslizando de regiões que ainda não deslizaram (Lay \& Wallace, 1995).

Devido ao movimento da placa, existe uma certa quantidade de energia potencial (energia gravitacional e de deformação) disponível dentro de uma dada região $S$. A 
energia de deformação acumulada é libertada nesta região pela ruptura do terremoto. Durante o processo de falhamento, parte da energia é irradiada como onda sísmica (energia irradiada $E_{S}$ ) e parte é dissipada mecanicamente (energia de fratura $E_{G}$ ) e termicamente (energia térmica ou de fricção $E_{F}$ ) (Kanamori \& Heaton, 2000).

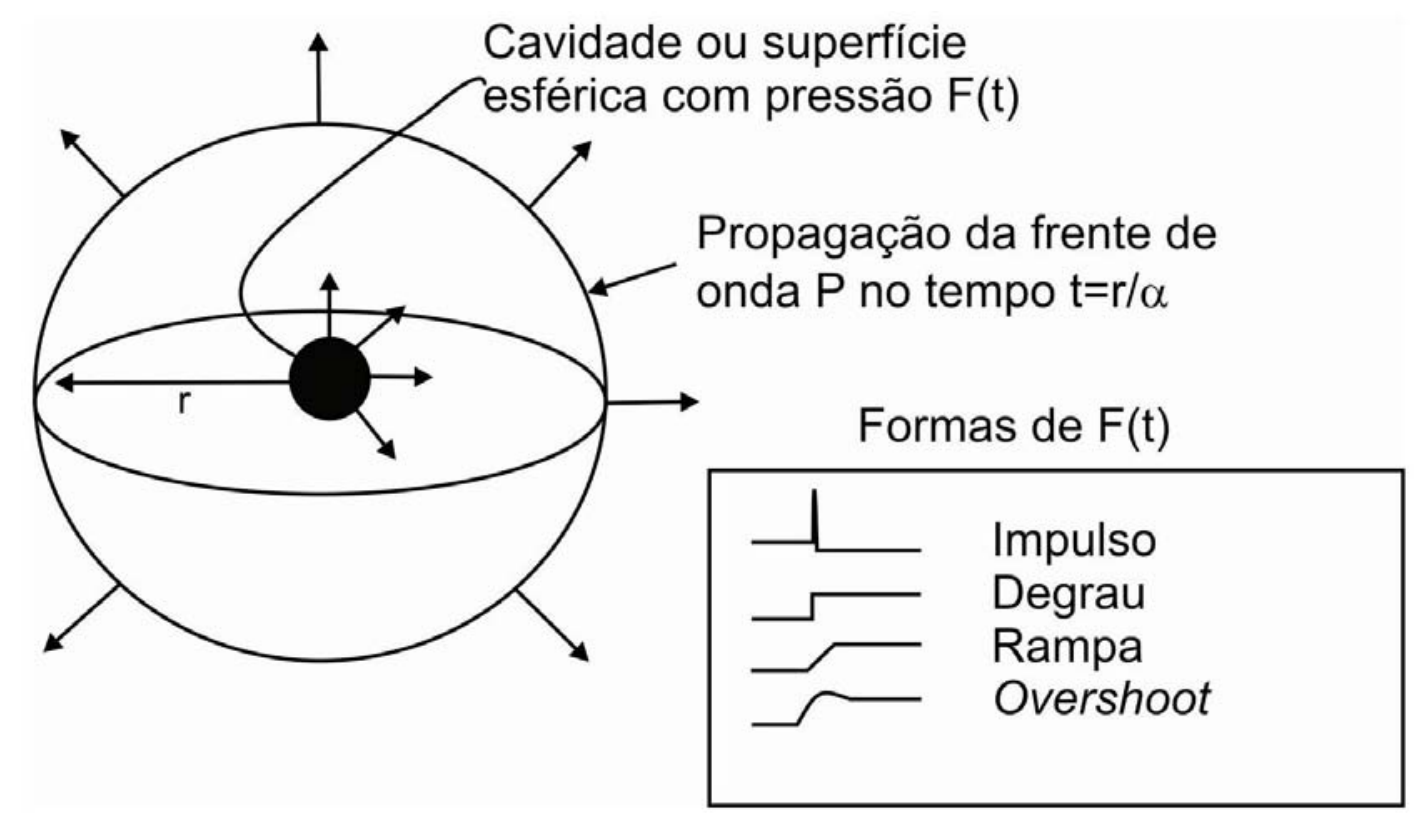

Figura 2.3: Representação de uma fonte sísmica com simetria esférica, em que a energia acumulada em um ponto é irradiada em todas as direções (modificado de Lay \& Wallace, 1995).

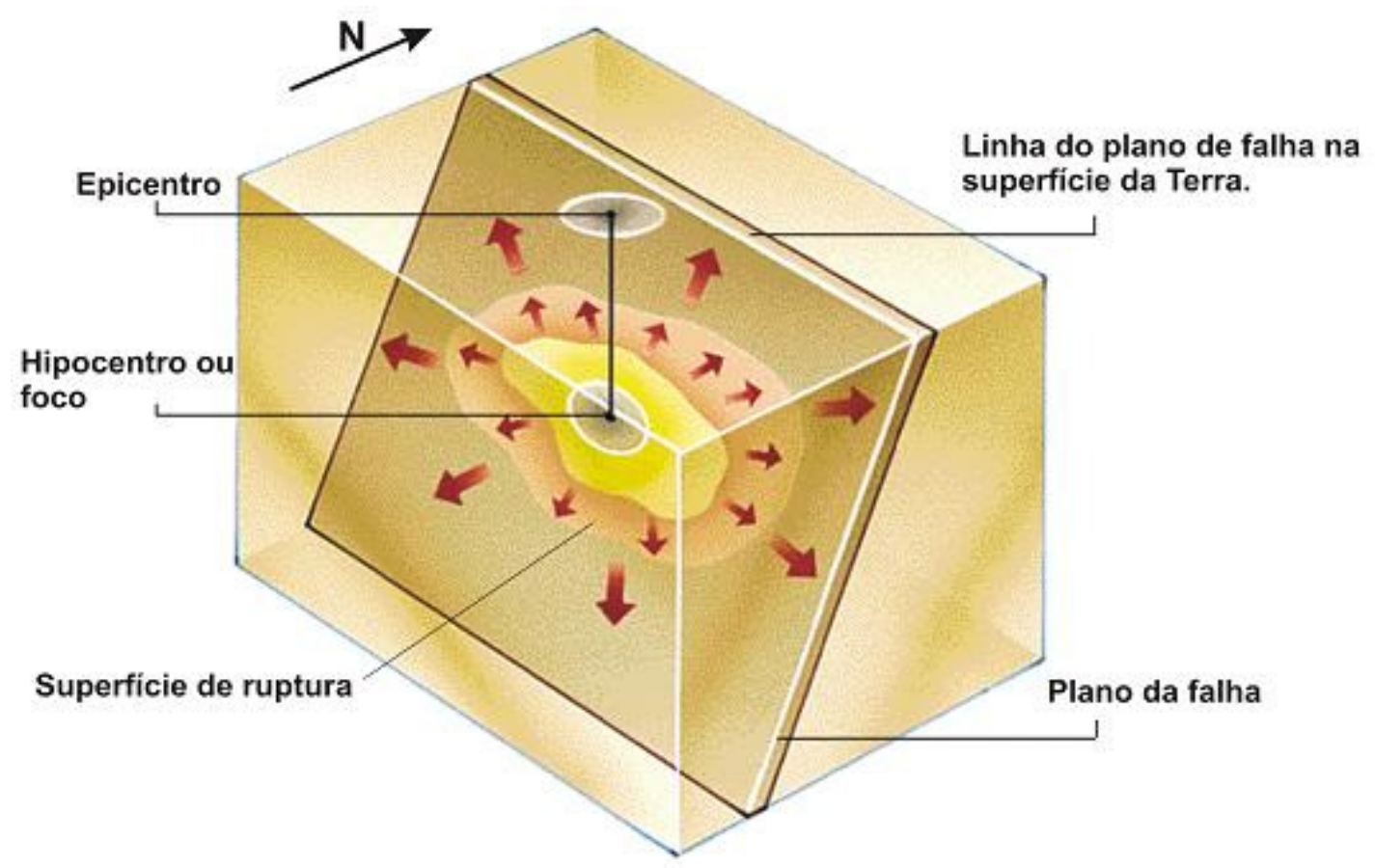

Figura 2.4: Esquema do processo de ruptura quando ocorre um terremoto (modificado de Lay e Wallace, 1995). 
Para ondas de longo comprimento de onda, excitadas pelos movimentos da fonte, a área de ruptura e o volume da fonte que liberam energia de tensão são relativamente pequenos, e podem ser aproximados como ponto fonte de ondas sísmicas, concentrado no espaço. $\mathrm{O}$ armazenamento da energia de tensão elástica na região da fonte é liberado como calor e ondas sísmicas, e eventualmente deslizamento final da falha. Muitos fenômenos são ignorados num processo de deslizamento, tais como aquecimento ou até mesmo fusão das rochas, fratura, dentre outros processos cinemáticos.

As ondas sísmicas liberadas, quando ocorre um terremoto, têm amplitudes de no máximo alguns centímetros. Falhas geológicas observadas na superfície da Terra, às vezes, mostram deslocamentos relativos da ordem de algumas centenas de kilometros, mostrando que as falhas acumulam deslocamentos ao longo de sua história (Scholz, 1990).

\subsubsection{Parâmetros Estáticos e Dinâmicos do Terremoto}

Para entender a física de um terremoto, é fundamental quantificar o comportamento de alguns parâmetros sísmicos que descrevem o processo de ruptura, os quais podem ser estáticos ou dinâmicos. Serão considerados parâmetros estáticos, aqueles que dependem apenas dos estado inicial e final da ruptura, enquanto que os dinâmicos dependem do comportamento e história da ruptura.

\section{Momento Sísmico}

Considere uma falha muito pequena (que pode ser aproximada por um ponto fonte) na qual um deslocamento $D$ (diferença entre os deslocamentos dos dois lados de uma falha) acontece. Pode ser mostrado que uma força de duplo-binário (Figura 2.5) pode produzir um campo deslocamento equivalente ao deslocamento de um ponto (Shearer, 1999). O momento sísmico estático escalar* $M_{0}$ de uma fonte de duplo-binário é dado por (Kanamori \& Anderson, 1975; Shearer, 1999):

$$
M_{0}=\mu D A
$$

\footnotetext{
* Para efeito de simplificação, será chamado apenas de momento sísmico.
} 
em que $\mu$ é a rigidez ou módulo cisalhante do meio, $D$ é o deslocamento da falha e $A$ é a área de ruptura. $M_{0}$ é uma medida da deformação inelástica irreversível na área de ruptura (Bormann et al., 2002). Assim, o seu cálculo se torna muito difícil, e às vezes, até impossível no caso dos sismos que não deixam nenhuma marca visível na superfície, de modo que se possam medir as dimensões físicas das fontes. O momento sísmico tem dimensão força x comprimento, assim é frequentemente usada a unidade $N \cdot m$.
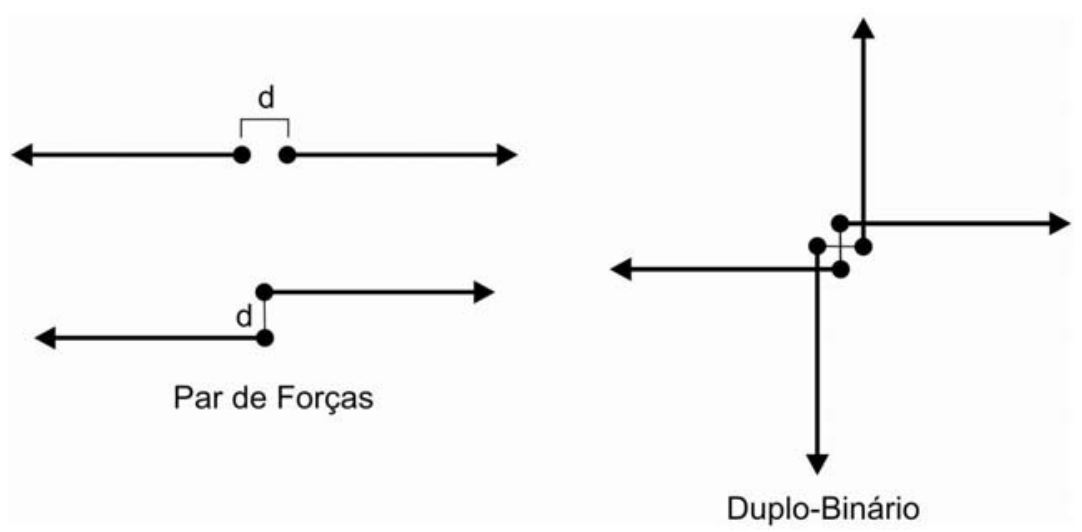

Figura 2.5: A figura representa um par de forças e um duplo-binário. O par de forças são pontos de forças opostas separadas por uma pequena distância. Um duplo-binário é um conjunto de pares de forças complementares, de forma que nenhum torque resultante seja produzido (modificado de Shearer, 1999).

Como a ruptura na Terra sólida é irreversível, o deslocamento que ocorre entre os dois lados da falha é permanente. Este deslocamento não ocorre instantaneamente, mas tem duração finita. Assim, o deslocamento do campo-próximo (muito perto da falha) que pode ser representado como uma rampa (Figura 2.6a) é função do tempo (Shearer, 1999).

O deslocamento do campo-distante, por outro lado, não é permanente e é proporcional à derivada no tempo do deslocamento do campo-próximo (Aki \& Richards, 1980), conforme pode ser visto na Figura 2.6b. Considerando que a estação sísmica está no campo-distante (supondo que não existe atenuação ou espalhamento) e que há conservação da energia, o momento sísmico pode ser representado pela área sob o pulso deslocamento (Kanamori \& Anderson, 1975; Shearer, 1999).

$$
M_{0}=\mu \bar{D} A
$$

onde $\bar{D}$ é o deslocamento transiente médio através da falha. 
O momento sísmico é considerado a medida física mais útil, e fácil de se quantificar, sobre o tamanho do terremoto pois, ao contrário de outras estimativas de magnitude (magnitude local e magnitude de ondas de superfície), $M_{0}$ não satura para grandes terremotos (Kanamori, 1977). Porém, como mencionado acima, $M_{0}$ é uma medida estática do terremoto e portanto, não provê qualquer informação sobre as propriedades dinâmicas da fonte.

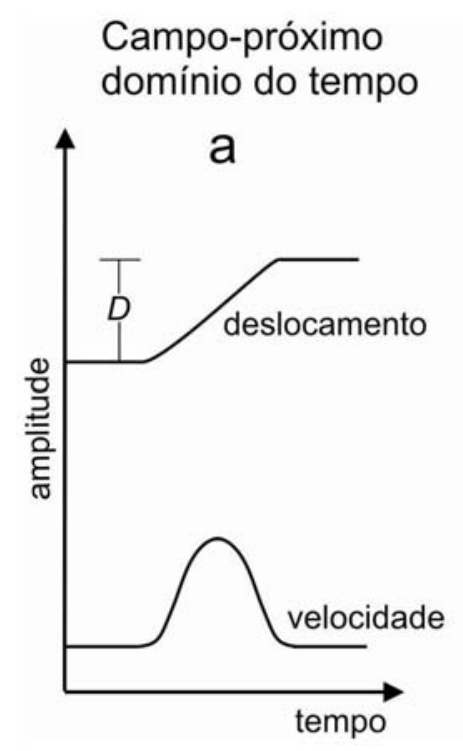

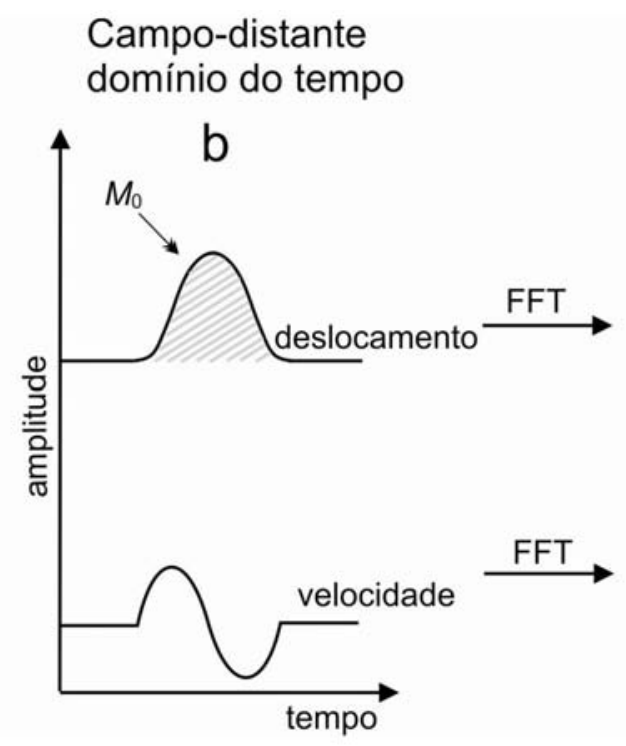

\section{Campo-distante domínio da frequência}

Figura 2.6: Relação entre o deslocamento e a velocidade do campo-próximo (a), campo-distante (b) e o correspondente espectro de amplitude (c). $\mathrm{O}$ momento sísmico $M_{0}$ é proporcional à área achurada sob a curva de deslocamento do campo-distante. A figura (c) representa o espectro de amplitude (modificado de Prieto, 2007).

\section{Stress Drop Estático}

O stress drop estático* $(\Delta \sigma)$ é definido como a diferença média entre o esforço na falha antes e depois de um terremoto (Kanamori \& Anderson, 1975; Mori et al., 2003). Para um ponto-fonte, $\Delta \sigma$ é escrito como:

$$
\Delta \sigma=\sigma_{0}-\sigma_{1}
$$

onde $\sigma_{0}$ e $\sigma_{1}$ representam o esforço num ponto antes e depois do terremoto, respectivamente. O stress drop estático também pode ser representado por (Kanamori \& Anderson, 1975):

\footnotetext{
* Para efeito de simplificação, será chamado apenas de stress drop.
} 


$$
\Delta \sigma=C \mu \frac{\bar{D}}{\tilde{L}}
$$

em que $\mu$ é o módulo cisalhante do meio, $C$ é uma constante adimensional que depende da geometria do plano de falha e $\tilde{L}$ é a dimensão da fonte. A razão $\bar{D} / \tilde{L} \equiv \Delta \tilde{e}$ é a mudança representativa do strain, ou strain drop. Segundo Eshelby (1957), para uma falha circular $\tilde{L}=r$ e $C=7 \pi / 16$. Assim, usando a equação (2.2) e sabendo que a área é dada por $\pi r^{2}$, a equação (2.4) pode ser reescrita como:

$$
\Delta \sigma=\frac{7 M_{0}}{16 r^{3}}
$$

onde $M_{0}$ é o momento sísmico $(N \cdot m)$ e $r$ é o raio da fonte $(m)$.

Da equação (2.5), nota-se que qualquer incerteza no raio da fonte é muito amplificada na estimativa do stress drop. A incerteza na determinação do raio de ruptura do terremoto e, consequentemente no stress drop, depende da qualidade dos dados, da técnica utilizada e do modelo de fonte considerado.

\section{Frequência de Corte e Raio da Fonte}

Como mencionado acima, o stress drop pode ser obtido através dos valores do momento sísmico e do raio da fonte.

Para uma falha circular de raio $r$ e velocidade de ruptura $v_{r}=0,9 \beta$ ( $\beta$ é a velocidade da onda S) (Madariaga, 1976), o tempo de duração da ruptura é:

$$
\tau=\frac{r}{v_{r}}
$$

onde $\tau$ pode ser extraído da duração do pulso de deslocamento (Figura 2.6b).

A duração da ruptura também pode ser calculada através do espectro de deslocamento. A Figura 2.6c representa o espectro de deslocamento do campo-distante. 
Observe que o espectro permanece constante até um certo ponto, a partir do qual a amplitude decai rapidamente. Este ponto é conhecido como frequência de corte $\left(f_{c}\right)$, que está relacionada com a duração do pulso $\left(\tau \propto f_{c}^{-1}\right)$. Substituindo esta relação na equação (2.6), é possível relacionar o raio da fonte com a frequência de corte por:

$$
r=\frac{k \beta}{f_{c}}
$$

em que $k$ é uma constante adimensional. Para este trabalho será utilizado $k_{B}=0,372$ e $k_{M}=0,21$ para os modelos de Brune e Madariaga, respectivamente. Ambos valores são para a onda $S$, já que apenas esta onda foi utilizada para determinar os parâmetros de fonte. O motivo para isto será explicado detalhadamente no próximo capítulo.

\section{Balanço da Energia Sísmica}

Quando ocorre um terremoto, parte da energia total é irradiada como onda sísmica, enquanto que a outra parte é liberada como energia térmica e de fratura; estes dois tipos representam a energia dissipada. A energia total envolvida no processo de ruptura fornece uma compreensão geral dos processos observacionais e físicos envolvidos (Abercrombie et al., 2006). Aqui será considerado que o modelo de enfraquecimento do deslize* (Ida, 1972; Palmer \& Rice, 1973) é valido. Na Figura 2.7 é mostrada uma ilustração da energia relacionada à fratura.

Como explicado por Kanamori \& Rivera (2006), na expansão de uma fratura o esforço $\sigma_{0}$ aumenta até o pico de esforço (também conhecido como limite de elasticidade) no início da ruptura (Figura 2.7) e então decai seguindo a curva $\sigma_{f}(s)$ como função do deslize. No caso particular do modelo de enfraquecimento do deslize, o esforço diminui ao valor final na distância crítica Dc, permanecendo constante até o final da ruptura.

O comportamento do esforço friccional $\sigma_{f}(s)$ mostra a condição particular do esforço durante o processo de ruptura. A variação de $\sigma_{f}(s)$ no decorrer do falhamento pode ser muito mais complexo do que como mostrado na Figura 2.7, assim as estimativas

\footnotetext{
* O termo enfraquecimento do deslize é a tradução para o termo em inglês slip weakening.
} 
sismológicas são muito provavelmente versões suavizadas do comportamento real (Kanamori \& Rivera, 2006).

Na Figura 2.7, a energia dissipada $\left(E_{G}+E_{F}\right)$ está representada pela área abaixo da curva $\sigma_{f}$. Esta energia inclui a energia usada para criar novas falhas, a energia liberada como calor, devido ao atrito entre os lados da falha, quando estão deslizando umas sobre as outras, e outros tipos de energias dissipativas. Apesar da Figura 2.7 mostrar uma clara separação entre a energia de fratura $E_{G}$ e a energia térmica $E_{F}$, isto nem sempre é tão claro e é dependente de muitas suposições (Abercrombie \& Rice, 2005).

A energia irradiada por um terremoto é dada pela diferença entre a área total e a energia dissipada (Figura 2.7). Como $E_{S}$ é liberada na forma de ondas sísmicas, ela pode ser estimada diretamente de um sismograma (Rivera \& Kanamori, 2005).

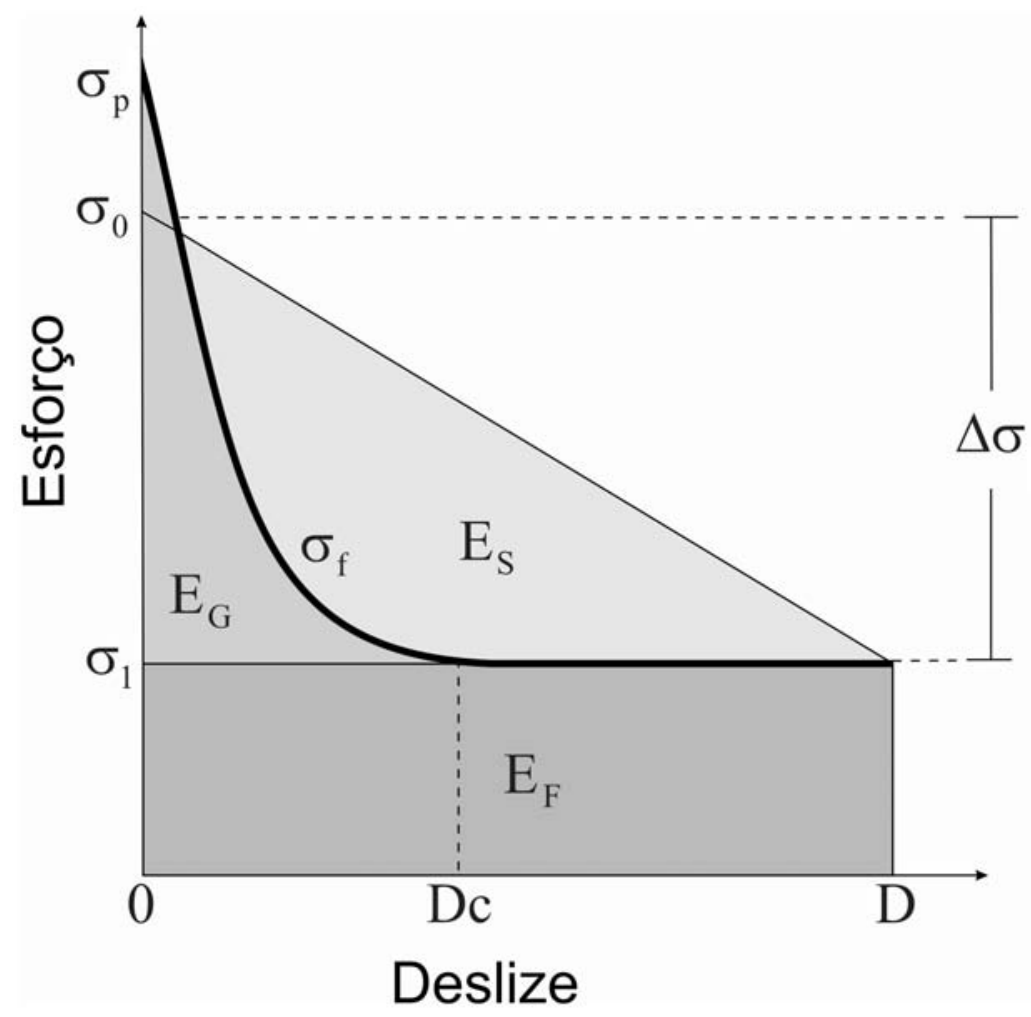

Figura 2.7: Variação do esforço em um ponto na falha como função do deslize, baseado no modelo de enfraquecimento do deslize. Este modelo explica a partição da energia durante a ruptura e a relação entre a energia irradiada $\mathrm{E}_{\mathrm{S}}$ e o stress drop $\Delta \sigma$. O esforço friccional $\sigma_{f}(\mathrm{~s})$ está representado pela curva espessa. Esta figura representa uma unidade da falha, o comportamento do esforço pode ser diferente em várias regiões da falha (modificado de Prieto, 2007).

Através da Figura 2.7 é possível perceber que existe uma relação entre a energia sísmica irradiada e o stress drop. Usando a definição dada pela equação (2.3), pode-se 
retirar algumas conclusões a cerca da relação entre $\Delta \sigma$ e $E_{S}$. Por exemplo, considere uma situação em que o esforço decai instantaneamente para $\sigma_{1}$, neste caso não haveria energia de fratura e muito mais energia seria irradiada como ondas sísmicas. Por outro lado, se o esforço decai lentamente (por exemplo, terremotos lentos), a irradiação como ondas sísmicas será mínima ou quase nenhuma. A Figura 2.7 mostra um dos casos intermediários.

A energia irradiada de uma fonte sísmica é uma estimativa fundamental nos estudos de parâmetros de fonte, pois, ao contrário do momento sísmico e do stress drop que são estáticos, a energia é um parâmetro dinâmico.

A razão para isso é a seguinte: $M_{0}$ depende da área de ruptura e do deslocamento médio (equação 2.2), e $\Delta \sigma$ é a diferença entre o esforço inicial e final (equação 2.3); a energia sísmica é uma função do comportamento do esforço (função $\sigma_{f}$ ) durante a ruptura de um terremoto.

Na Figura 2.8 estão representadas duas situações em que o momento sísmico e o stress drop permanecem constantes, enquanto que a energia sísmica varia. Nesta figura é possível observar a dependência da energia com o esforço friccional. Na Figura $2.8 \mathrm{a} \sigma_{f}$ decai até o esforço final, permanecendo constante até o fim da ruptura. Na Figura 2.8b $\sigma_{f}$ decresce além do esforço final e então volta a aumentar antes da ruptura parar. Assim, na Figura 2.8b, a energia irradiada como ondas sísmicas é maior que na Figura 2,8a. Portanto, a energia sísmica irradiada está relacionada à característica e história da ruptura, e não apenas aos estado inicial e final.

\subsection{Escalamento dos Terremotos}

As grandezas físicas discutidas na seção anterior são alguns dos parâmetros de fonte mais comumente usados para descrever um terremoto. A relação entre eles, fornece informações importantes sobre o processo de ruptura.

A relação entre alguns destes parâmetros com a medida do terremoto (momento sísmico) é usada para verificar se terremotos grandes e pequenos possuem ou não o mesmo processo de ruptura (auto-similaridade). 


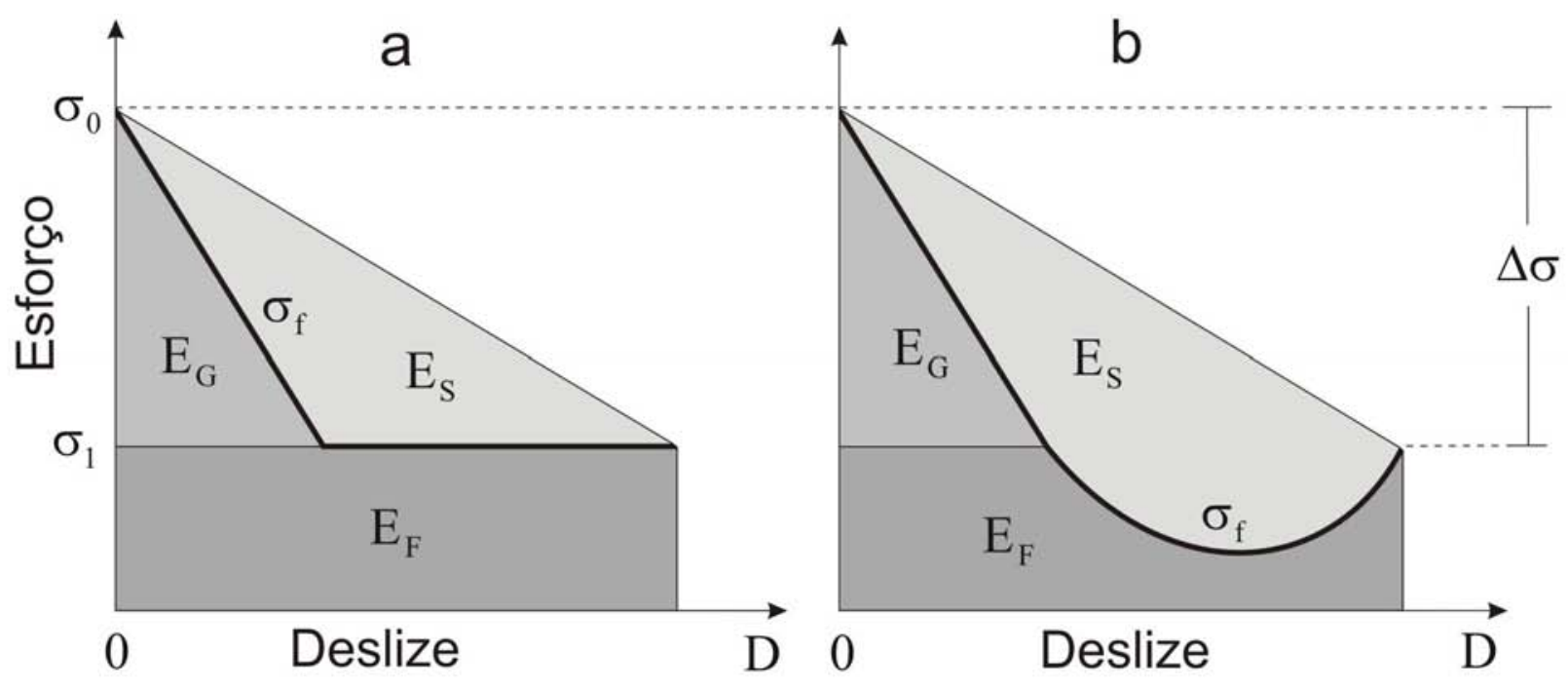

Figura 2.8: Comparação entre os parâmetros estático e dinâmicos da fonte. Por simplicidade, foi considerado $\sigma_{\mathrm{p}}=\sigma_{0}$. Note que enquanto o stress drop depende apenas do esforço inicial e final, a energia sísmica irradiada $\mathrm{E}_{\mathrm{S}}$ é uma função do esforço friccional $\sigma_{f}(\mathrm{~s})$ (curva mais espessa) durante o processo de ruptura (modificado de Prieto, 2007).

\section{Momento Sísmico e Frequência de Corte}

A relação entre os parâmetros estáticos, momento sísmico e escala de comprimento ou dimensão característica de ruptura $\tilde{L}$ (ver equação 2.4), tem sido amplamente usada (Walter et al., 2006). Da equação (2.7) é possível observar que, sob certos aspectos, a frequência de corte $f_{c}$ ou a duração da fonte $\tau$ podem ser usadas como uma representação para a dimensão da fonte.

Da equação (2.5) e (2.7) é possível observar que há uma relação entre o momento sísmico e a frequência de corte $\left(M_{0} \propto f_{c}^{-3}\right)$. Caso isto aconteça (considerando uma velocidade de ruptura constante), haverá uma relação do stress drop com o momento sísmico, conhecida como relação de escala*, o que implica numa independência de $\Delta \sigma$ com o tamanho do terremoto. No entanto, alguns estudos (Abercrombie, 1995; Kanamori \& Rivera, 2004) sugerem que, na realidade, a relação deveria ser $M_{0} \propto f_{c}^{-(3+\varepsilon)}$, onde $\varepsilon \leq 1$, representa a divergência da auto-similaridade e é usualmente pensado ser um número positivo e pequeno (Walter et al., 2006). Nesta situação, $\Delta \sigma$ seria dependente do tamanho do terremoto.

Devido às incertezas na determinação do stress drop, às vezes, é preferível usar o stress aparente na comparação com o momento sísmico (Ide \& Beroza, 2001), o qual será definido a seguir.

O termo, relação de escala, traduz o termo scaling em inglês. 


\section{Momento Sísmico e Energia Irradiada}

A energia irradiada tem grande importância nos estudos de parâmetros de fonte, pois ela fornece informações relevantes sobre a dinâmica de ruptura durante um terremoto (Mori et al., 2003). Um outro parâmetro dinâmico útil, proporcional à razão entre a energia sísmica irradiada $E_{S}$ e o momento sísmico $M_{0}$ é o stress aparente (Aki, 1967; Wyss \& Brune, 1968):

$$
\sigma_{a}=\mu \frac{E_{S}}{M_{0}}
$$

Este parâmetro tem sido usado com o propósito de comparar as características dinâmicas de pequenos e grandes terremotos, provendo a relação mais útil entre a física macroscópica e microscópica de um terremoto (Kanamori \& Rivera, 2006).

O módulo cisalhante do meio $(\mu)$, pode ser obtido conhecendo-se os valores da densidade e da velocidade da onda $S$, através da equação:

$$
\beta=\sqrt{\frac{\mu}{\rho}}
$$

o que resulta em $\mu=3,28 \times 10^{10} \mathrm{~Pa}$.

Usando a definição de momento sísmico dada pela equação (2.2), pode-se reescrever a equação (2.8) como:

$$
\sigma_{a}=\frac{E_{S}}{\bar{D} A}
$$

Nesta expressão, $\sigma_{a}$ pode ser interpretado como a energia sísmica irradiada, por unidade de área, por unidade de deslocamento.

O comportamento do stress aparente como função da magnitude, a relação de escala $\left(\sigma_{a} \propto M_{0}\right)$, é de grande importância. Alguns autores encontraram que o stress 
aparente aumenta com a magnitude (Kanamori et al., 1993; Abercrombie, 1995; Kanamori \& Heaton, 2000; Mori et al., 2003), enquanto que para outros, este parâmetro é independente desta (Ide \& Beroza, 2001; Ide et al., 2003; Prieto et al., 2004; Imanishi \& Ellsworth, 2006). Na Figura 2.9 estão representados alguns resultados desses estudos.

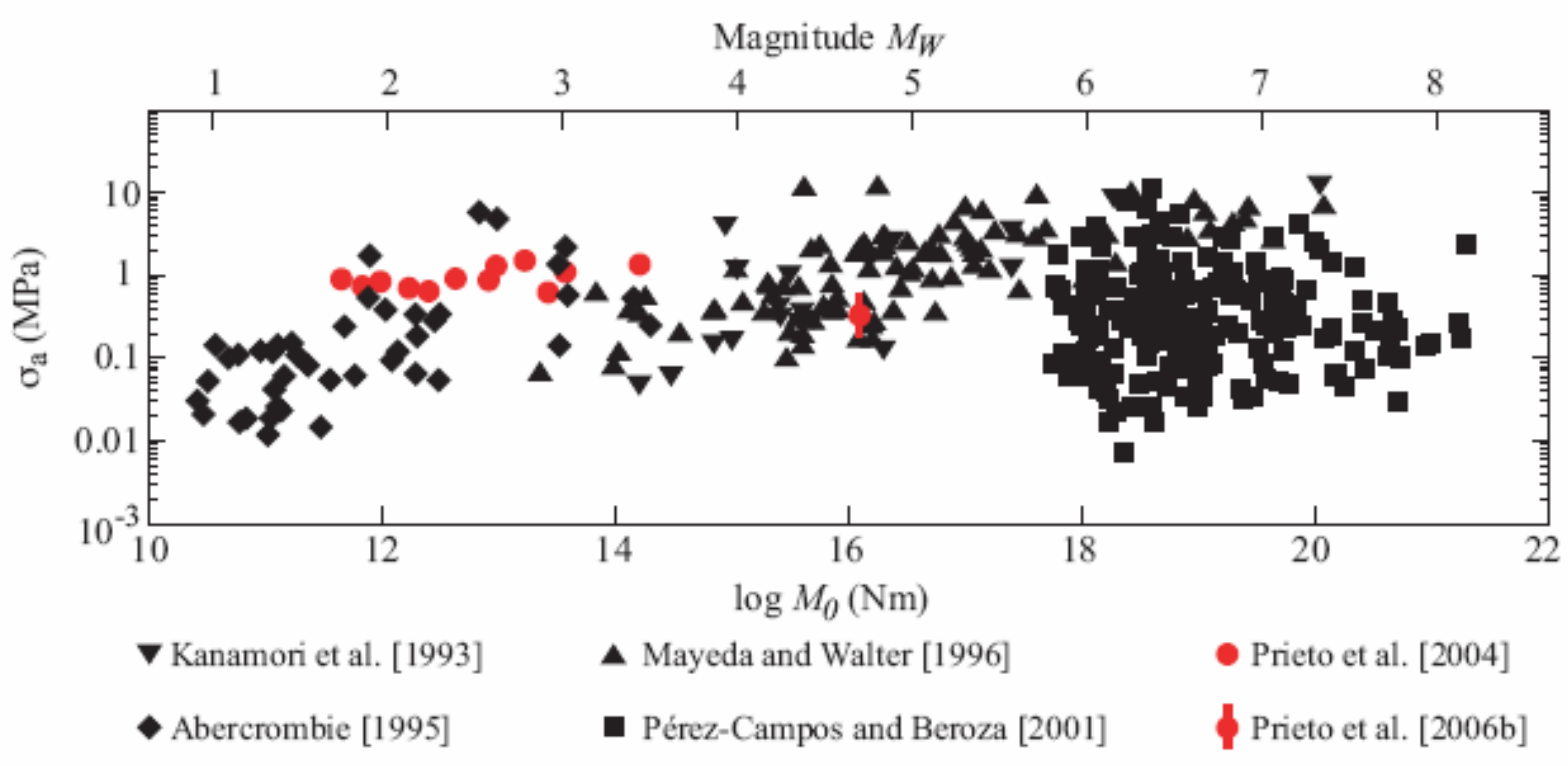

Figura 2.9: Relação do stress aparente com a magnitude e o momento sísmico para alguns estudos (Prieto, 2007).

Caso o stress aparente permaneça constante, ou seja, se a razão $E_{S} / M_{0}$ for invariante, os terremotos grandes e pequenos são auto-similares, de forma que a física da ruptura é a mesma para ambos, diferindo apenas por um fator multiplicativo, conforme pode ser observado na Figura 2.10. Porém, se o stress aparente aumentar com a magnitude, isto implica que os terremotos maiores são irradiadores de energia mais eficientes que os terremotos menores (Prieto et al., 2004).

$\mathrm{Na}$ literatura, para grandes terremotos $\left(M_{W}>3\right), \sigma_{a}$ parece ser constante, implicando numa auto-similaridade dos terremotos grandes e pequenos. Porém, alguns estudos de pequenos terremotos, têm encontrado uma quebra na relação de escala para magnitudes menores que 3 (Abercrombie, 1995; Mori et al., 2003). Isto pode ser observado na Figura 2.9.

A Figura 2.11 mostra alguns modelos de ruptura para terremotos grandes e pequenos. Através destes modelos é possível observar o comportamento de alguns 
parâmetros (stress drop, energia irradiada, stress aparente, dentre outros) com a magnitude do terremoto, representada pelo deslize $\bar{D}$.

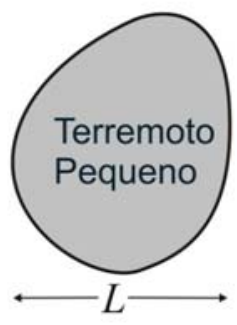

$$
\text { área }=A \sim L^{2}
$$$$
\text { deslize }=\bar{D} \sim \frac{\Delta \sigma_{e}}{\mu} L
$$$$
M_{0}=\mu \bar{D} A \sim \Delta \sigma_{e} L^{3}
$$$$
\text { duração }=T \sim \bar{D} / V \sim L
$$$$
\text { energia }=E_{S} \sim P^{2} / T
$$

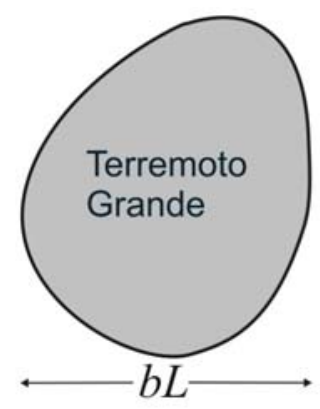

área $=b^{2} A$

deslize $=b \bar{D}$

$M_{0}=b^{3} M_{0}$

duração $=x \bar{D}$

energia $=b^{3} E_{S}$

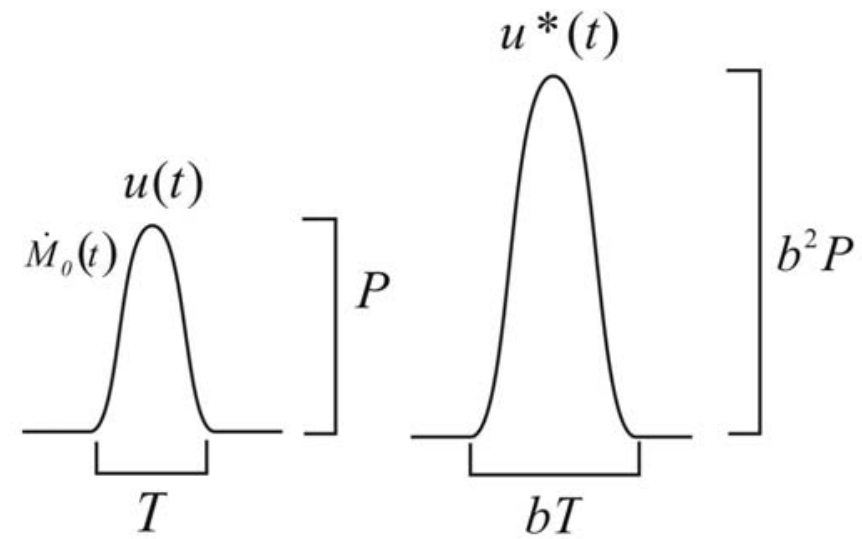

Figura 2.10: Auto-similaridade. A figura superior mostra dos terremotos que diferem na área por um fator b. No meio estão alguns parâmetros que dependem da dimensão L e como eles escalam com b para os terremotos que possuem a mesma física de ruptura. A figura inferior mostra o pulso deslocamento do campo-distante, em que a largura é aumenta por um fator $\mathrm{b}$ e altura por $\mathrm{b}^{2}$, de forma que a energia é aumentada por $\mathrm{b}^{3}$. Observe que a razão energia/momento permanece constante (modificado de Walter et al., 2006).

O modelo da auto-similaridade (Prieto et al., 2004) representado pela Figura 2.11a, considera que a energia de fratura $\left(E_{G}\right)$ permanece constante de forma que $E_{S}$ escala proporcionalmente com o deslize D. Neste caso, ambos stress drop e stress aparente serão constante para terremotos de qualquer magnitude.

Na Figura 2.11b, $E_{G}$ aumenta proporcionalmente com o deslize D. Assim, $\sigma_{\mathrm{a}}$ não será constante, porém, o stress drop $\Delta \sigma$ é independente da magnitude. Neste modelo, a medida do terremoto está relacionada à energia de fratura. 
Já no modelo da Figura 2.11c, conhecido como modelo de lubrificação da falha (Kanamori \& Heaton, 2000), . a ruptura comporta-se como o modelo da auto-similaridade até uma certa distância quando, então, ocorre uma queda adicional no esforço de fricção. Este modelo sugere que há um processo físico diferente durante a ruptura de pequenos e grandes terremotos. Neste caso, ambos stress drop e stress aparente aumentam com a magnitude.

Como visto na Figura 2.11b, podem existir situações em que o stress drop permanece constante com o aumento da magnitude, enquanto que o stress aparente varia. Assim, serão examinados estes dois parâmetros para, então, verificar se há ou não um processo de ruptura semelhante (auto-similaridade) para os eventos estudados.

\subsection{Como Estimar os Parâmetros de Fonte?}

Até este momento, foram discutidos alguns dos parâmetros usados para descrever a ruptura do terremoto, através dos registros obtidos em uma estação sísmica (usando principalmente sensores de velocidade e/ou acelerômetros) que registra o movimento do solo associado com a ruptura do terremoto e a energia sísmica irradiada.

As ondas, geradas por um terremoto, que se propagam dentro da crosta e do manto da Terra são afetadas pelas variações na atenuação, velocidade e densidade nas proximidades da superfície terrestre, sendo espalhadas até chegarem em uma estação sísmica (Prieto, 2007). Estas perturbações sofridas pela onda original precisam ser consideradas e corrigidas, para então obter uma estimativa confiável dos parâmetros de fonte. Diferentes métodos usados para corrigir os efeitos de propagação podem gerar resultados muito diferentes, até mesmo quando aplicados aos mesmos dados (Ide et al., 2003).

Alguns autores (Abercrombie, 1995; Ide et al., 2003; Tomic et al., 2008) usam o espectro de amplitude das ondas sísmicas para estimar os parâmetros de fonte. Porém, resultados similares podem ser obtidos trabalhando no domínio do tempo (Kanamori et al., 1993; Domanski et al, 2002; Mori et al., 2003). Todavia, em muitos casos, as correções para atenuação são mais facilmente feitas no domínio da frequência (Prieto, 
2007). As correções feitas neste trabalho serão explicadas com base no que é registrado por uma estação sísmica.

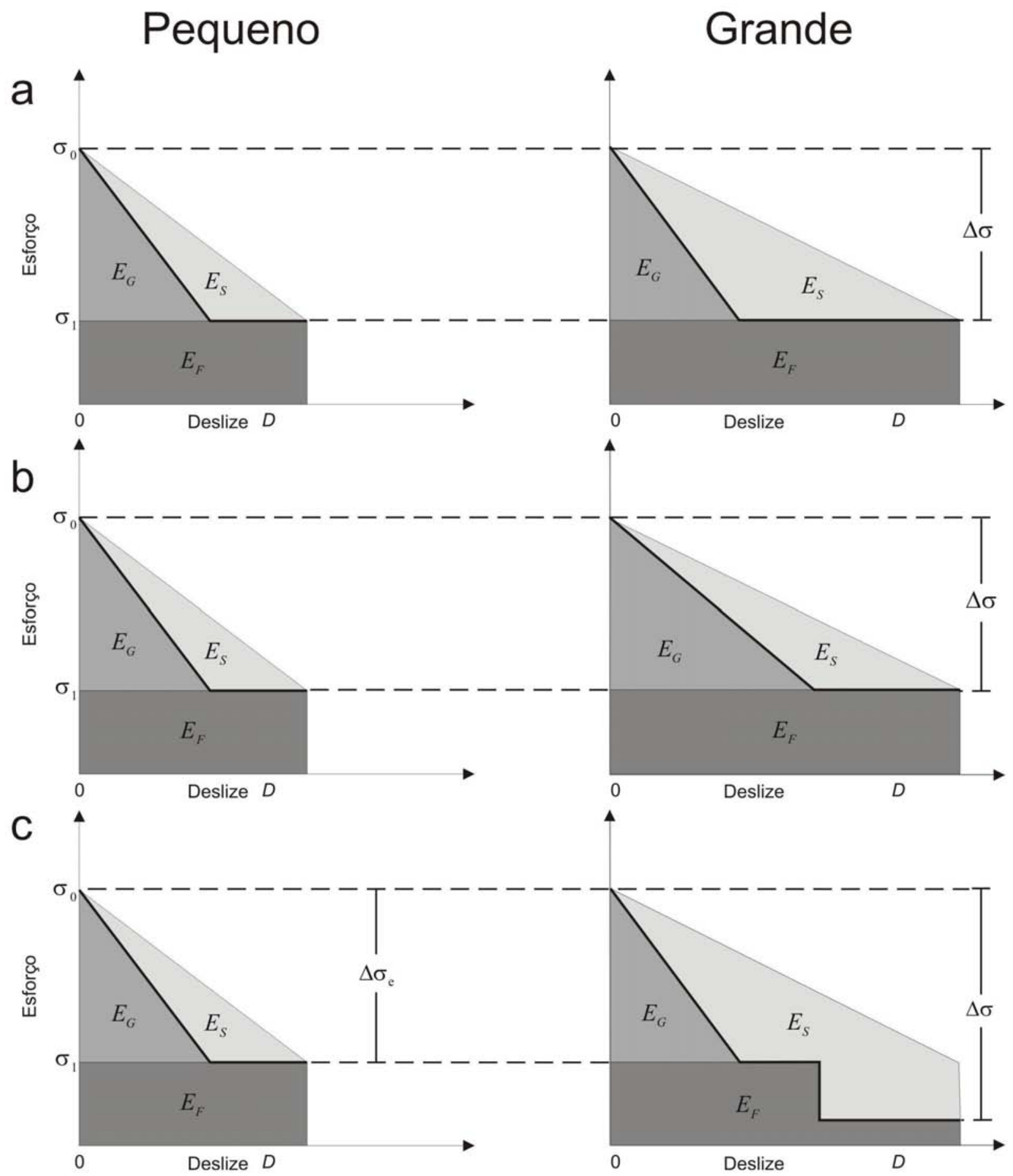

Figura 2.11: Modelos de ruptura para terremotos grandes e pequenos. Por simplicidade foi considerado $\sigma_{p}=\sigma_{0}$. A linha espessa representa o esforço friccional $\sigma_{\mathrm{f}}$. Devido à ruptura, o esforço inicial $\sigma_{0}$ decai até o esforço final $\sigma_{1}$ com o aumento do deslize D. a) No modelo da auto-similaridade, a energia irradiada $\mathrm{E}_{\mathrm{S}}$ aumenta como função do deslize $\mathrm{D}$; b) neste caso, a energia de fratura varia com o deslize $\mathrm{D}$ assim, $\mathrm{E}_{\mathrm{S}}$ não escala proporcionalmente como uma função de $\mathrm{D}$, o que implica numa dependência do stress aparente $\sigma_{\mathrm{a}}$ com a magnitude; c) no modelo de lubrificação da falha de Kanamori \& Heaton (2000) o esforço friccional decresce como no modelo da autosimilaridade até um certa distância quando, então, decresce ainda mais, gerando um alto stress drop e irradiando muito mais energia (modificado de Prieto, 2007). 
O registro em um sismograma pode ser representado por:

$$
u(t)=x(t) * g(t) * i(t)
$$

o símbolo $(*)$ representa a operação de convolução, em que $x(t)$ é a assinatura da fonte, $g(t)$ é a resposta de um operador representando os efeitos da estrutura da Terra ao longo da trajetória das ondas sísmicas e $i(t)$ é a reposta do sismômetro. A Figura 2.12 é uma representação esquemática de um sismograma resultante da convolução de uma fonte com função trapezoidal, que representa o sinal emitido por um sismo com os operadores que representam os efeitos produzidos pela estrutura da Terra e pelo sismômetro.

No domínio da frequência a convolução torna-se uma operação de multiplicação:

$$
U(\omega)=X(\omega) G(\omega) I(\omega)
$$

em que $\omega$ é a frequência angular. Assim, é preciso corrigir os efeitos de propagação e instrumentais para então calcular os parâmetros de fonte. A correção da atenuação varia de estudo para estudo. A idéia básica é que o espectro da fonte é atenuado por uma crosta anelástica através da qual a onda viaja.

Sabe-se que atenuação é proporcional ao inverso do fator de qualidade Q. Assim, é preciso fazer um estudo acerca deste parâmetro para, então, poder corrigir o sinal registrado pela estação sísmica. É possível representar o fator de qualidade como uma constante Q (Abercombrie, 1995; Prieto et al., 2006) ou como uma função dependente da frequência $Q=Q_{0} f^{b}$, onde $\mathrm{Q}_{0}$ e b são ambas constantes (Dias \& Souza, 2004; Walter et al., 2006). Como não foi feito ainda nenhum estudo para a região de Cascavel - CE, de forma que se determinassem esses parâmetros, foi considerado um valor constante de 250 para o fator de qualidade. Este valor foi baseado nas estimativas obtidas por Tomic el al. (2008) na região de Açu - RN, sendo razoável, já que as duas regiões estão dentro do embasamento cristalino do Pré-Cambriano.

Porém, separar as características da fonte dos efeitos causados pela propagação e estrutura da Terra é bastante complicado, especialmente quando a frequência de corte do terremoto é próxima ou maior que a frequência dominante gerada pela resposta da 
propagação e estrutura (Frankel, 1982; Frankel \& Wennerberg, 1989). Frankel e Wennerberg (1989) mostraram que para terremotos com magnitudes menores que $M_{L} 3,0$ registrados em Anza, Califórnia, a resposta da estrutura da Terra domina o espectro de frequência, mascarando a frequência de corte do terremoto.

Outro passo importante a se fazer para determinar os parâmetros de fonte, além de corrigir os efeitos de propagação e atenuação, é remover a resposta do equipamento. O procedimento necessário para remover a influência do sismômetro será descrito no próximo capítulo.

$x(t)$
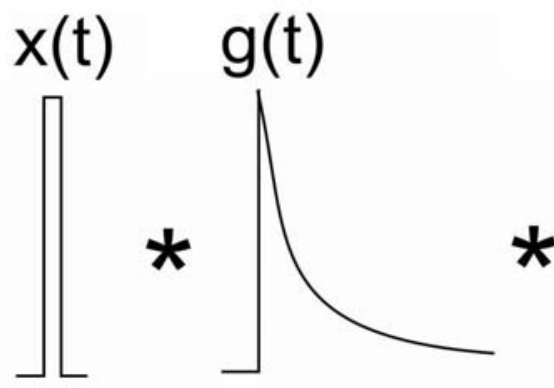

$\mathrm{i}(\mathrm{t})$

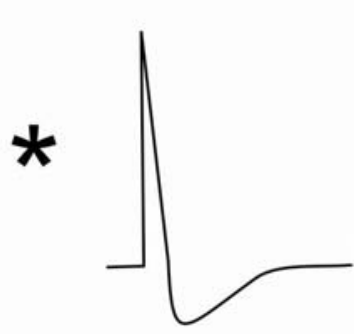

Fonte Estrutura Instrumento $\mathrm{u}(\mathrm{t})$

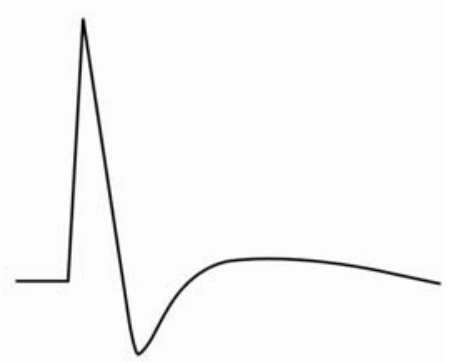

Sismograma

Figura 2.12: Um sismograma pode ser representado pela convolução do sinal emitido pela fonte com os operadores que representam os efeitos da estrutura da Terra e do instrumento. 


\section{CAPÍTULO 3 -DADOS SISMOLOGICOS}

Neste capítulo será apresentado o tipo de equipamento utilizado na aquisição dos dados, a localização das estações sismográficas e os epicentros dos sismos usados para calcular os parâmetros de fonte.

\subsection{Aquisição e Seleção dos Dados}

No período compreendido entre setembro de 1997 e março de 1998, a UFRN manteve em operação na região de Cascavel - CE, uma rede com seis estações sismográficas digitais de três componentes (Figura 1.7). Cada estação era composta por três sismômetros S-13 (um para a componente vertical e os outros dois orientados nas direções E-W e N-S) e um registrador do tipo PDAS - 100 (Portable Digital Acquisition System), todos fabricados pela Teledyne Geotech. A frequência natural desses sismômetros é de $1 \mathrm{~Hz}$ e sua constante de transdução é 629Volt/m/s. O registrador digitaliza os sinais em 16 bits, permitindo um ganho dinâmico de até 96 dB (do Nascimento, 1997). Durante o período de operação foram utilizadas taxas de 200 e 500 amostras por segundo.

Além das estações digitais, também foi instalada uma estação analógica (CH8A) com registro em papel enfumaçado, a qual era composta por um sismômetro vertical, Wilmore MK3FS, frequência de $1 \mathrm{~Hz}$ e um sismógrafo MEQ - 800 B com velocidade de registro de $120 \mathrm{~mm} / \mathrm{s}$. As estações CH8A e CH08 operaram no mesmo local.

A estação analógica, além ser utilizada para contabilizar os números de sismos, também serviu para calcular as suas magnitudes, usando a duração como parâmetro (Blum e Assumpção, 1990):

$$
\begin{aligned}
& m_{B}=1,90 \log D-1,25 \text { se } m_{R}>1,5 \\
& m_{B}=1,15 \log D-0,16 \text { se } m_{R}<1,5
\end{aligned}
$$

em que $D(\mathrm{~cm})$ é a duração do sismo no registro em papel enfumaçado. 
Alguns dos sismos utilizados neste trabalho não foram registrados pela estação analógica. Assim, foi feita uma relação entre a duração dos eventos que tiveram registros em ambas estações (digital e analógica), para que então fosse possível determinar a magnitude daqueles que não haviam sido registrados na estação CH8A.

Os valores das coordenadas das estações utilizadas neste trabalho estão na Tabela 3.1, sendo que a maioria, conforme visto na Figura 1.7, foi instalada sobre afloramentos graníticos/gnáissicos do escudo Pré-Cambriano (exceto a estação CH11, que por falta de afloramentos, foi enterrada na cobertura sedimentar para melhorar a relação sinal-ruído), fazendo com que a maioria dos registros seja de boa qualidade (chegadas das ondas $\mathrm{P}$ e $\mathrm{S}$ bastante claras).

\begin{tabular}{cccc}
\hline Estação & Latitude & Longitude & Método de Localização \\
\hline CH06 & $4^{\circ} 23,63^{\prime} \mathrm{S}$ & $38^{\circ} 16,44^{\prime} \mathrm{W}$ & GPS \\
CH08 & $4^{\circ} 25,20^{\prime} \mathrm{S}$ & $38^{\circ} 17,96^{\prime} \mathrm{W}$ & GPS \\
CH09 & $4^{\circ} 26,09^{\prime} \mathrm{S}$ & $38^{\circ} 17,44^{\prime} \mathrm{W}$ & GPS \\
CH10 & $4^{\circ} 24,89^{\prime} \mathrm{S}$ & $38^{\circ} 16,11^{\prime} \mathrm{W}$ & GPS \\
CH11 & $4^{\circ} 24,26^{\prime} \mathrm{S}$ & $38^{\circ} 17,61^{\prime} \mathrm{W}$ & GPS \\
CH13 & $4^{\circ} 25,45^{\prime} \mathrm{S}$ & $38^{\circ} 16,89^{\prime} \mathrm{W}$ & GPS \\
\hline
\end{tabular}

Tabela 3.1: Coordenadas das estações sismográficas obtidas pelo GPS.

Vilar (2000) encontrou a seguinte razão entre as velocidades das ondas $\alpha / \beta=1,63$, com $\alpha=5,68 \mathrm{Km} / \mathrm{s}$, em que $\alpha$ e $\beta$ são as velocidades das ondas $\mathrm{P}$ e $\mathrm{S}$, respectivamente. Com esses valores, Gomes (2007) localizou 92 eventos com erro horizontal $\leq 0,5 \mathrm{Km}$ e vertical $\leq 0,2 \mathrm{Km}$, determinando um plano de falha com azimute de $148^{\circ} \mathrm{N}$ e com um mergulho de $76^{\circ}$.

Para calcular os parâmetros de fonte, foram selecionados 21 dos 92 eventos localizados por Gomes (2007), os quais possuem magnitudes entre 0,7 e 2,1 $\mathrm{m}_{b}$ (Figura 3.1; Tabela 3.2). Todos os 21 eventos foram registrados nas seis estações, com as profundidades variando entre $5,1-6,9 \mathrm{Km}$ e com distância hipocentral entre 5,5-19,5 Km (Gomes, 2007). 


\begin{tabular}{|c|c|c|c|c|c|c|c|c|}
\hline \multicolumn{2}{|c|}{ Data } & Hora & $\begin{array}{c}\text { Mag. } \\
m_{b}\end{array}$ & Latitude & Longitude & $\begin{array}{c}\text { Prof. } \\
(\mathrm{Km})\end{array}$ & Sismo \\
\hline 22 & 10 & 97 & $22: 24: 37.06$ & 1,6 & $-4,4220$ & $-38,2888$ & $-6,18$ & 1 \\
\hline 09 & 11 & 97 & $23: 18: 43.30$ & 0,7 & $-4,4057$ & $-38,2915$ & $-6,49$ & 5 \\
\hline 15 & 11 & 97 & $11: 22: 56.28$ & 1,2 & $-4,4020$ & $-38,2977$ & $-5,97$ & 15 \\
\hline 17 & 11 & 97 & $21: 45: 01.92$ & 0,9 & $-4,4040$ & $-38,2985$ & $-6,83$ & 17 \\
\hline 22 & 11 & 97 & $13: 20: 43.67$ & 1,2 & $-4,4127$ & $-38,2927$ & $-6,02$ & 20 \\
\hline 22 & 11 & 97 & $15: 58: 36.32$ & 1,1 & $-4,4152$ & $-38,2917$ & $-6,69$ & 21 \\
\hline 25 & 11 & 97 & $00: 11: 35.73$ & 1,5 & $-4,4118$ & $-38,2935$ & $-6,26$ & 24 \\
\hline 27 & 11 & 97 & $07: 39: 04.69$ & 0,8 & $-4,4008$ & $-38,2983$ & $-6,10$ & 30 \\
\hline 09 & 01 & 98 & $09: 55: 47.53$ & 1,2 & $-4,4063$ & $-38,2935$ & $-6,53$ & 36 \\
\hline 05 & 02 & 98 & $06: 29: 07.98$ & 1,3 & $-4,3248$ & $-38,4107$ & $-5,09$ & 54 \\
\hline 07 & 02 & 98 & $10: 25: 42.15$ & 1,5 & $-4,3987$ & $-38,2997$ & $-5,73$ & 59 \\
\hline 18 & 02 & 98 & $21: 28: 52.20$ & 1,3 & $-4,4015$ & $-38,3002$ & $-5,48$ & 62 \\
\hline 21 & 02 & 98 & $02: 38: 56.85$ & 2,1 & $-4,4037$ & $-38,2980$ & $-6,48$ & 65 \\
\hline 21 & 02 & 98 & $05: 41: 53.46$ & 1,2 & $-4,4027$ & $-38,2985$ & $-6,36$ & 66 \\
\hline 21 & 02 & 98 & $10: 08: 09.40$ & 1,6 & $-4,4018$ & $-38,2982$ & $-6,41$ & 69 \\
\hline 22 & 02 & 98 & $01: 22: 11.78$ & 1,3 & $-4,4005$ & $-38,2988$ & $-5,86$ & 71 \\
\hline 26 & 02 & 98 & $14: 20: 15.84$ & 1,0 & $-4,4062$ & $-38,2970$ & $-6,93$ & 76 \\
\hline 02 & 03 & 98 & $05: 53: 22.58$ & 1,4 & $-4,4198$ & $-38,2870$ & $-5,56$ & 83 \\
\hline 02 & 03 & 98 & $05: 59: 34.06$ & 1,3 & $-4,4197$ & $-38,2877$ & $-5,53$ & 85 \\
\hline 02 & 03 & 98 & $06: 01: 36.99$ & 1,3 & $-4,4185$ & $-38,2900$ & $-5,60$ & 86 \\
\hline 02 & 03 & 98 & $09: 54: 20.76$ & 1,6 & $-4,4187$ & $-38,2897$ & $-5,51$ & 92 \\
\hline
\end{tabular}

Tabela 3.2: Localização dos 21 sismos usados neste trabalho. Também está incluída a magnitude de cada evento, bem como o dia em cada um aconteceu. 


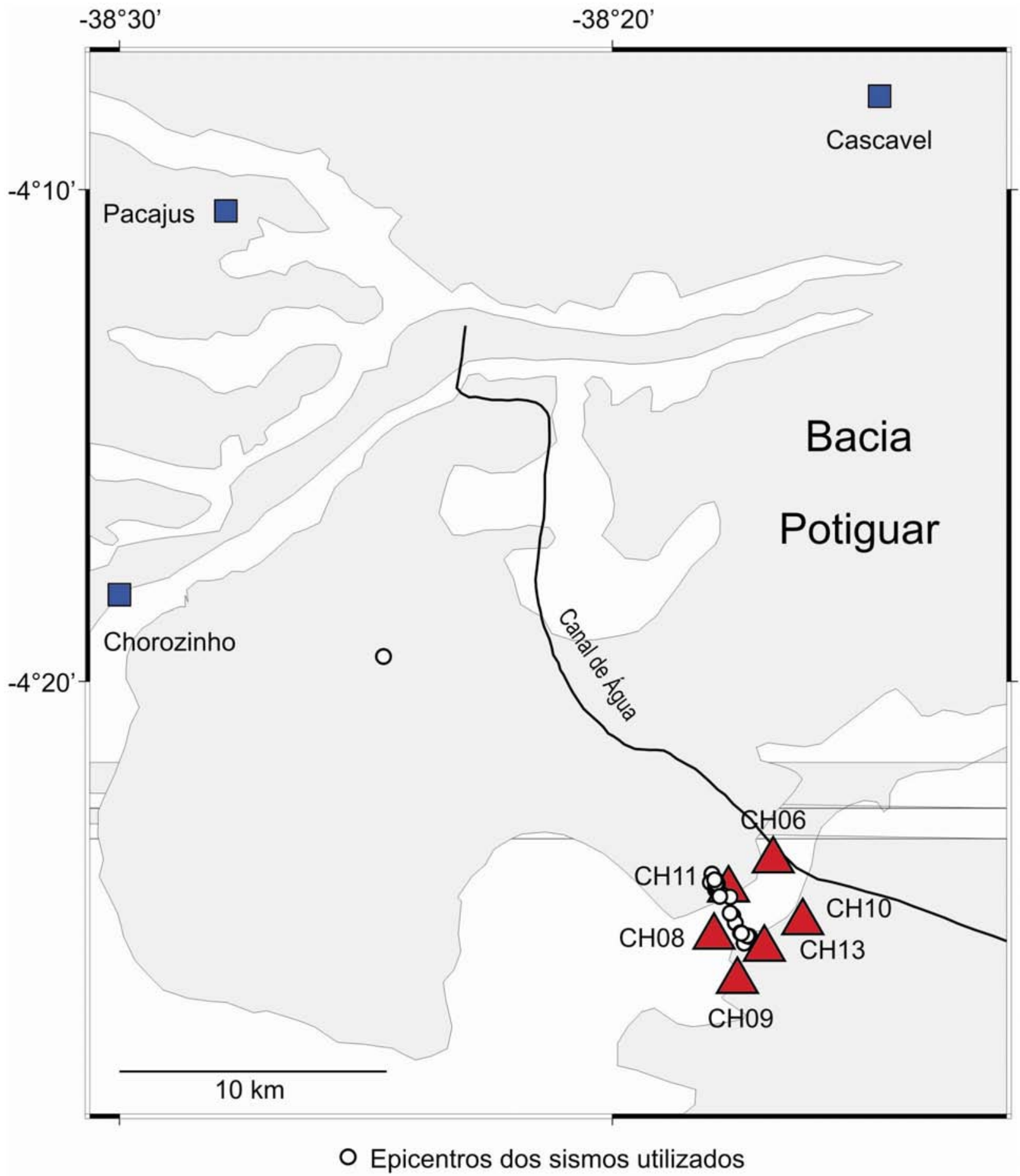

Figura 3.1: O mapa representa a Bacia Potiguar e o embasamento cristalino. Os quadrados azuis denotam as principais cidades e os triângulos vermelhos são as estações usadas neste estudo. Os círculos brancos representam os epicentros dos sismos usados para obter os parâmetros de fonte. 


\subsection{Remoção da Resposta do Equipamento}

Como mostrado no capítulo anterior, o registro em um sismômetro é um conjunto de efeitos causados pela fonte, pela estrutura da Terra e pela resposta do equipamento. A resposta do sismômetro pode ser retirada conhecendo-se os seus pólos e zeros (para mais detalhes ver Haskov \& Alguacil, 2004).

Como o sismômetro S-13 é um transdutor de velocidade, é necessário integrar o sinal no tempo para obter o deslocamento. Isto é feito para que se possa analisar os espectros de deslocamento. Todos estes procedimentos foram feitos usando o SAC (Seismic Analysis Code) desenvolvido pelo Lawrence Livermore National Laboratory da Universidade da Califórnia, Estados Unidos.

A Figura 3.2 mostra dois sismogramas, em que (a) representa o dado digital registrado pela estação $\mathrm{CH} 08$, enquanto que (b) é o mesmo sismograma após a resposta do equipamento ter sido removida e realizada a integração no tempo, para obtenção do deslocamento. 

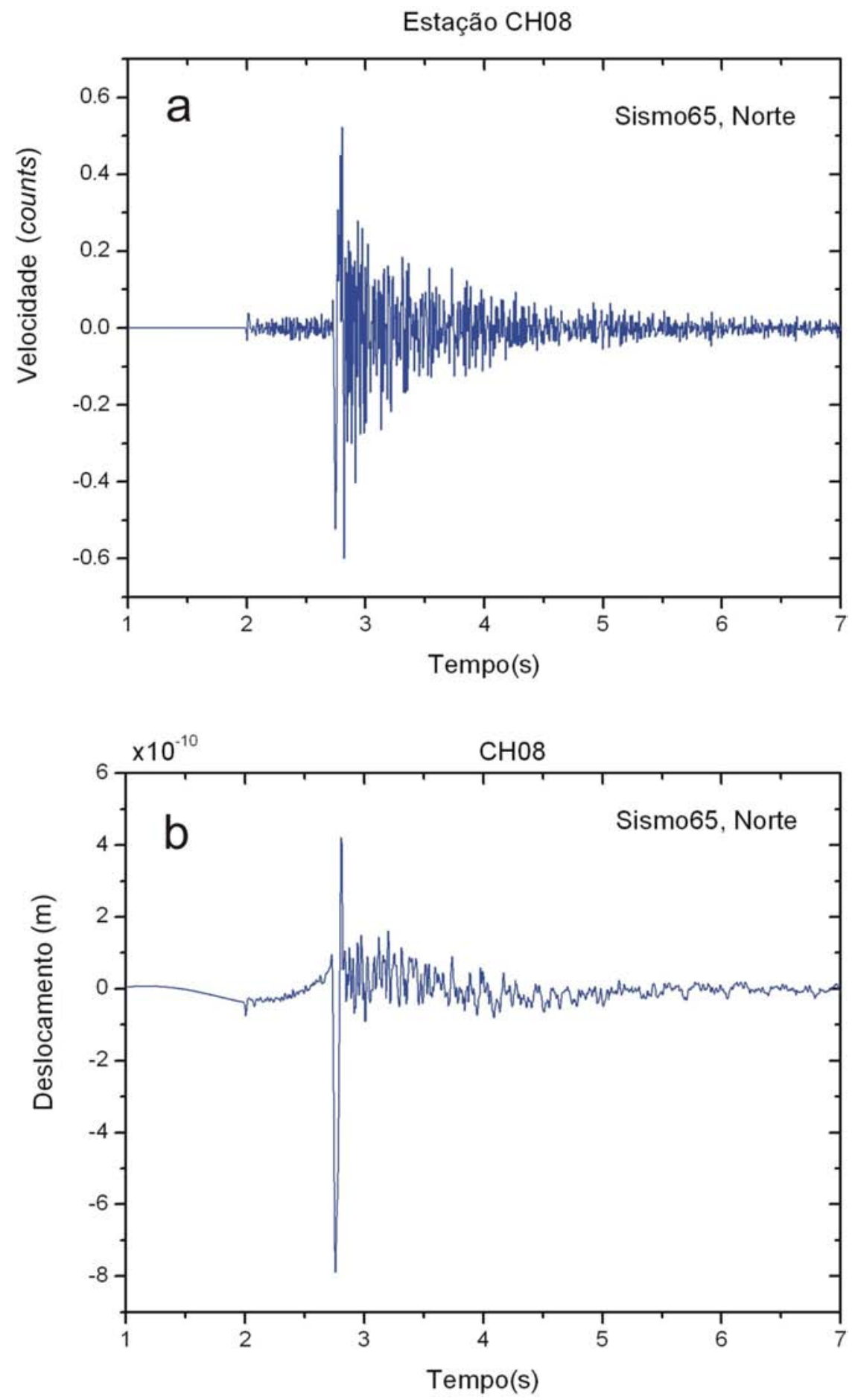

Figura 3.2: a) Registro do sismo65 na estação CH08 (canal Norte). b) O mesmo sismo após a resposta do equipamento ter sido removida e realizada a integração no tempo. 


\section{CAPÍTULO 4 - METODOLOGIA}

Este capítulo traz uma abordagem de como foi feito o cálculo do momento sísmico $\left(M_{0}\right)$, do raio da fonte $(r)$, do stress drop $(\Delta \sigma)$, da energia sísmica irradiada $\left(\mathrm{E}_{\mathrm{S}}\right)$ e da magnitude momento $\left(\mathrm{M}_{\mathrm{W}}\right)$ para o sismos de interesse. $\mathrm{O}$ momento sísmico é relativamente confiável de se estimar a partir do espectro de deslocamento (Tomic, 2004). A dimensão da fonte foi estimada a partir da frequência de corte, obtida ajustandose o espectro de deslocamento de cada sismo. Com os valores do momento e do raio, podem-se obter os demais parâmetros. Para tal foi utilizado o modelo de fonte circular (Brune, 1970; Madariaga, 1976).

\subsection{Análise Espectral}

\subsubsection{Modelo}

O espectro de deslocamento do movimento do solo causado por um terremoto tem uma forma característica quando representado em um gráfico log-log (Abercombrie, 1991). A amplitude é constante em baixas frequências (assíntota de baixa frequência) e decai linearmente (no gráfico log-log) em altas frequências (assíntota de alta frequência) (Figura 4.1). A assíntota de baixa frequência $\left(\Omega_{0}\right)$ (também conhecida como amplitude de longo período) depende da área da falha e do deslize total (Brune 1970, 1971), sendo desta forma proporcional ao momento sísmico (Aki, 1966).

A frequência na qual as assíntotas de baixa e alta frequência se interceptam é conhecida como frequência de corte $\left(f_{c}\right)$ (Figura 4.1); esta caracteriza a forte mudança no comportamento do espectro de amplitude. A frequência de corte, no domínio do tempo, está relacionada à duração da ruptura da falha (Brune 1970, 1971; Madariaga 1976). A duração da ruptura depende da velocidade de ruptura e do tamanho da fonte (equação 2.6). 


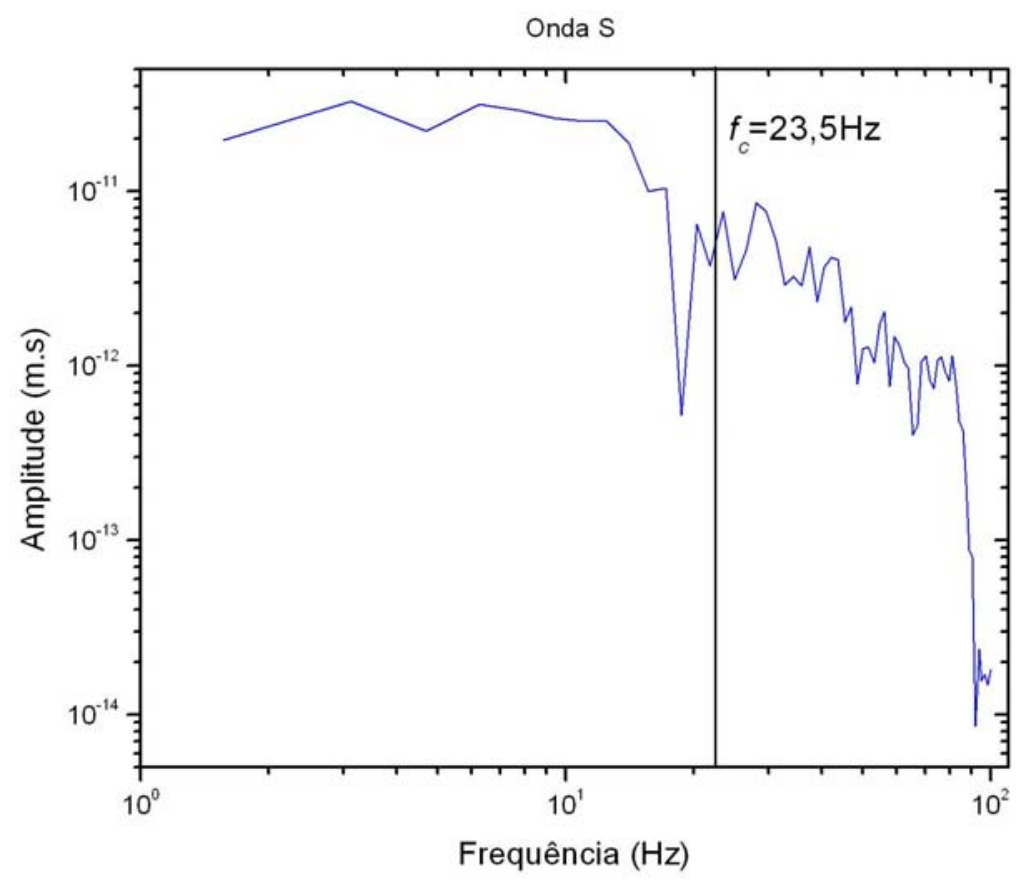

Figura 4.1: Representação do espectro de deslocamento de um sismo plotado num gráfico log-log. A reta vertical representa a frequência de corte, a qual separa o espectro em duas regiões conhecidas como assintota de baixas e altas frequências.

\subsubsection{Análise Padrão no Domínio da Frequência}

A determinação de parâmetros de fonte tais como momento sísmico, raio da fonte e stress drop a partir da assíntota de baixa frequência e da frequência de corte é um procedimento bastante conhecido (Brune 1970, 1971). Para isto, foi feita uma análise no domínio da frequência seguindo proposta de Brune (1970). Como este método é extensamente utilizado (Abercrombie \& Leary, 1993; Ide \& Beroza, 2001; Ide et al., 2003; Sonley \& Abercrombie, 2006; Tomic et al., 2008; dentre outros), é possível fazer comparações dos resultados encontrados neste trabalho com estudos anteriores de parâmetros de fonte.

Devido à taxa de amostragem utilizada, o conteúdo de frequência da onda $\mathrm{P}$ é mais afetado que o da onda S (ver do Nascimento, 1997), podendo gerar frequências de corte com valores superiores ao intervalo usado, ao contrário das ondas $\mathrm{S}$ que possuem baixas frequências de corte. Assim, foi feita a análise espectral apenas das ondas S. Como a energia, principalmente nos sismos rasos, vem na forma de onda de cisalhamento, apenas 
os dados das componentes Norte/Sul e Leste/Oeste foram usados, já que estas possuem melhores registros deste tipo de onda.

Para obter os espectros de deslocamento da onda $S$, foi utilizada uma janela de tempo de 0,4 segundo iniciando-a 0,02 segundo antes da chegada desta fase. Na Figura 4.2 (a) está representado o intervalo da onda $\mathrm{S}$ utilizado, em (b) o mesmo intervalo, removido a resposta do equipamento e integrado no tempo e em (c) o seu espectro de deslocamento.

Todas as leituras e procedimentos necessários para analisar os registros digitais, antes do ajuste dos espectros, foram feitos utilizando o programa SAC.
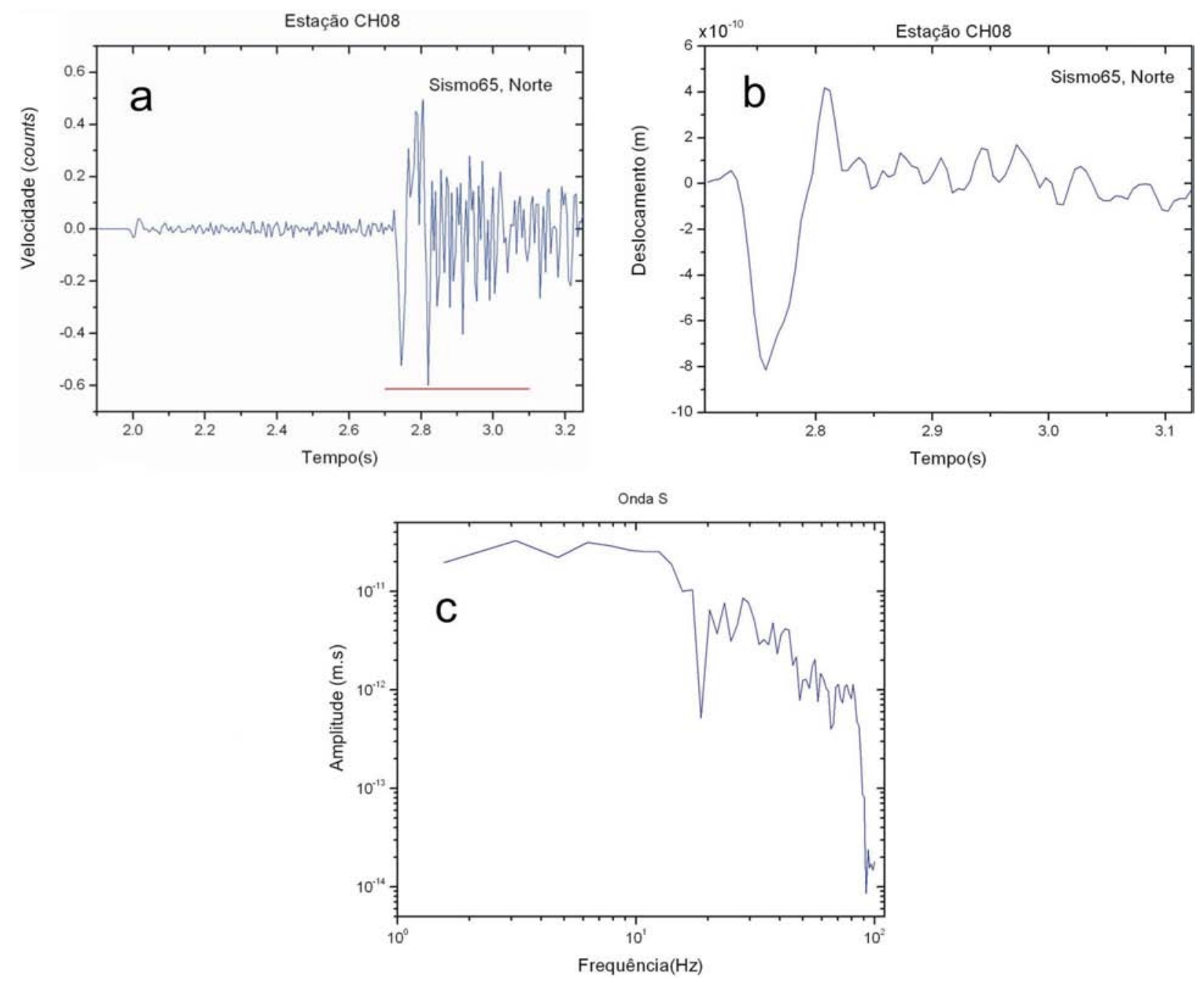

Figura 4.2: Dado antes do ajuste. a) O intervalo da onda S utilizado para determinar os parâmetros de fonte está representado pela linha vermelha. b) Intervalo anterior após ter a resposta do equipamento removida e ser integrado no tempo. c) Espectro de deslocamento do intervalo da onda S após aplicar a Transformada de Fourier. 


\subsubsection{Ajustando o Espectro}

A equação usada para ajustar o espectro de cada sismo é a mesma que foi utilizada por Brune (1970), Abercrombie (1995) e Tomic et al. (2008):

$$
\Omega(f)=\frac{\Omega_{0} e^{-\pi t / Q}}{\left[1+\left(f / f_{c}\right)^{n \gamma}\right]^{1 / \gamma}}
$$

onde $\Omega_{0}(m \cdot s)$ é a amplitude de longo período (equivalente a área sob o pulso deslocamento) do espectro sísmico de ondas $\mathrm{P}$ ou $\mathrm{S}$, removidos os efeitos instrumentais e de propagação, $f(H z)$ é a gama de frequência, $f_{c}$ é a frequência de corte da onda utilizada (neste caso da onda $\mathrm{S}$ ), $t(s)$ é o tempo de viagem fonte-receptor desta onda, $Q$ é o fator de qualidade independente da frequência, $n$ é a taxa de queda da alta frequência (no gráfico log-log) e $\gamma$ é uma constante que controla a agudez do corte no espectro.

Para esta dissertação foi considerado um Q constante de 250, valor razoável para a região de estudo que se encontra no embasamento cristalino do Pré-Cambriano. Assim como no modelo utilizado por Brune (1970), neste trabalho foi usado $n=2$ e $\gamma=1$.

Para ajustar o espectro de deslocamento de cada sismo, foi utilizado o método de Levenberg-Marquardt (LM). Para a maior parte dos dados, o melhor ajuste foi obtido até o ponto em que a iteração não apresentava novos valores, porém, para alguns casos, a curva que melhor se ajustava ao espectro de deslocamento foi obtida visualmente, já que uma nova iteração não produzia valores melhores que o anterior.

Após o ajuste foi possível obter os dois parâmetros livres da equação (4.1): $\Omega_{0} \mathrm{e}$ $f_{c}$ (ver apêndice A, na tabela também estão os erro destes dois parâmetros). A Figura 4.3 mostra o mesmo intervalo para a onda $\mathrm{S}$ da Figura 4.2 com o espectro ajustado.

O momento $\left(M_{0}\right)$ é obtido através dos valores de $\Omega_{0}$ seguindo Brune (1970):

$$
M_{0}=\frac{4 \pi \rho \beta^{3} R \sqrt{\Omega_{0}(N)^{2}+\Omega_{0}(E)^{2}}}{U_{\phi \theta}}
$$


considerando que ambas componentes N-S e E-W têm sinal de boa qualidade. A densidade, $\rho$, é $2700 \mathrm{~kg} / \mathrm{m}^{3}, R$ é a distância hipocentral medida em metros, $\beta=3485 \mathrm{~m} / \mathrm{s}$ é a velocidade da onda $\mathrm{S}$ e $U_{\phi \theta}$ é o fator de correção das amplitudes sísmicas observadas devido à influência do padrão de radiação da fonte sísmica. Na literatura, o efeito da correção média do padrão de radiação varia entre 0,55 a 0,85 . De acordo com Aki e Richard (1980), a média é de 0,52 e 0,63 para as ondas P e S, respectivamente. Neste trabalho foi considerado $U_{\phi \theta}=0,63$ já que apenas a onda $S$ foi utilizada.
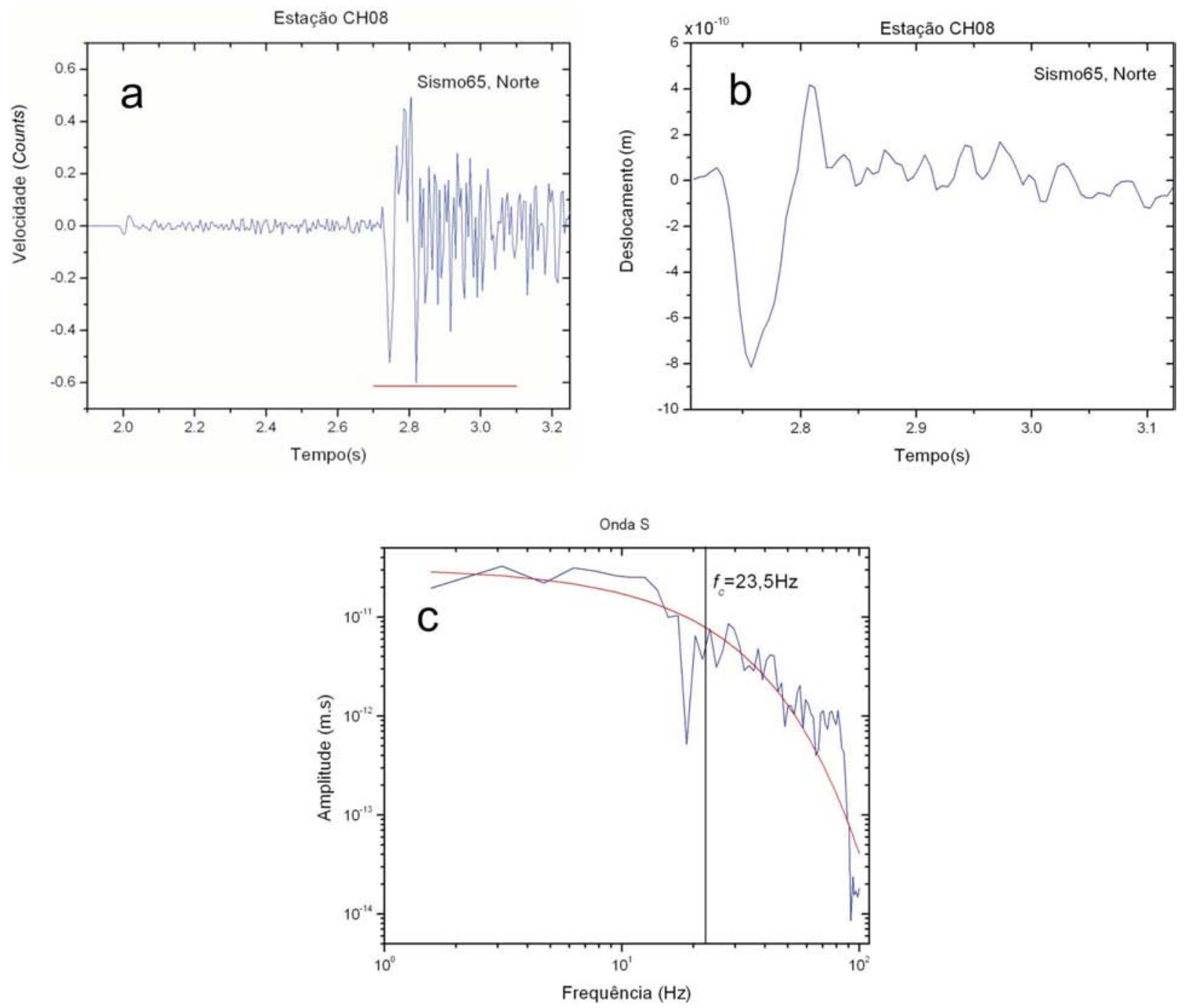

Figura 4.3: a) $\mathrm{O}$ intervalo da onda $\mathrm{S}$ utilizado para determinar os parâmetros de fonte está representado pela linha vermelha. b) Intervalo anterior após ter a resposta do equipamento removida e ser integrado no tempo. c) Espectro de deslocamento do intervalo da onda $\mathrm{S}$ (linha azul) após aplicar a Transformada de Fourier e ajustar o espectro (linha vermelha) através da equação (4.1), obtendo a frequência de corte. 
O raio da fonte $(r)$ é então calculado usando equação (2.7), porém ela é modificada de forma que se inclua a frequência de corte das componentes Norte/Sul e Leste/Oeste. Portanto, o raio é dado por:

$$
r=\frac{2 k \beta}{f_{c}(N)+f_{c}(E)}
$$

$\mathrm{Na}$ equação (4.3), são usadas as frequências de corte da componente Norte/Sul e Leste/Oeste, assim sendo, caso não seja possível ajustar o espectro em uma das componentes (ver apêndice A e B), também não será possível obter os parâmetros de fonte, já que o raio e consequentemente o stress drop estão condicionados aos valores das frequências de corte. Como mencionado no início, o modelo de Brune (1970) dá um raio cerca de 1,8 vezes maior que o de Madariaga para uma dada $f_{c}$, implicando num stress drop 5,5 vezes menor.

Após estimar o momento sísmico e o raio da fonte, foram usados esses valores para obter o stress drop de cada sismo, através da equação (2.5). Com esses resultados será possível verificar se há alguma dependência do stress drop com o momento sísmico. Como o stress drop possui muita instabilidade, também será usado o stress aparente para verificar algum tipo de relação com a medida do terremoto. Na literatura, é mais comumente utilizada a comparação entre stress aparente e momento do que entre stress drop e momento (Ide \& Beroza, 2001).

Variação da forma da fonte e qualquer efeito de directividade resultarão em erros na determinação dos parâmetros de fonte de um terremoto quando usada a suposição de modelo de fonte circular (Abercrombie, 1995).

\subsection{Energia Sísmica e Magnitude Momento $M_{W}$}

Recentemente, muitos estudos têm sido realizados para estimar a energia sísmica irradiada de um terremoto (Abercrombie, 1995: Ide et al., 2003; Prieto et al., 2006; entre outros). O conhecimento deste parâmetro é muito importante para entender melhor o processo de ruptura de um terremoto. A sua estimativa também é importante para 
calcular o stress aparente (equação 2.8), o qual tem sido mais preferido que o stress drop, já que este último apresenta muitas incertezas $\left(\Delta \sigma \propto f_{\mathrm{c}}^{3}\right)$.

A energia sísmica total irradiada por uma falha $E_{S}$ pode ser determinada, em principio, examinando a energia do campo distante registrada nas estações sísmicas (Shearer, 1999). Isto consiste em um método complicado, pois é preciso fazer as correções para a propagação. Porém, estimativas são possíveis através da magnitude do terremoto. Gutenberg \& Richter (1956) encontraram uma relação empírica entre a energia e a magnitude:

$$
\log _{10} E_{S}(\text { ergs }) \approx 5,8+2,4 m_{b} \approx 11,8+1,5 M_{S}
$$

Obviamente, o cálculo da energia através da equação (4.4) possui todos os problemas de determinação da magnitude. Em particular, desde que $m_{b}$ satura, a estimativa da energia para qualquer terremoto com magnitude maior que aproximadamente 6,5 é provavelmente baixa. Da equação (4.4) é possível notar que um terremoto com $M_{S}=7,0$ libera aproximadamente 32 vezes mais energia que um evento com $M_{S}=6,0$ e 1000 vezes mais que um evento com $M_{S}=5,0$.

Segundo Abercrombie (1995), a energia sísmica é proporcional à integral da velocidade quadrática em ambos os domínios (tempo e frequência). Aqui foi usada a frequência, já que neste domínio foram feitas as correções necessárias. Para estimar a energia, foi utilizado o espectro de deslocamento sem ajuste, o qual foi convertido para a velocidade quadrática e então integrado no mesmo intervalo de frequência usado para o ajuste do espectro. A energia sísmica é proporcional à área abaixo da curva, conforme mostrado na Figura 4.4.

A estimativa da energia irradiada $\left(E_{S}\right)$ é calculada somando as integrais (I) de todas as três componentes usando a equação (Boatwright \& Fletcher, 1984):

$$
\mathrm{E}_{\mathrm{S}}=\frac{4 \pi \rho \beta \mathrm{R}^{2}\left\langle\mathrm{U}_{\phi \theta}\right\rangle^{2}}{\left(\mathrm{U}_{\phi \theta}\right)^{2}}(\mathrm{I}(\mathrm{V})+\mathrm{I}(\mathrm{N})+\mathrm{I}(\mathrm{E}))
$$


Assim como no trabalho de Abercrombie (1995), $\left\langle U_{\phi \theta}\right\rangle=U_{\phi \theta}$. As três integrais da equação acima representam as componentes Vertical, Norte/Sul e Leste/Oeste, respectivamente. A Figura 4.5 representa o espetro de velocidade quadrática, após converter-se um dos espectros de deslocamento (Figura 4.1) em velocidade e elevá-lo ao quadrado.

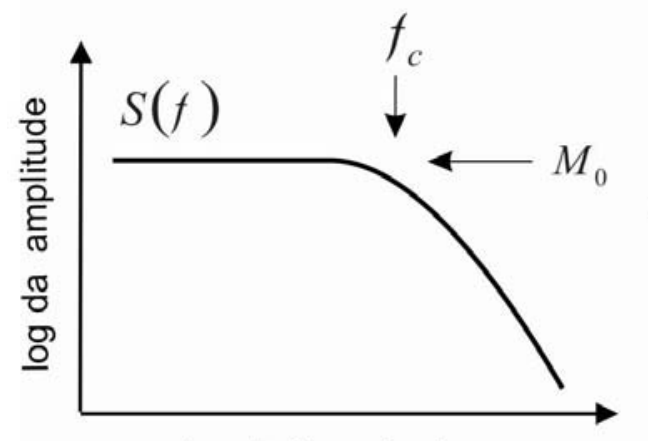

$\log$ da frequência

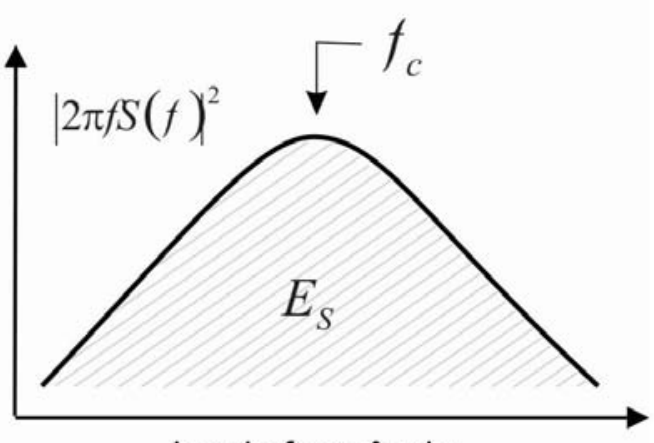

$\log$ da frequência

Figura 4.4: Ilustração da relação entre o espectro da fonte (após corrigir todos os efeitos de propagação e outros efeitos da fonte) e os parâmetros estáticos e dinâmicos. $\mathrm{O}$ momento sísmico $\mathrm{M}_{0}$ e a frequêcia de corte $f_{\mathrm{c}}$ podem ser relacionados ao espectro de deslocamento (esquerda). A energia sísmica está relacionada à área sob o espectro da velocidade quadrática (direita) (Modificado de Prieto, 2007).

As escalas $m_{b}$ e $M_{L}$ começam a saturar em aproximadamente 5,5 e 6,5, respectivamente para grandes eventos, o que motivou o desenvolvimento da magnitude momento $M_{W}$ por Kanamori (1977), definida por:

$$
M_{W}=\frac{2}{3} \log _{10} M_{0}-10,7
$$

onde $M_{0}$ é a medida do momento sísmico em dyne $\cdot \mathrm{cm} \quad\left(10^{5}\right.$ dyne $=1 \mathrm{~N}$; assim $10^{7}$ dyne $\left.\cdot \mathrm{cm}=1 \mathrm{~N} \cdot \mathrm{m}\right)$. A magnitude momento deriva inteiramente do momento sísmico. A vantagem dessa escala é que ela está claramente relacionada com as propriedades físicas da fonte e não satura até mesmo para grandes terremotos.

Estudos anteriores encontraram uma relação linear entre a magnitude momento $M_{W}$ e a magnitude local $M_{L}$ (Prieto et al., 2004; Prieto, 2007). Nesta dissertação será 
usado a magnitude $m_{b}$ no lugar de $M_{L}$, para verificar se existe alguma relação e se os valores estimados para a magnitude momento são compatíveis com $m_{b}$.

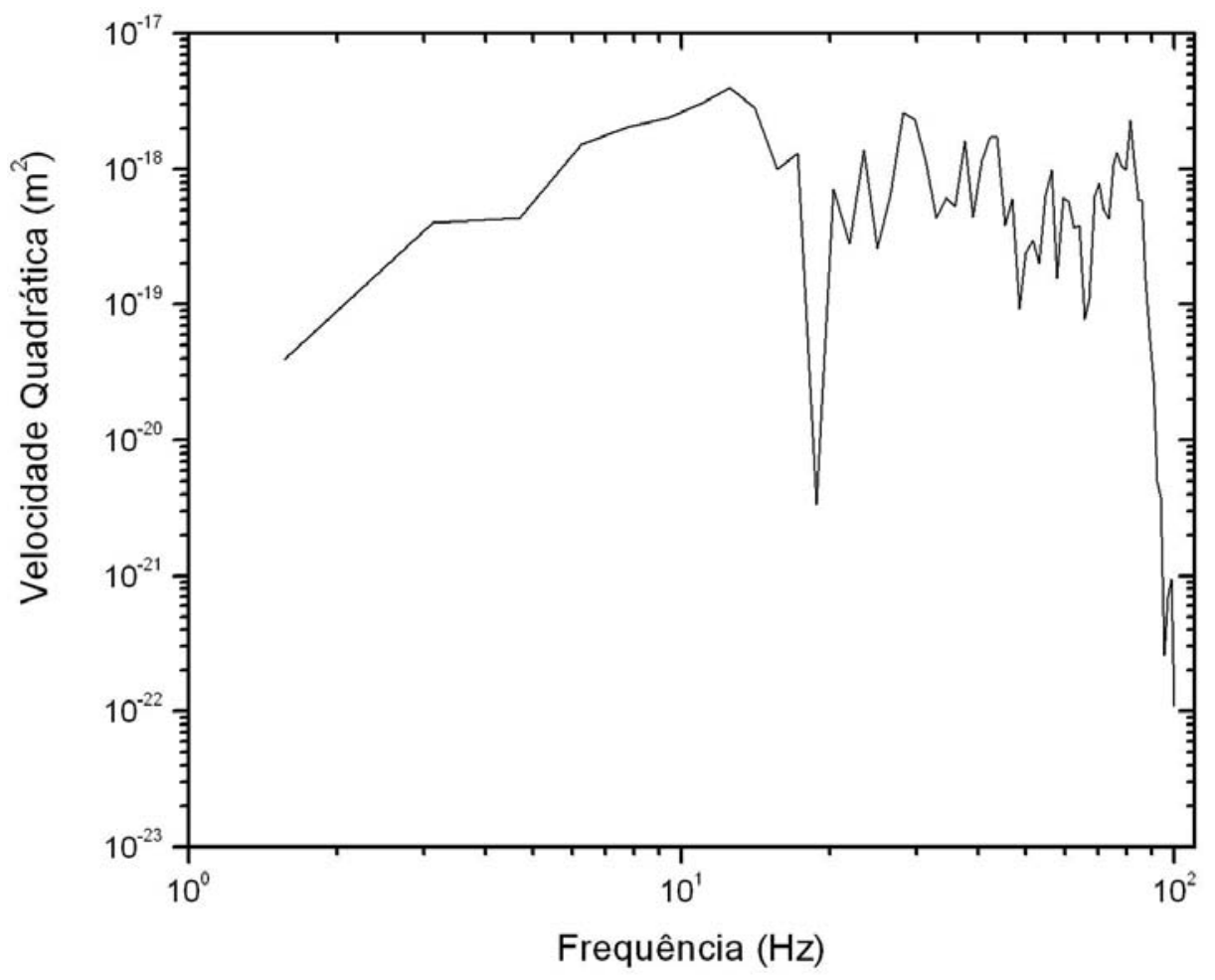

Figura 4.5: Espectro de velocidade quadrática do sismo65, componente Norte. A energia sísmica é obtida integrando este espectro. 


\section{CAPÍTULO 5 - RESULTADOS DOS PARÂMETROS DE FONTE}

Neste capítulo serão apresentados os resultados obtidos para os parâmetros de fonte dos 21 sismos selecionados. Durante o ajuste do espectro de deslocamento, não foi possível obter os parâmetros de fonte de alguns sismos em determinadas estações.

\subsection{Raio da Fonte}

Com os valores obtidos para as frequências de corte, nas componentes Norte/Sul e Leste/Oeste, ajustando-se o espectro de deslocamento através da equação (4.1), foi calculado o raio da fonte pela equação (4.3), para os dois modelos utilizados neste trabalho. Em ambos modelos, os raios obtidos não passaram dos $100 \mathrm{~m}$, sendo compatíveis com os resultados de outros estudos na mesma escala de magnitude (Abercrombie, 1995; Tomic et al., 2008).

Para as estimativas (Tabela 5.1) usando o modelo de Brune, a maior variação nos valores, ocorreu no sismo69, que teve as medidas do raio entre 45 e $91 \mathrm{~m}$ nas estações CH11 e CH13, respectivamente (Figura 5.1). No modelo de Madariaga, $r$ ficou entre 25 e $51 \mathrm{~m}$, nas mesmas estações (Tabela 5.2; Figura 5.2). Tomic et al. (2008) também obtiveram resultados próximos a este intervalo, quando ajustaram os espectros dos eventos da Barragem de Açu - RN.

Como dito anteriormente e que pode ser observado nas Tabelas 5.1 e 5.2, o raio obtido a partir do modelo de Brune é aproximadamente 1,8 vezes maior que o encontrado utilizando o modelo de Madariaga. 


\begin{tabular}{|c|c|c|c|c|c|c|}
\hline \multicolumn{7}{|c|}{ Raio da Fonte (m) - Modelo de Brune } \\
\hline Sismo & $\mathrm{CH} 06$ & $\mathrm{CHO8}$ & $\mathrm{CH} 09$ & $\mathrm{CH} 10$ & CH11 & CH13 \\
\hline 1 & - & - & - & - & - & 37 \\
\hline 5 & - & - & - & 40 & 33 & 25 \\
\hline 15 & - & 24 & - & - & - & 62 \\
\hline 17 & 32 & 20 & - & - & - & 57 \\
\hline 20 & 30 & - & - & - & 18 & 58 \\
\hline 21 & - & - & - & 31 & - & 31 \\
\hline 24 & 31 & 42 & - & 28 & 27 & 65 \\
\hline 30 & - & 34 & - & 17 & - & - \\
\hline 36 & - & 24 & - & 34 & - & - \\
\hline 54 & - & 24 & - & - & - & - \\
\hline 59 & - & - & - & 30 & - & 27 \\
\hline 62 & 58 & 31 & - & - & - & 67 \\
\hline 65 & 27 & 46 & - & 20 & 44 & - \\
\hline 66 & - & 42 & - & - & 79 & 40 \\
\hline 69 & 51 & 89 & - & 85 & 45 & 91 \\
\hline 71 & - & 29 & - & - & 38 & 50 \\
\hline 76 & 28 & 22 & - & - & 24 & - \\
\hline 83 & 42 & 51 & - & - & 42 & - \\
\hline 85 & 28 & 35 & - & - & 35 & 51 \\
\hline 86 & 42 & 36 & - & - & 24 & 49 \\
\hline 92 & 50 & 46 & - & - & 30 & - \\
\hline
\end{tabular}

Tabela 5.1: Raio da fonte obtido através da equação (4.3) utilizando o modelo de fonte proposto por Brune (1970). $\mathrm{Na}$ tabela acima não foi obtido nenhum valor para a estação $\mathrm{CH09}$, pois não foi possível ajustar os seus espectros de deslocamento. 


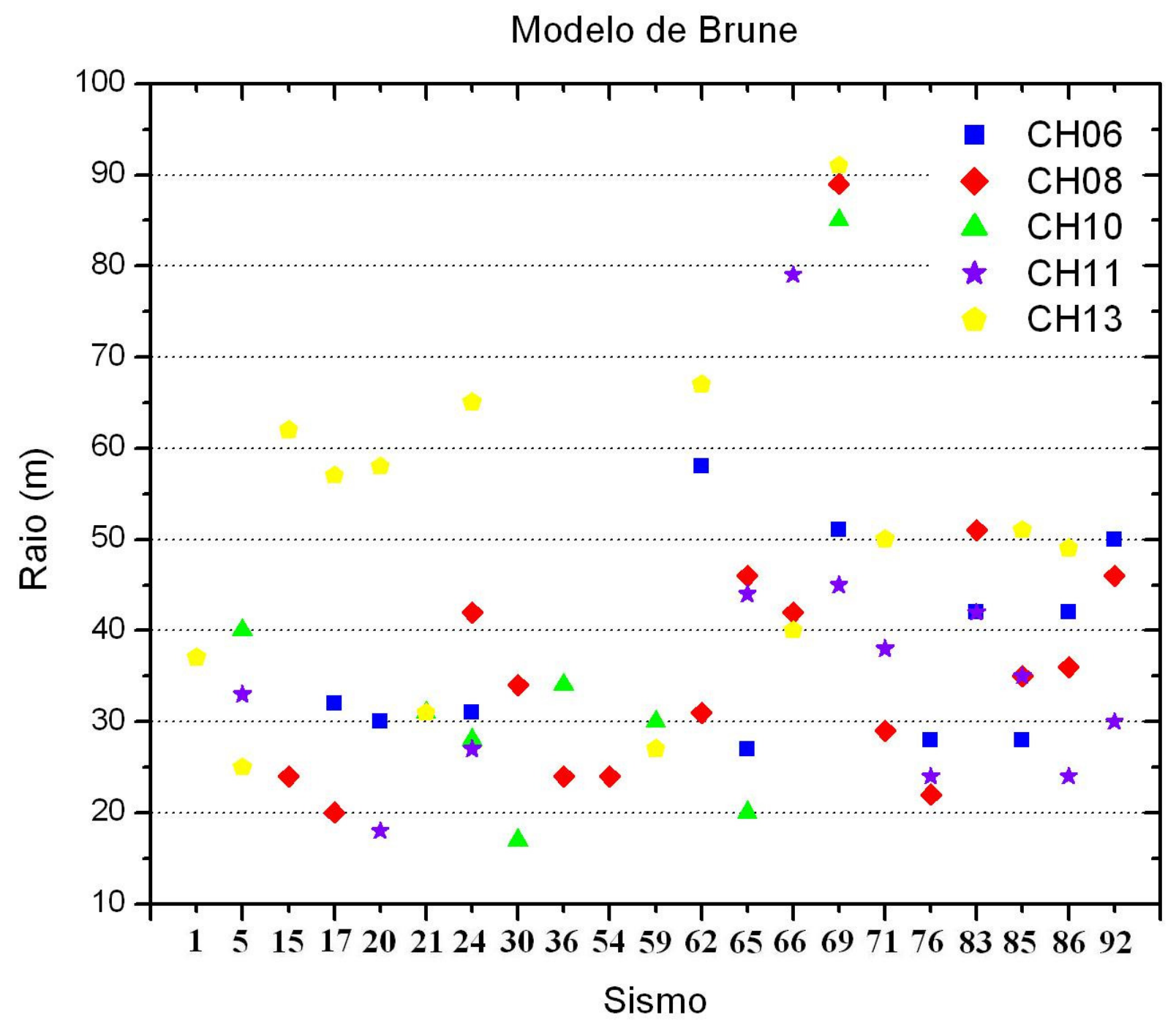

Figura 5.1: Variação nos valores dos raios da fonte dos 21 sismos utilizados neste trabalho. Os raios foram obtidos a partir da equação (4.3) usando o Modelo de Brune. A maior variação ocorreu no sismo69, com uma diferença de 46 m entre o valor máximo (CH13) e o mínimo (CH11). 


\begin{tabular}{|c|c|c|c|c|c|c|}
\hline \multicolumn{7}{|c|}{ Raio da Fonte (m) - Modelo de Madariaga } \\
\hline Sismo & CH06 & $\mathrm{CH} 08$ & CH09 & CH10 & CH11 & CH13 \\
\hline 1 & - & - & - & - & - & 21 \\
\hline 5 & - & - & - & 23 & 19 & 14 \\
\hline 15 & - & 14 & - & - & - & 35 \\
\hline 17 & 18 & 11 & - & - & - & 32 \\
\hline 20 & 17 & - & - & - & 10 & 33 \\
\hline 21 & - & - & - & 17 & - & 17 \\
\hline 24 & 18 & 24 & - & 16 & 15 & 37 \\
\hline 30 & - & 19 & - & 10 & - & - \\
\hline 36 & - & 14 & - & 19 & - & - \\
\hline 54 & - & 14 & - & - & - & - \\
\hline 59 & - & - & - & 17 & - & 15 \\
\hline 62 & 33 & 17 & - & - & - & 38 \\
\hline 65 & 15 & 26 & - & 11 & 25 & - \\
\hline 66 & - & 24 & - & - & 44 & 22 \\
\hline 69 & 29 & 50 & - & 48 & 25 & 51 \\
\hline 71 & - & 16 & - & - & 21 & 28 \\
\hline 76 & 16 & 13 & - & - & 13 & - \\
\hline 83 & 24 & 29 & - & - & 23 & - \\
\hline 85 & 16 & 20 & - & - & 20 & 29 \\
\hline 86 & 24 & 20 & - & - & 13 & 28 \\
\hline 92 & 28 & 26 & - & - & 17 & - \\
\hline
\end{tabular}

Tabela 5.2: Raio da fonte obtido através da equação (4.3) utilizando o modelo de fonte proposto por Madariaga (1976). Na tabela acima não foi obtido nenhum valor para a estação CH09, pois não foi possível ajustar os seus espectros de deslocamento. 


\section{Modelo de Madariaga}

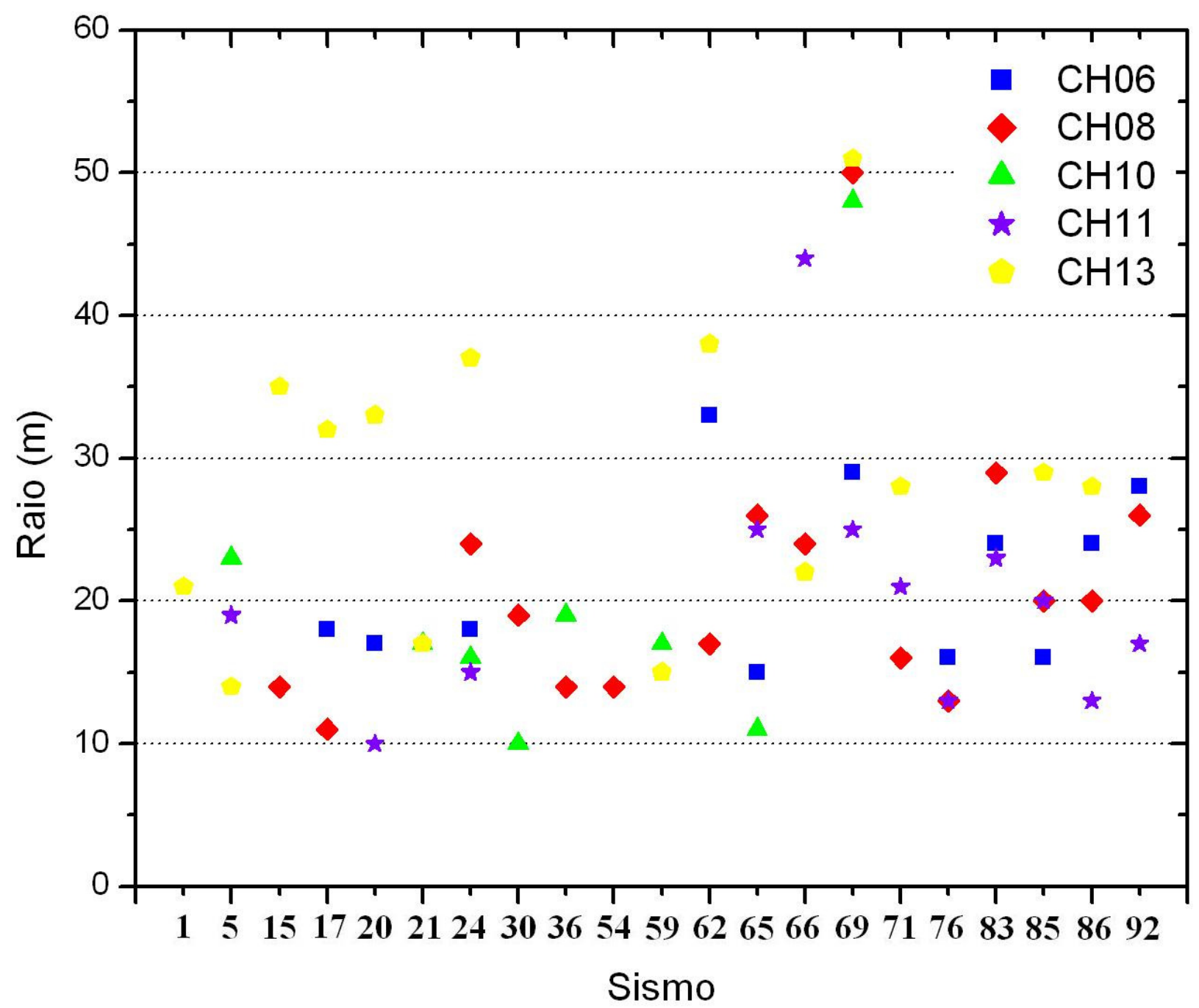

Figura 5.2: Variação nos valores dos raios da fonte dos 21 sismos utilizados neste trabalho. Os raios foram obtidos a partir da equação (4.3) usando o Modelo de Madariaga. A maior variação ocorreu no sismo69, com uma diferença de 26 m entre o valor máximo e o mínimo. 


\subsection{Momento Sísmico}

O valor do momento sísmico (Tabela 5.3) foi calculado através da equação (4.2), utilizando os valores da amplitude de longo período obtidos pelo ajuste (equação 4.1) dos espectros de deslocamento nas componentes Norte/Sul e Leste/Oeste.

Através da Tabela 5.3 é possível observar que o momento sísmico ficou dentro do intervalo $\left(10^{10}<\mathrm{M}_{0}<10^{13} \mathrm{~N} \cdot \mathrm{m}\right)$. Esses valores são compatíveis com os obtidos em outros estudos (Abercrombie, 1995; Plicka \& Zahradník, 1998; Ide et al., 2003; Abercrombie \& Rice, 2005; Tomic et al., 2008; dentre outros) para o mesmo intervalo de magnitude.

Já foram feitos diversos estudos para se estimar parâmetros de fonte (Kanamori et al., 1993; Abercrombie, 1995; Ide et al., 2003; Mori et al., 2003; Tomic et al., 2008), a Figura 5.3 mostra os resultados de alguns estudos anteriores, que servirão para comparar com os resultados obtidos neste trabalho.

Nas Figuras 5.4 e 5.5 estão representados os valores do momento sísmico em função do raio da fonte para todas as estações usadas neste trabalho, as estimativas foram obtidas utilizando os modelos de Brune e Madariaga, respectivamente. Nessas figuras também foram colocadas as linhas que representam valores de stress drop constante.

A Figura 5.6 mostra o momento sísmico médio em função do raio médio para cada sismo. Ao contrário dos resultados anteriores (Figura 5.3), as estimativas deste trabalho não parecem seguir linhas de stress drop constante. 


\section{Modelo de Madariaga}

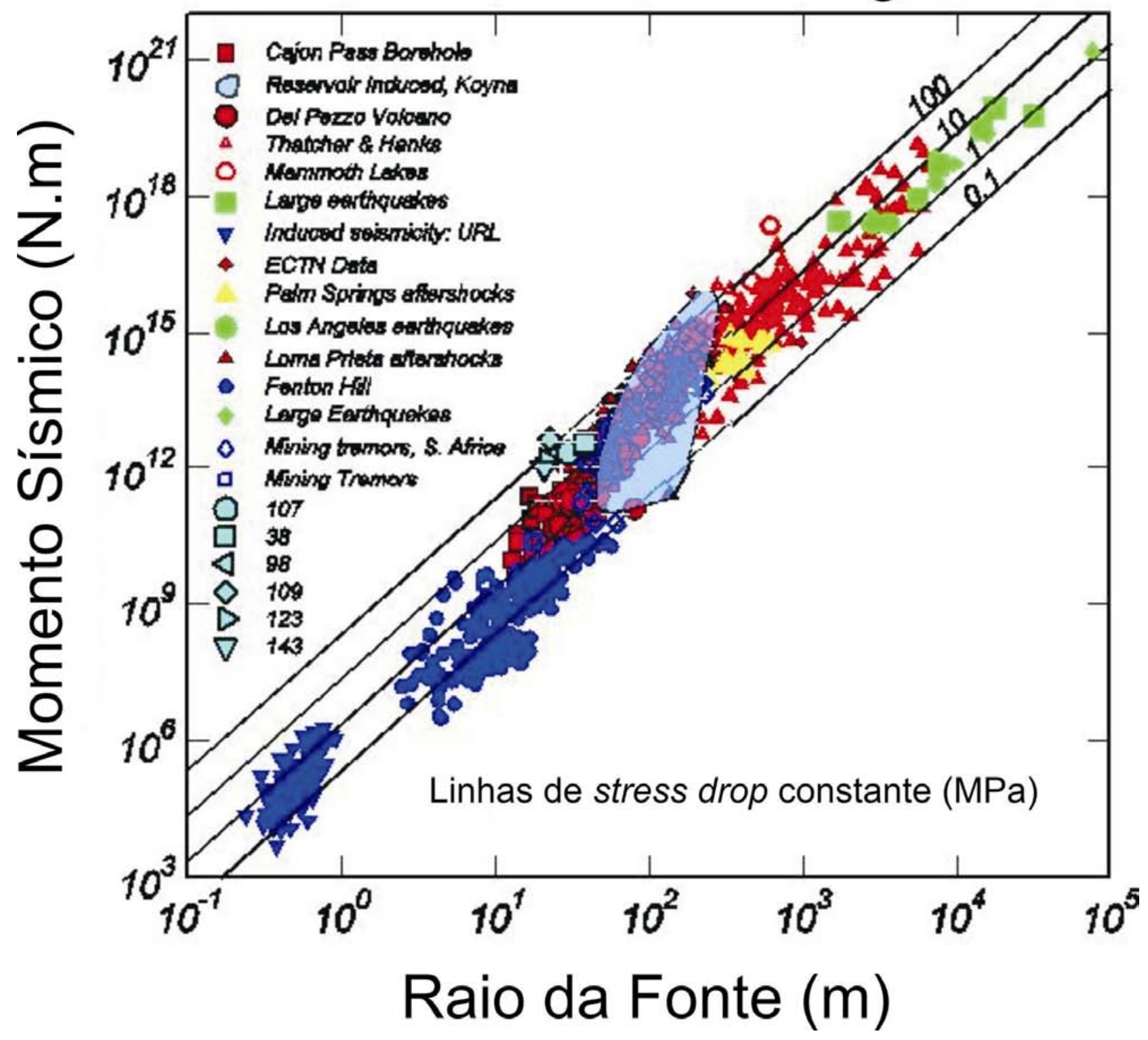

Figura 5.3: Momento Sísmico versu Raio da Fonte para diversos trabalhos, os números (107, 38, 98, 109, 123, 143) denotam os sismos usados por Tomic (2004) para obter os parâmetros de fonte (modificado de Tomic, 2004). 


\begin{tabular}{|c|c|c|c|c|c|c|}
\hline \multicolumn{7}{|c|}{ Momento Sísmico $(\mathrm{N} \cdot \mathrm{m})$} \\
\hline Sismo & $\mathrm{CH} 06$ & $\mathrm{CH} 08$ & CH09 & $\mathrm{CH} 10$ & CH11 & $\mathrm{CH} 13$ \\
\hline 1 & - & - & - & - & - & $2,8 \mathrm{E}+12$ \\
\hline 5 & - & - & - & $2,7 \mathrm{E}+10$ & $9,9 E+10$ & $1,2 \mathrm{E}+11$ \\
\hline 15 & - & $4,3 E+11$ & - & - & - & $1,1 \mathrm{E}+12$ \\
\hline 17 & $2,2 \mathrm{E}+11$ & $2,3 \mathrm{E}+11$ & - & - & - & $8,5 \mathrm{E}+11$ \\
\hline 20 & $2,6 \mathrm{E}+11$ & - & - & - & $5,6 \mathrm{E}+11$ & $9,8 \mathrm{E}+11$ \\
\hline 21 & - & - & - & $1,9 \mathrm{E}+11$ & - & $3,3 E+11$ \\
\hline 24 & $1,8 \mathrm{E}+12$ & $2,1 \mathrm{E}+12$ & - & $6,1 \mathrm{E}+11$ & $4,1 E+12$ & $3,5 \mathrm{E}+12$ \\
\hline 30 & - & $1,2 \mathrm{E}+11$ & - & $3,9 \mathrm{E}+10$ & - & - \\
\hline 36 & - & $1,9 \mathrm{E}+11$ & - & $2,3 E+11$ & - & - \\
\hline 54 & - & $5,0 \mathrm{E}+11$ & - & - & - & - \\
\hline 59 & - & - & - & $2,4 \mathrm{E}+11$ & - & $9,8 \mathrm{E}+11$ \\
\hline 62 & $4,3 \mathrm{E}+11$ & $5,7 \mathrm{E}+11$ & - & - & - & $1,9 \mathrm{E}+12$ \\
\hline 65 & $2,4 \mathrm{E}+12$ & $5,5 \mathrm{E}+12$ & - & $2,2 \mathrm{E}+12$ & $7,4 \mathrm{E}+12$ & - \\
\hline 66 & - & $3,0 \mathrm{E}+11$ & - & - & $5,5 \mathrm{E}+11$ & $1,1 \mathrm{E}+12$ \\
\hline 69 & $2,0 \mathrm{E}+12$ & $1,3 \mathrm{E}+12$ & - & $1,2 \mathrm{E}+12$ & $2,9 \mathrm{E}+12$ & $2,3 \mathrm{E}+12$ \\
\hline 71 & - & $6,1 \mathrm{E}+11$ & - & - & $4,1 \mathrm{E}+11$ & $1,0 \mathrm{E}+12$ \\
\hline 76 & $3,3 \mathrm{E}+11$ & $2,3 \mathrm{E}+11$ & - & - & $3,7 \mathrm{E}+11$ & - \\
\hline 83 & $1,8 \mathrm{E}+12$ & $1,7 \mathrm{E}+12$ & - & - & $4,3 \mathrm{E}+12$ & - \\
\hline 85 & $4,8 \mathrm{E}+11$ & $5,0 \mathrm{E}+11$ & - & - & $1,3 \mathrm{E}+12$ & $1,5 \mathrm{E}+12$ \\
\hline 86 & $6,5 \mathrm{E}+11$ & $7,1 \mathrm{E}+11$ & - & - & $1,4 \mathrm{E}+12$ & $2,0 \mathrm{E}+12$ \\
\hline 92 & $2,2 \mathrm{E}+12$ & $2,1 \mathrm{E}+12$ & - & - & $4,1 \mathrm{E}+12$ & - \\
\hline
\end{tabular}

Tabela 5.3: Momento sísmico obtido através da equação (4.2). Na tabela acima não foi obtido nenhum valor para a estação CH09, pois não foi possível ajustar os seus espectros. 


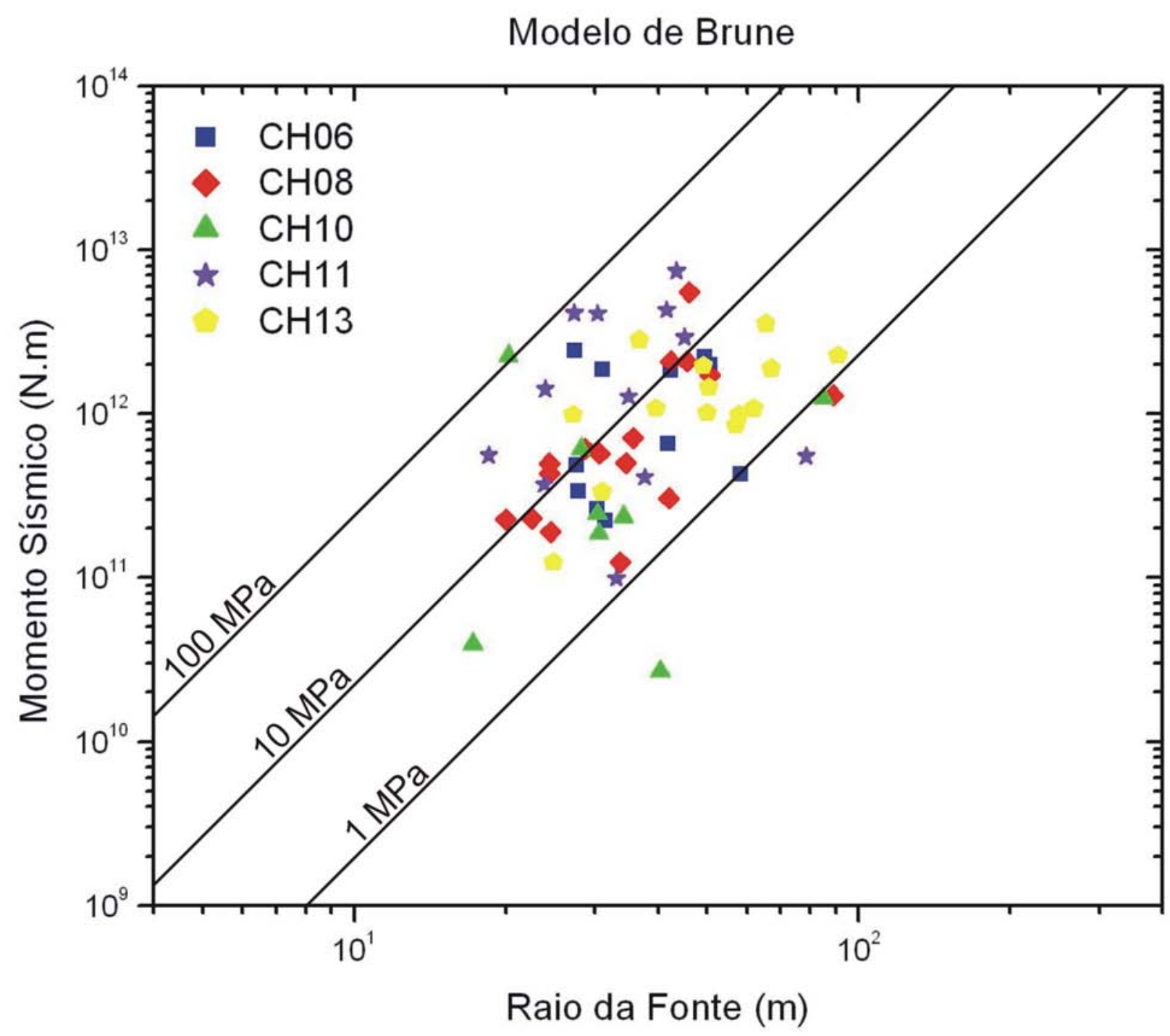

Figura 5.4: Momento Sísmico versus Raio da Fonte (Modelo de Brune). O momento sísmico foi obtido da equação (4.2) e o raio da fonte da equação (4.3). Os símbolos coloridos representam os resultados de cada estação. As linhas transversais são valores de stress drop constante. 


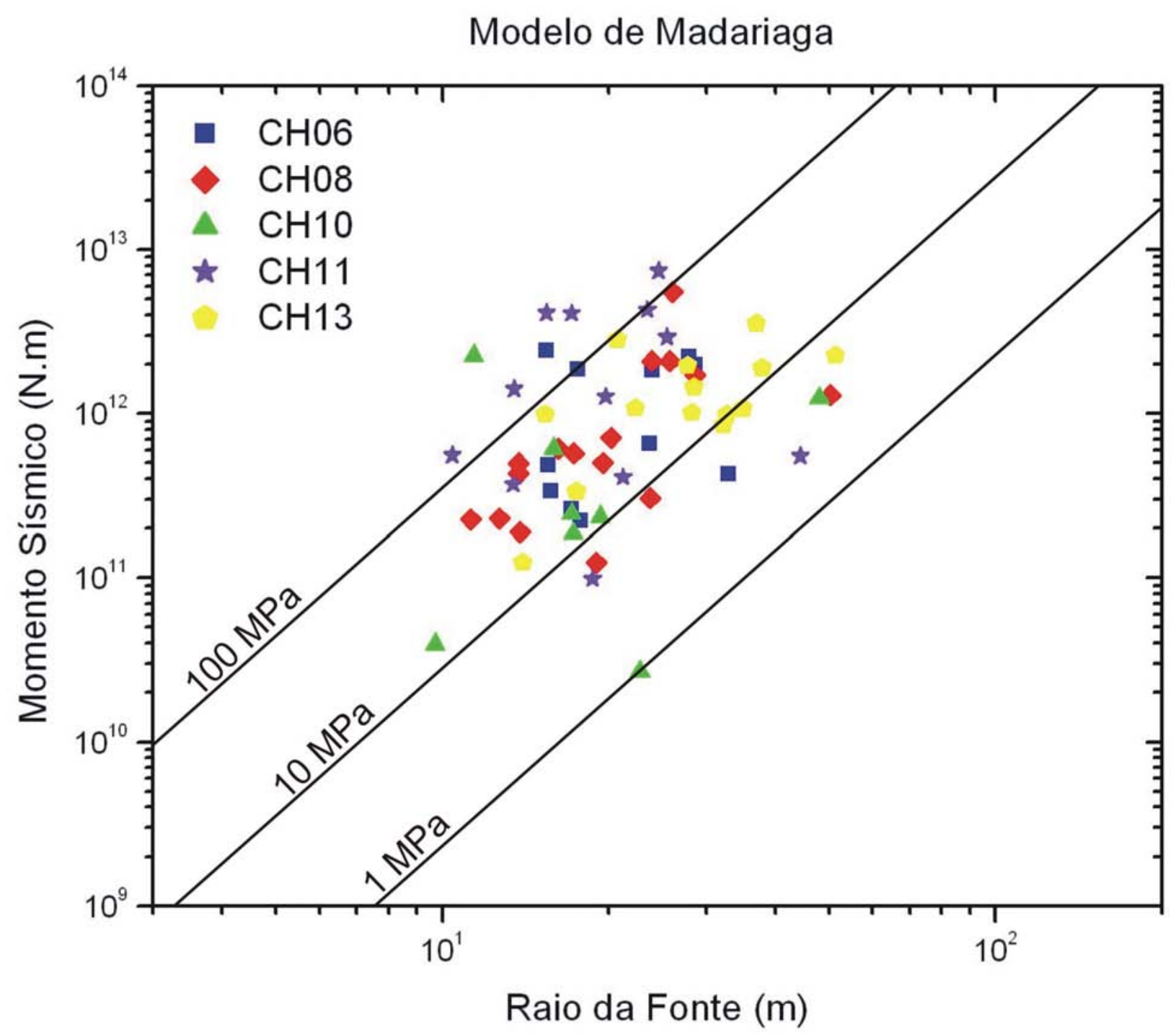

Figura 5.5: Momento Sísmico versus Raio da Fonte (Modelo de Madariaga). O momento sísmico foi obtido da equação (4.2) e o raio da fonte da equação (4.3). Os símbolos coloridos representam os resultados de cada estação. As linhas transversais são valores de stress drop constante. 


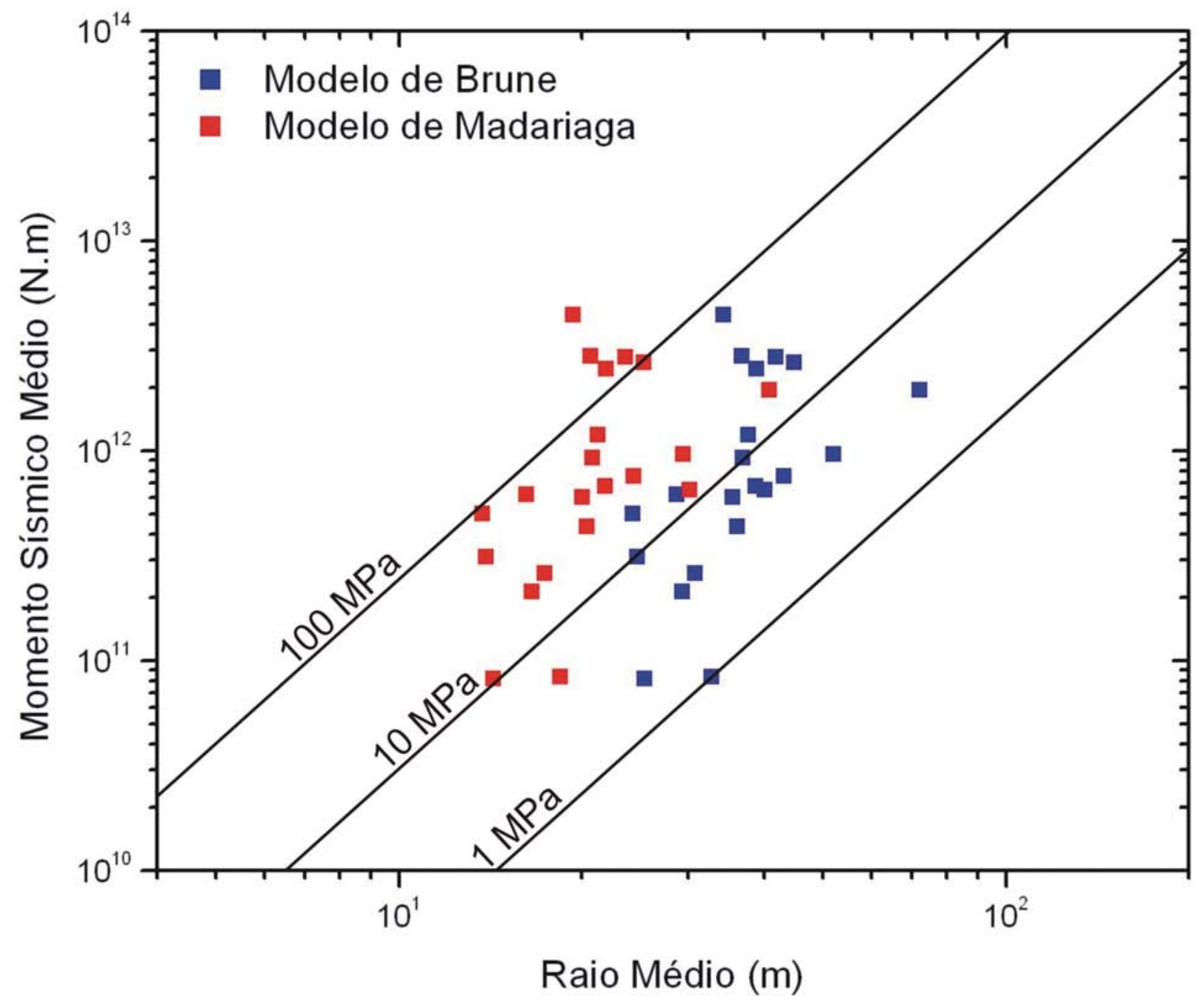

Figura 5.6: Momento Sísmico Médio versus Raio Médio. As linhas transversais representam valores de stress drop constante. 


\subsection{Momento Sísmico e Frequência de Corte}

Como discutido no capítulo 2, existe uma relação entre o momento sísmico e a frequência de corte. Com os resultados obtidos foi encontrada a relação $\left(M_{0} \propto f_{c}^{-2,5}\right)$, gerando $\varepsilon=-0,5$, com coeficiente de correlação de $-0,56$ entre os dados. Porém, devido ao baixo número de dados e, principalmente, ao pequeno intervalo do momento sísmico, não é possível afirmar se este resultado é relevante.

Segundo Walter et al. (2006), é esperado que $\varepsilon$ seja positivo e pequeno. No entanto, o valor encontrado neste trabalho foi negativo, por isso esta relação é apenas apresentada e nenhuma conclusão será feita com este resultado.

Na Figura 5.7 é mostrada a relação entre o momento sísmico e a frequência para este trabalho (linha vermelha) e para a discutida no capítulo 2 (linha azul).

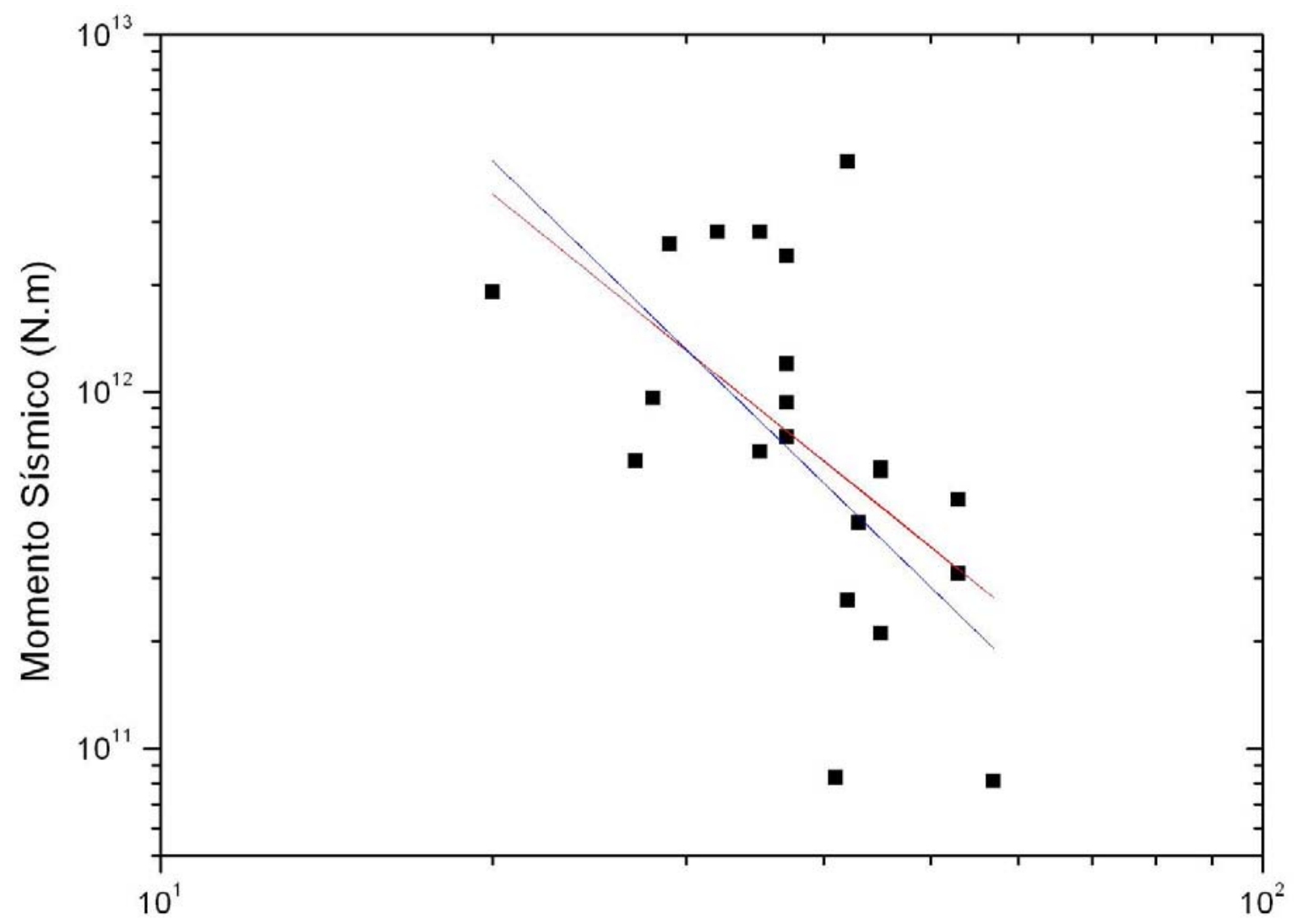

Frequência de Corte $(\mathrm{Hz})$

Figura 5.7: Relação entre o momento sísmico e a frequência de corte. Aqui foi encontrado que $M_{0} \propto f_{c}^{-2,5}$ representada pela linha vermelha. A linha azul representa a relação $M_{0} \propto f_{c}^{-3,0}$. 


\subsection{Stress Drop}

Com os valores do momento sísmico e do raio da fonte, obtiveram-se as estimativas do stress drop, para os dois modelos utilizados. Os valores do stress drop de cada sismo, obtidos a partir da equação (2.5), estão na Tabela 5.4 e 5.5, para os modelos de Brune e Madariaga, respectivamente.

O stress drop médio, para o primeiro modelo, ficou dentro do intervalo $1<\Delta \sigma<60 \mathrm{MPa}$, sendo que a maior variação ocorreu no sismo65, em que a diferença entre o valor máximo e o mínimo foi de aproximadamente $95 \mathrm{MPa}$. Enquanto que no segundo, os valores médios ficaram entre $9<\Delta \sigma<330 \mathrm{MPa}$, com maior variação de aproximadamente $530 \mathrm{MPa}$, também para o sismo65.

Os sismos usados neste estudo são intraplaca. É aceitável que sismos tectônicos intraplaca tenham alto stress drop (Kanamori \& Anderson, 1975). A estimativa desse parâmetro está sujeita a muita incerteza, já que a energia de alta frequência nos terremotos que possuem baixa magnitude afeta a determinação da frequência de corte (Abercrombie, 1995), provocando essa grande variação nos resultados. Além do mais, os modelos de Brune e Madariaga são muito simplistas e não consideram uma propagação unilateral, assim o que pode estar sendo visto é uma aparente variação no stress drop.

Os resultados obtidos neste trabalho mostraram um aumento do valor stress drop com o incremento do momento sísmico (Figura 5.8) e, consequentemente, com a magnitude do evento (equação 4.6). Assim, surge a hipótese de que os eventos analisados neste trabalho não são auto-similares, concordando com outros estudos para sismos com magnitudes menores que três $M_{W}<3,0$. Porém, devido a grande incerteza nos valores do stress drop, também será considerado a relação entre o momento sísmico e o stress aparente para, então, concluir de fato se há ou não uma relação de escala, conforme discutido no capítulo 2 . 


\begin{tabular}{|c|c|c|c|c|c|c|}
\hline \multicolumn{7}{|c|}{ Stress Drop (MPa) - Modelo de Brune } \\
\hline Sismo & CH06 & CH08 & CH09 & $\mathrm{CH} 10$ & CH11 & CH13 \\
\hline 1 & - & - & - & - & - & 24,9 \\
\hline 5 & - & - & - & 0,2 & 1,2 & 3,6 \\
\hline 15 & - & 13,0 & - & - & - & 2,0 \\
\hline 17 & 3,1 & 12,5 & - & - & - & 2,0 \\
\hline 20 & 4,1 & - & - & - & 38,6 & 2,2 \\
\hline 21 & - & - & - & 2,8 & - & 4,9 \\
\hline 24 & 26,8 & 11,9 & - & 11,9 & 88,4 & 5,5 \\
\hline 30 & - & 1,4 & - & 3,4 & - & - \\
\hline 36 & - & 5,7 & - & 2,6 & - & - \\
\hline 54 & - & 15,1 & - & - & - & - \\
\hline 59 & - & - & - & 3,8 & - & 21,5 \\
\hline 62 & 0,9 & 8,7 & - & - & - & 2,7 \\
\hline 65 & 52,0 & 24,6 & - & 119,4 & 39,3 & - \\
\hline 66 & - & 1,8 & - & - & 0,5 & 7,6 \\
\hline 69 & 6,6 & 0,8 & - & 0,9 & 13,9 & 1,3 \\
\hline 71 & - & 11,3 & - & - & 3,4 & 3,5 \\
\hline 76 & 6,8 & 8,9 & - & - & 12,0 & - \\
\hline 83 & 10,4 & 5,7 & - & - & 26,0 & - \\
\hline 85 & 10,1 & 5,3 & - & - & 12,9 & 4,9 \\
\hline 86 & 3,9 & 6,8 & - & - & 45,1 & 7,2 \\
\hline 92 & 8,0 & 9,5 & - & - & 63,7 & - \\
\hline
\end{tabular}

Tabela 5.4: Stress drop obtido através da equação (2.5) utilizando o modelo de fonte proposto por Brune (1970). Na tabela acima não foi obtido nenhum valor para a estação $\mathrm{CH} 09$, pois não foi possível ajustar os seus espectros. 


\begin{tabular}{|c|c|c|c|c|c|c|}
\hline \multicolumn{7}{|c|}{ Stress Drop $(\mathrm{MPa})$ - Modelo de Madariaga } \\
\hline Sismo & CH06 & CH08 & CH09 & CH10 & CH11 & CH13 \\
\hline 1 & - & - & - & - & - & 138,5 \\
\hline 5 & - & - & - & 1,0 & 6,6 & 19,8 \\
\hline 15 & - & 72,5 & - & - & - & 11,0 \\
\hline 17 & 17,1 & 69,7 & - & - & - & 11,1 \\
\hline 20 & 22,8 & - & - & - & 214,5 & 12,3 \\
\hline 21 & - & - & - & 15,8 & - & 27,2 \\
\hline 24 & 149,1 & 66,4 & - & 66,1 & 491,6 & 30,6 \\
\hline 30 & - & 7,9 & - & 18,8 & - & - \\
\hline 36 & - & 31,5 & - & 14,2 & - & - \\
\hline 54 & - & 84,2 & - & - & - & - \\
\hline 59 & - & - & - & 21,3 & - & 119,4 \\
\hline 62 & 5,2 & 48,3 & - & - & - & 15,1 \\
\hline 65 & 289,0 & 136,6 & - & 663,6 & 218,2 & - \\
\hline 66 & - & 10,0 & - & - & 2,7 & 42,4 \\
\hline 69 & 36,7 & 4,4 & - & 4,9 & 77,1 & 7,3 \\
\hline 71 & - & 63,0 & - & - & 18,7 & 19,5 \\
\hline 76 & 37,7 & 49,4 & - & - & 66,7 & - \\
\hline 83 & 58,0 & 31,9 & - & - & 144,8 & - \\
\hline 85 & 55,9 & 29,4 & - & - & 71,9 & 27,4 \\
\hline 86 & 21,5 & 37,9 & - & - & 250,9 & 40,0 \\
\hline 92 & 44,5 & 53,1 & - & - & 354,3 & - \\
\hline
\end{tabular}

Tabela 5.5: Stress drop obtido através da equação (2.5) utilizando o modelo de fonte proposto por Madariaga (1976). Na tabela acima não foi obtido nenhum valor para a estação CH09, pois não foi possível ajustar os seus espectros. 


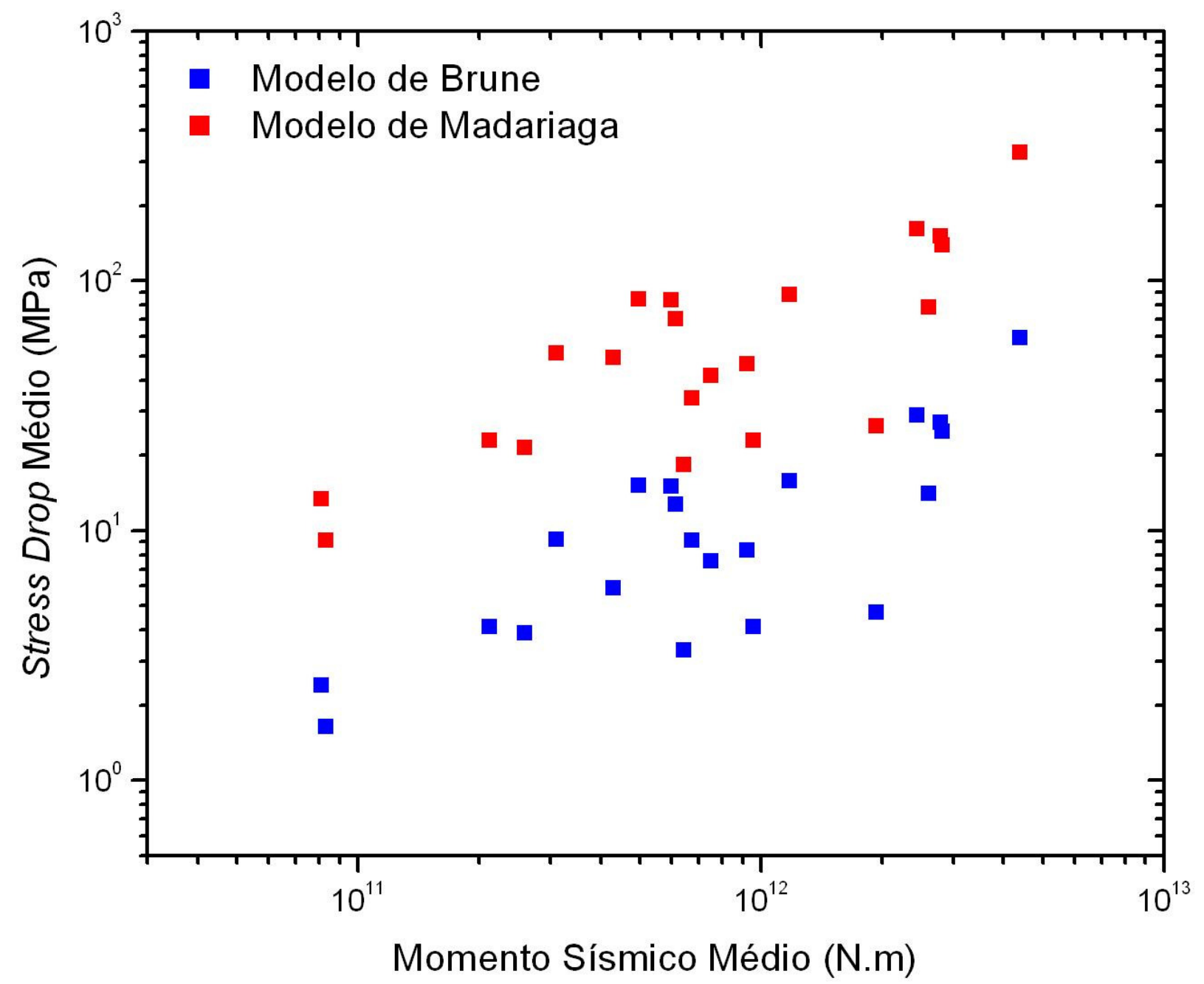

Figura 5.8: Stress Drop Médio versus Momento Sísmico Médio. A figura mostra um aumento no valor do stress drop com o aumento do momento sísmico, assim há uma quebra na relação de escala. 


\subsection{Energia Sísmica e Magnitude Momento $\mathrm{M}_{\mathrm{W}}$}

A energia sísmica irradiada foi calculada pela equação (4.5). Os resultados estão apresentados na Tabela 5.6. As estimativas obtidas neste trabalho ficaram dentro do

intervalo $\left(10^{5}<E_{S}<10^{8}\right) \mathrm{J}$, sendo compatíveis com os valores obtidos por outros estudos (Abercrombie, 1995; Ide et al., 2003; Prieto et al., 2004; Imanishi \& Ellswoth, 2006), para os mesmos valores de magnitude. A maior variação nos valores da energia ocorreu no sismo24, em que as estimativas ficaram entre $6,9 \times 10^{6} \mathrm{~J}$ e $1,7 \times 10^{8} \mathrm{~J}$. A Figura 5.9 mostra a energia em função do momento sísmico para todas as estações.

É possível observar pela Figura 5.9 que a energia aumenta com o incremento do momento sísmico, desta forma, a energia é proporcional à magnitude momento, já que esta última aumenta com o incremento do momento sísmico, como pode ser visto pela equação (4.6). Assim, os resultados obtidos são coerentes com os de outros estudos (Kanamori \& Heaton, 2000; Mori et al., 2003; Walter et al., 2006), como esperado. Na Figura 5.10 estão apresentados os valores médios da energia em função do momento sísmico médio.

Através da equação (4.6), foram calculados os valores da magnitude momento $M_{W}$ para cada sismo em todas as estações. Após fazer as médias dos resultados obtidos, foi plotado o valor de $m_{b}$ em função de $M_{W}$ (Figura 5.11). Na Tabela 5.7 estão apresentados os valores médios da magnitude momento $\left(M_{W}\right)$ e da magnitude local $\left(m_{b}\right)$ (calculada pela duração de cada sismo). A relação entre as duas escalas, após um ajuste linear é:

$$
M_{W}=0,92 m_{b}+0,66
$$

o coeficiente de correlação entre as escalas é de 0,89 .

Da Figura 5.11 é possível observar uma boa correlação entre as duas magnitudes. Também é possível observar na Tabela 5.7 que os valores obtidos para a magnitude momento diferem da magnitude local por menos de uma unidade. 


\begin{tabular}{|c|c|c|c|c|c|c|}
\hline \multicolumn{7}{|c|}{ Energia Sísmica (J) } \\
\hline Sismo & CH06 & CH08 & $\mathrm{CH} 09$ & CH10 & CH11 & CH13 \\
\hline 1 & - & - & - & - & - & $4,6 \mathrm{E}+07$ \\
\hline 5 & - & - & - & $2,7 \mathrm{E}+06$ & $4,5 \mathrm{E}+05$ & $1,6 \mathrm{E}+05$ \\
\hline 15 & - & $1,1 \mathrm{E}+06$ & - & - & - & $3,5 \mathrm{E}+06$ \\
\hline 17 & $7,2 \mathrm{E}+05$ & $8,7 \mathrm{E}+05$ & - & - & - & $2,5 \mathrm{E}+06$ \\
\hline 20 & $1,2 \mathrm{E}+06$ & - & - & - & $1,0 \mathrm{E}+07$ & $2,8 \mathrm{E}+06$ \\
\hline 21 & - & - & - & $5,5 \mathrm{E}+05$ & - & $1,7 \mathrm{E}+06$ \\
\hline 24 & $2,8 \mathrm{E}+07$ & $3,3 \mathrm{E}+07$ & - & $6,9 \mathrm{E}+06$ & $1,7 \mathrm{E}+08$ & $4,4 \mathrm{E}+07$ \\
\hline 30 & - & $2,5 \mathrm{E}+05$ & - & $1,1 \mathrm{E}+05$ & - & - \\
\hline 36 & - & $4,9 \mathrm{E}+05$ & - & $7,8 \mathrm{E}+05$ & - & - \\
\hline 54 & - & $2,7 \mathrm{E}+05$ & - & - & - & - \\
\hline 59 & - & - & - & $3,3 \mathrm{E}+06$ & - & $8,8 \mathrm{E}+06$ \\
\hline 62 & $1,6 \mathrm{E}+06$ & $2,2 \mathrm{E}+06$ & - & - & - & $8,8 \mathrm{E}+06$ \\
\hline 65 & $8,6 \mathrm{E}+07$ & $1,1 \mathrm{E}+08$ & - & $3,7 \mathrm{E}+08$ & $4,4 \mathrm{E}+08$ & - \\
\hline 66 & - & $4,5 \mathrm{E}+05$ & - & - & $2,6 \mathrm{E}+06$ & $5,4 \mathrm{E}+06$ \\
\hline 69 & $3,8 \mathrm{E}+06$ & $1,6 \mathrm{E}+06$ & - & $5,7 \mathrm{E}+06$ & $2,1 \mathrm{E}+07$ & $7,4 \mathrm{E}+06$ \\
\hline 71 & - & $1,6 \mathrm{E}+06$ & - & - & $1,8 \mathrm{E}+07$ & $4,5 \mathrm{E}+06$ \\
\hline 76 & $1,1 \mathrm{E}+06$ & $1,2 \mathrm{E}+06$ & - & - & $3,7 \mathrm{E}+06$ & - \\
\hline 83 & $1,1 \mathrm{E}+07$ & $1,0 \mathrm{E}+07$ & - & - & $8,9 \mathrm{E}+07$ & - \\
\hline 85 & $1,7 \mathrm{E}+06$ & $1,3 \mathrm{E}+06$ & - & - & $1,4 \mathrm{E}+07$ & $4,8 \mathrm{E}+06$ \\
\hline 86 & $3,9 \mathrm{E}+06$ & $3,8 \mathrm{E}+06$ & - & - & $3,3 \mathrm{E}+07$ & $1,1 \mathrm{E}+07$ \\
\hline 92 & $3,5 \mathrm{E}+07$ & $1,9 \mathrm{E}+07$ & - & - & $2,6 \mathrm{E}+08$ & - \\
\hline
\end{tabular}

Tabela 5.6: Energia Sísmica Irradiada obtida através da equação (4.5). 


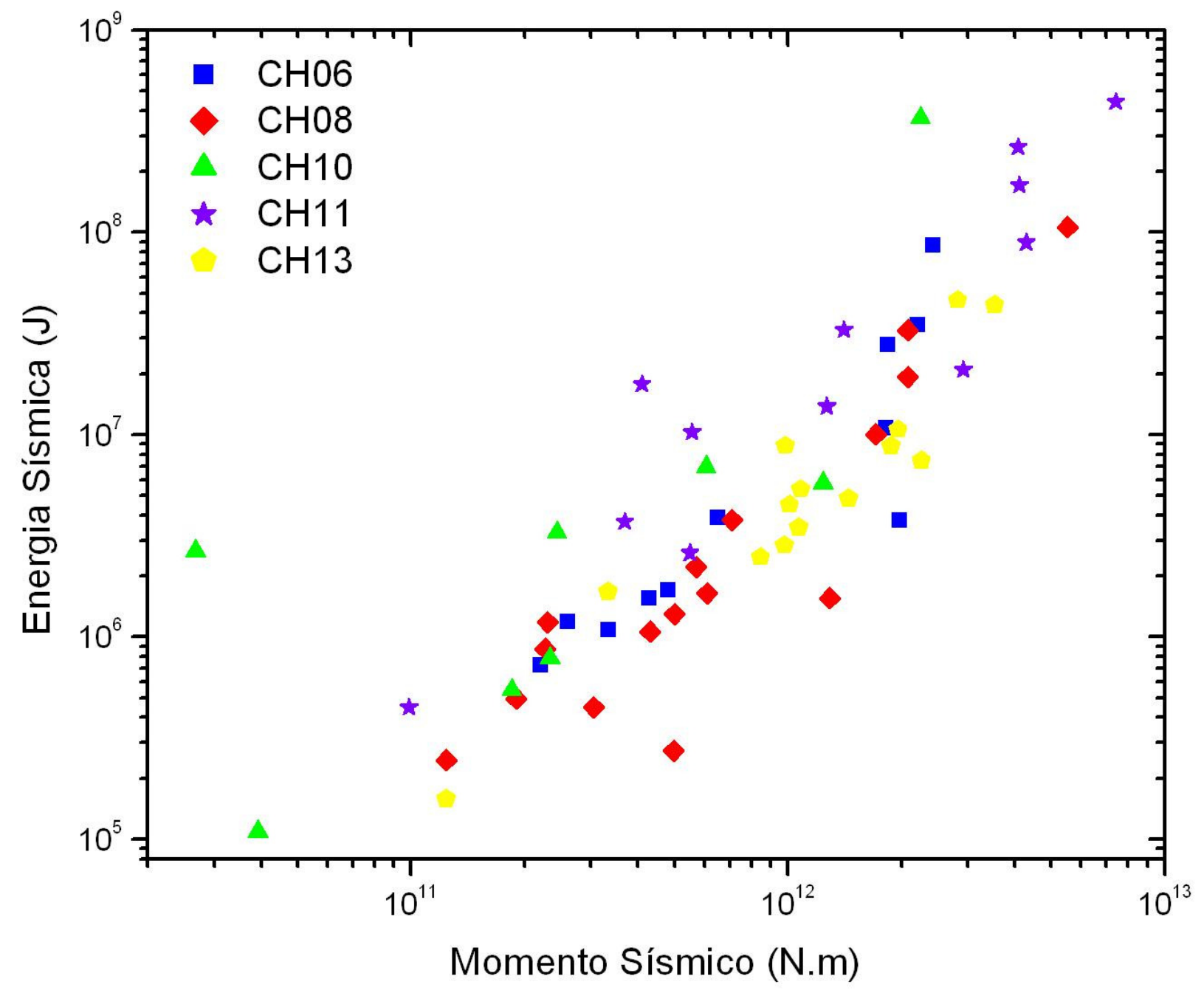

Figura 5.9: Energia Sísmica versus Momento Sísmico. A energia foi estimada a partir da equação (4.5), é possível perceber a dependência deste parâmetro com o momento sísmico e, conseqüentemente, com a magnitude. 


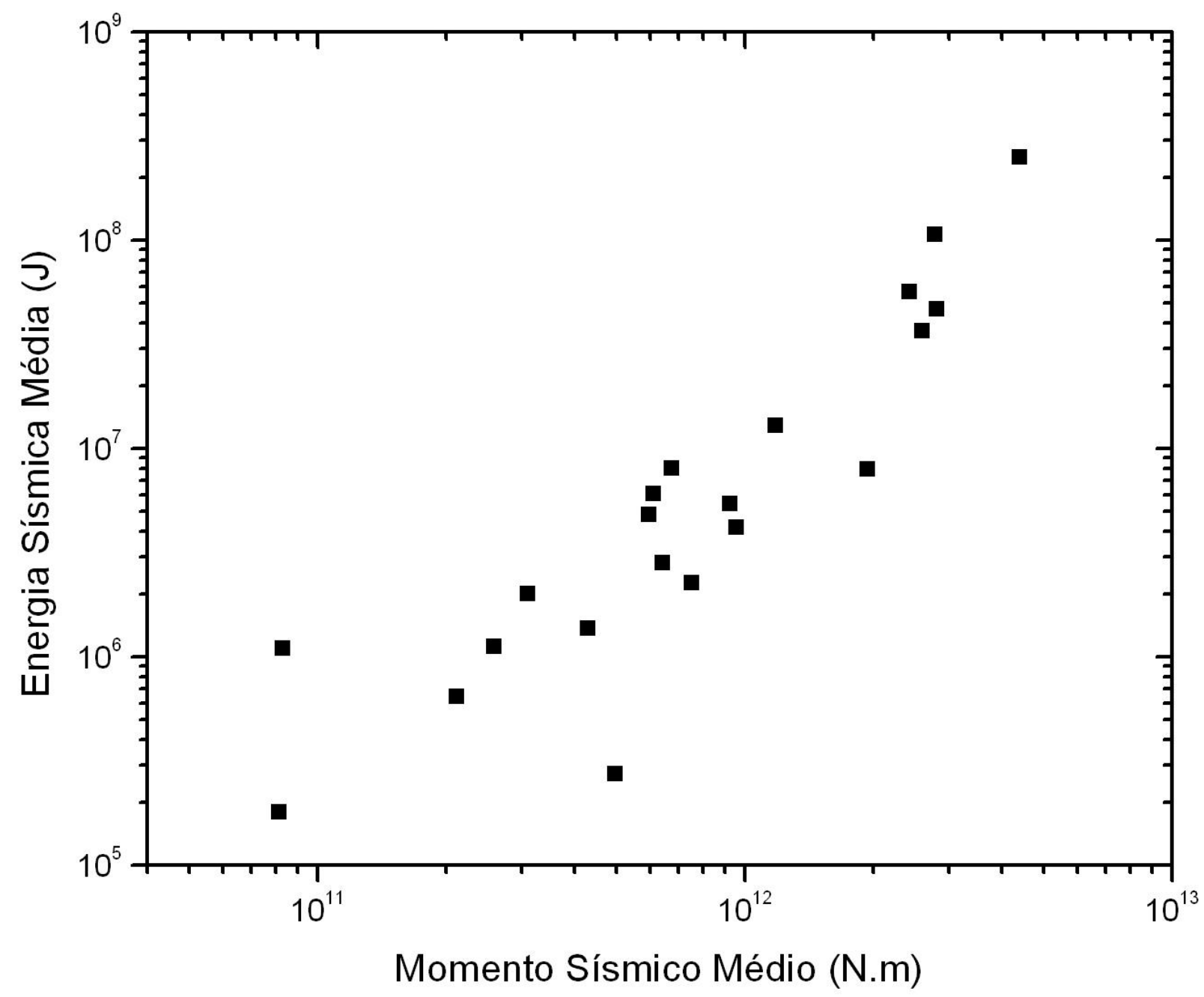

Figura 5.10: Energia Sísmica Média versus Momento Sísmico Médio. A energia aumenta com o incremento do momento sísmico. 


\begin{tabular}{|c|c|c|}
\hline Sismo & $M_{W}$ & $m_{b}$ \\
\hline 1 & 2,3 & 1,6 \\
\hline 5 & 1,2 & 0,7 \\
\hline 15 & 1,9 & 1,2 \\
\hline 17 & 1,7 & 0,9 \\
\hline 20 & 1,8 & 1,2 \\
\hline 21 & 1,6 & 1,1 \\
\hline 24 & 2,2 & 1,5 \\
\hline 30 & 1,2 & 0,8 \\
\hline 36 & 1,5 & 1,2 \\
\hline 54 & 1,8 & 1,3 \\
\hline 59 & 1,8 & 1,5 \\
\hline 62 & 1,9 & 1,3 \\
\hline 65 & 2,4 & 2,1 \\
\hline 66 & 1,8 & 1,2 \\
\hline 69 & 2,1 & 1,6 \\
\hline 71 & 1,8 & 1,3 \\
\hline 76 & 1,6 & 1,0 \\
\hline 83 & 2,2 & 1,4 \\
\hline 85 & 1,9 & 1,3 \\
\hline 86 & 2,0 & 1,3 \\
\hline 92 & 2,2 & 1,6 \\
\hline
\end{tabular}

Tabela 5.7: Os valores de $M_{W}$ foram obtidos pela média dos valores de cada estação calculados através da equação (4.6). Os valores de $m_{b}$ foram obtidos pela duração do evento, através das equações (3.1) e (3.2). 


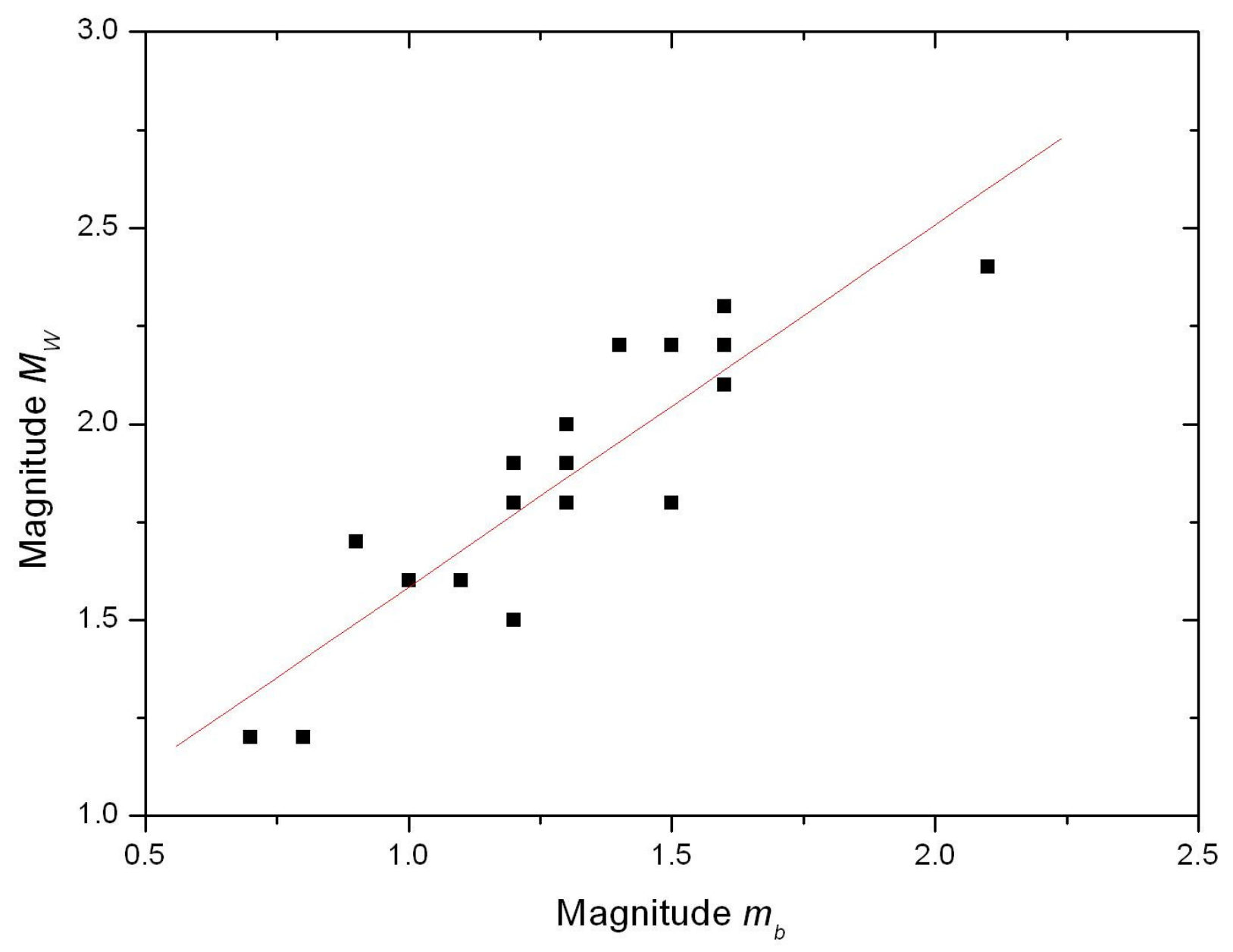

Figura 5.11: Comparação entre a magnitude $m_{b}$ e a magnitude momento $M_{W}$ estimada a partir do momento sísmico. É possível observar uma boa correlação entre as duas escalas. 


\subsection{Stress Aparente}

Devido à instabilidade na determinação do stress drop, alguns autores preferem usar o stress aparente (Ide \& Beroza, 2001; Ide et al., 2003). Com os valores da energia sísmica e do momento sísmico, foi obtido o stress aparente (equação 2.8). Na Tabela 5.8 estão apresentados os valores deste parâmetro.

Na Figura 5.12 estão os valores do stress aparente em função do momento sísmico, enquanto que a Figura 5.13 apresenta as médias dos respectivos parâmetros. Como pode ser observado nesta última figura, o stress aparente, assim como o stress drop, aumenta com o momento sísmico. Desta forma, os resultados deste trabalho concordam com os obtidos por Abercrombie (1995), sugerindo que este parâmetro depende da dimensão do terremoto para sismos com magnitudes menores que três $\left(M_{W}<3,0\right)$. Assim, fica a hipótese de que há uma quebra na relação de escala discutida anteriormente, o que implica em uma física de ruptura diferente para terremotos grandes e pequenos. 


\begin{tabular}{|c|c|c|c|c|c|c|}
\hline \multicolumn{7}{|c|}{ Stress Aparente (MPa) } \\
\hline Sismo & CH06 & $\mathrm{CH} 08$ & CH09 & CH10 & CH11 & CH13 \\
\hline 1 & - & - & - & - & - & 0,54 \\
\hline 5 & - & - & - & 3,26 & 0,15 & 0,04 \\
\hline 15 & - & 0,08 & - & - & - & 0,11 \\
\hline 17 & 0,11 & 0,13 & - & - & - & 0,10 \\
\hline 20 & 0,15 & - & - & - & 0,61 & 0,10 \\
\hline 21 & - & - & - & 0,10 & - & 0,16 \\
\hline 24 & 0,49 & 0,52 & - & 0,37 & 1,36 & 0,41 \\
\hline 30 & - & 0,07 & - & 0,09 & - & - \\
\hline 36 & - & 0,09 & - & 0,11 & - & - \\
\hline 54 & - & 0,02 & - & - & - & - \\
\hline 59 & - & - & - & 0,44 & - & 0,29 \\
\hline 62 & 0,12 & 0,13 & - & - & - & 0,15 \\
\hline 65 & 1,16 & 0,63 & - & 5,34 & 1,94 & - \\
\hline 66 & - & 0,05 & - & - & 0,16 & 0,16 \\
\hline 69 & 0,06 & 0,04 & - & 0,15 & 0,24 & 0,11 \\
\hline 71 & - & 0,09 & - & - & 1,42 & 0,15 \\
\hline 76 & 0,11 & 0,17 & - & - & 0,33 & - \\
\hline 83 & 0,19 & 0,19 & - & - & 0,68 & - \\
\hline 85 & 0,12 & 0,09 & - & - & 0,36 & 0,11 \\
\hline 86 & 0,20 & 0,17 & - & - & 0,77 & 0,18 \\
\hline 92 & 0,51 & 0,30 & - & - & 2,12 & - \\
\hline
\end{tabular}

Tabela 5.8: Stress aparente obtido através da equação (2.8) utilizando as estimativas da energia sísmica e do momento sísmico. 


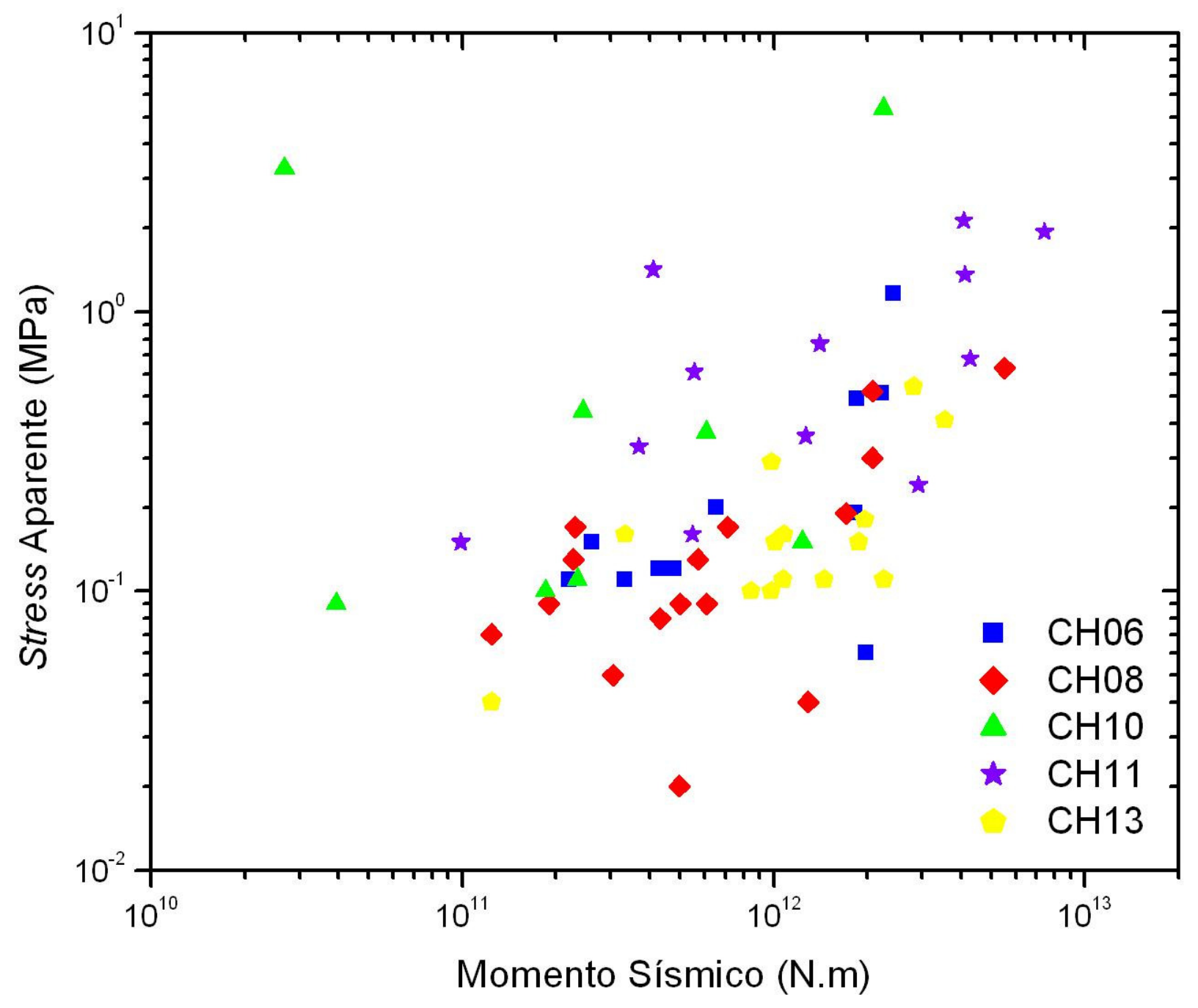

Figura 5.12: Stress Aparente versus Momento Sísmico. A figura mostra um aumento no valor do stress aparente com o aumento do momento sísmico. Assim há uma quebra na relação de escala. 


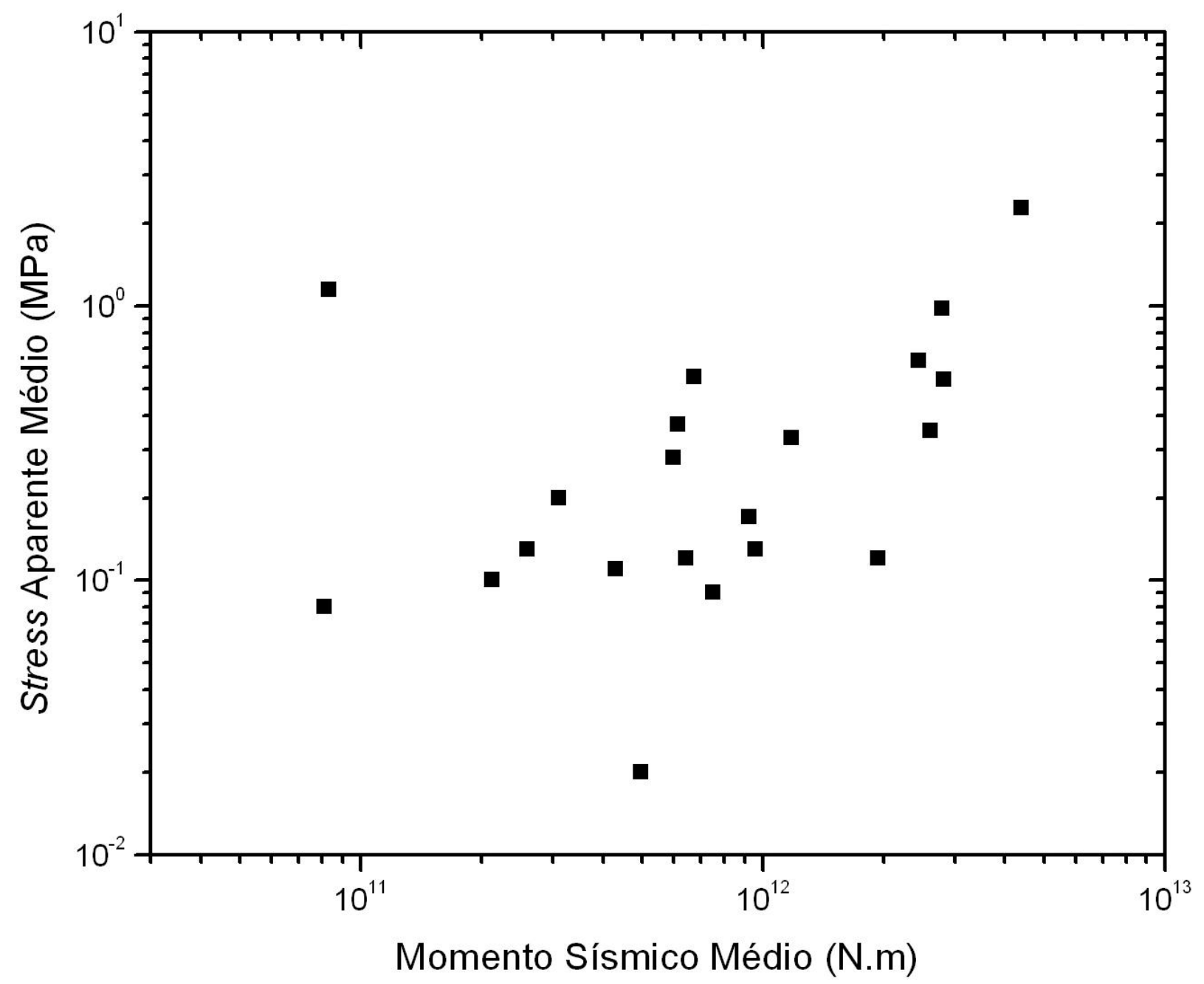

Figura 5.13: Stress Aparente Médio versus Momento Sísmico Médio. A figura mostra um aumento no valor do stress aparente com o aumento do momento sísmico. 


\section{CAPÍTULO 6 - CONCLUSÕES E PERSPECTIVAS}

Este trabalho foi realizado utilizando dados coletados por uma rede composta por seis estações digitais, cada uma contendo três sismômetros S-13 e um registrador PDAS - 100, e uma estação analógica, instaladas na região de Cascavel - CE entre 1997 e 1998. A maioria das estações foi instalada sobre afloramentos do embasamento cristalino do Pré-Cambriano, o que resulta em registros de ótima qualidade, com início das ondas $\mathrm{P}$ e $\mathrm{S}$ bem definidas.

A análise espectral dos 21 sismos utilizados neste trabalho com magnitude $0,7 \leq m_{b} \leq 2,1$ e profundidades entre $5,1-6,9 \mathrm{Km}$, mostrou os seguintes resultados.

1) Momento sísmico com valores $\left(10^{10}<\mathrm{M}_{0}<10^{13} \mathrm{~N} \cdot \mathrm{m}\right)$ dentro do intervalo obtido por outros estudos na mesma escala de magnitude (Abercrombie, 1995; Plicka \& Zahradník, 1998; Ide et al., 2003; Abercrombie \& Rice, 2005; Tomic et al., 2008). Estes valores podem ser usados no cálculo da magnitude momento.

2) Altos valores de stress drop $(1<\Delta \sigma<60) \mathrm{MPa}$ e $(9<\Delta \sigma<330) \mathrm{MPa}$, para os modelos de Brune e Madariaga, respectivamente. Como esperado, o stress drop máximo foi do sismo65 $\left(2,1 m_{b}\right)$ e o mínimo do $\operatorname{sismo5}\left(0,7 m_{b}\right)$ que representam a maior e menor magnitudes deste trabalho. Esses altos valores são aceitáveis, já que se trata de sismos tectônicos intraplaca.

3) Pobre correlação entre o momento sísmico e a frequência de corte, o que pode estar associado com o pequeno número de dados ou com o pequeno intervalo do momento. Assim, não foi possível retirar nenhuma conclusão desta relação.

4) Uma boa relação entre a magnitude momento $M_{W}$ e a magnitude local $m_{b}$. Sendo que $M_{W}$ tem uma grande vantagem, já que ela está ligada as propriedades físicas da fonte através do momento sísmico. 
5) A energia sísmica irradiada aumenta com o incremento do momento sísmico, sendo desta forma, dependente da magnitude do evento (tamanho da fonte). Os valores da energia e, consequentemente, do stress aparente também dependem do método utilizado, por isso é possível encontrar valores diferentes para estes dois parâmetros na mesma escala de magnitude.

6) O stress drop e o stress aparente aumentam com o incremento do momento sísmico, concordando com os resultado obtidos por Abercrombie (1995) para a mesma escala de magnitude. Assim, este trabalho sugere a hipótese de que os sismos utilizados não são auto-similares (quebra na relação de escala), o que implicaria em um processo de ruptura diferente para pequenos e grandes sismos na escala investigada. Se esta hipótese for válida, os eventos maiores (maior magnitude) são irradiadores de energia mais eficientes que os menores.

7) Uma relação melhor entre o stress drop e o momento sísmico do que entre o stress aparente e este último, o que pode estar relacionado com a técnica utilizada para calcular a energia sísmica irradiada. Talvez por isso, ao contrário do stress drop, o menor valor do stress aparente não esteja associado ao sismo5 $\left(0,7 m_{b}\right)$ que possui a menor magnitude.

8) Parâmetros de fonte compatíveis com outros estudos (Abercrombie, 1995; Ide et al., 2003; Mori et al., 2003; Prieto et al., 2006; Tomic et al, 2008; dentre outros) para o mesmo intervalo de magnitude, de forma que, apesar de ser uma técnica sujeita a incertezas, ela dá bons resultados.

Como as estimativas dos parâmetros de fonte obtidas neste trabalho foram compatíveis com a de outros estudos (Kanamori et al., 1993; Abercrombie, 1995; Ide et al., 2003; Imanishi \& Ellsworth, 2006; Tomic et al., 2008; entre outros), fica a proposta de aplicar a mesma técnica em outras regiões do Brasil, já que há poucos trabalhos sobre este assunto realizados no País. 
Também fica a proposta de tentar utilizar outra técnica de inversão de parâmetros de fonte, como por exemplo, a "Função de Green Empírica" (Frankel \& Kanamori, 1983), para comparar com os resultados obtidos neste trabalho. Esta técnica fornece outras informações importantes sobre a natureza da ruptura, tal como, velocidade de ruptura e directividade.

Algo interessante a ser feito é determinar o fator de qualidade $Q$ da região estudada, já que aqui foi usado um valor constante obtido para a região de Açu - RN (Tomic et al., 2008). Isto seria muito proveitoso pois, um dois fatores que influenciam a determinação de parâmetros de fonte, é a correção para a atenuação.

Com o término deste trabalho, a região de Cascavel - CE tem um dos mais completos estudos de sismicidade do Brasil, já que foram feitos estudos de localização de epicentros e mecanismo focal (Vilar, 2000; Gomes, 2007), de anisotropia sísmica (Gomes, 2007) e, este trabalho, de parâmetros de fonte.

Fica a proposta, para trabalhos futuros, de tentar utilizar outro método de ajuste do espectro, de forma que seja possível ajustar os espectros daqueles sismos para os quais não foram obtidos nenhum resultado e determinar o valor do fator de qualidade Q da região. Também seria interessante incorporar vínculos durante o ajuste, para que seja possível diminuir os erros nas estimativas dos parâmetros livres. Com isto, os resultados obtidos terão maior confiabilidade.

Para confirmar que os sismos analisados neste trabalho não são auto-similares é preciso ampliar a escala de magnitude, para que se possa afirmar com maior precisão, que de fato há um processo de ruptura diferente para terremotos grandes e pequenos na região estudada. 


\section{REFERÊNCIAS BIBLIOGRÁFICAS}

ABERCROMBIE, R.E. - 1991 - Earthquake rupture dynamics and neotectonics of the Aegean area, Ph.D. Thesis, University of Reading.

ABERCROMBIE, R.E. \& LEARY, P. - 1993 - Source parameters of small earthquakes recorded at $2.5 \mathrm{~km}$ depth, Cajon Pass, Southern California: implications for earthquake scaling, Geophysical Research Letters, 20: 1511-1514.

ABERCROMBIE, R.E. - 1995 - Earthquake source scaling relationships from -1 to 5 ML using seismograms recorded at 2.5-km depth. J. Geophys. Res., 100: 24015-24036.

ABERCROMBIE, R.E. \& RICE, J.R. - 2005 - Can observations of earthquake scaling constrain slip weakening? Geophys. J. Int., 162, 406-424.

ABERCROMBIE, R., MCGARR, A., KANAMORI, H. \& DI TORO, G. - 2006 Earthquakes: Radiated Energy and the Physics of Faulting, pages. AGU Geophys. Monograph 170.

AKI, K. - 1966 - Generation and propagation of G waves from the Niigata earthquake of June 16, 1964, 2, Estimation of earthquake moment, released energy, and stress-strain drop from G-wave spectrum, Bull. Earthquake Res. Inst., Tokyo Univ., 44, 73-88.

AKI, K. - 1967 - Scaling law of seismic spectrum. J. Geophys. Res., 72, 1217-1231.

AKI, K. \& RICHARDS, P. - 1980 - Quantitative Seismology, 932, pp., W. H. Freeman, New York.

ALMEIDA, F.F.M., HASUI, Y., BRITO NEVES, B.B. \& FUCK, R.A. - 1977 Províncias estruturais brasileiras. In: SBG/ Nordeste, Simp. Geol. Do NE, 7, Campina Grande, Atas, p. 242-258. 
ALMEIDA, F.F.M., HASUI, Y., BRITO NEVES, B.B. \& FUCK, R.A. - 1981 Brazilian structural Provinces: an introduction. Earth Sci. Ver., 17: 1-29

ALMEIDA, F.F.M. \& HASUI, Y. - 1984 - O pré-cambriano do Brasil. São Paulo, Edgar Blucher, 378p.

ALMEIDA, F.F.M., BRITO NEVES, B.B., DAL RÉ CARNEIRO, C. - 2000 - The origin and evolution of the South American Platform. Earth-Science Reviews, Volume 50, Issues 1-2, May 2000, 77-111.

ASSUMPÇÃO, M., FERREIRA, J.M., CARVALHO, J.M., BLUM, M.L., MENEZES, E.A., FONTENELE, D. \& AIRES, A. - 1989 - Seismic activity in palhano, CE, October 1988, preliminary results. Ver. Brás. Geofís., 7: 11-17.

ASSUMPÇÃO, M. - 1992 - The regional intraplate stress field in South America, J. Geophys. Res., 97 (B8), 11889-11903.

ASSUMPÇÃO, M. - 1998 - Seismicity and stresses in the Brazilian continental margins, Bull. Seism. Soc. Am., 88: 160-169.

BERROCAL, J., ASSUMPÇÃO, M., ANTEZANA, R., DIAS NETO, C.M., ORTEGA, R., FRANÇA, H. \& VELOSO, J.A. - 1984 Sismicidade do Brasil. IAG - Universidade de São Paulo/CNEN, 420 pp.

BLUM, M.L. \& ASSUMPÇÃO, M. - 1990 - Estimativa do parâmetro b dos sismos de Palhano, CE, de outubro de 1988. XXXVI Congr. Brasileiro de Geologia, Natal, RN. Anais, 5: 2160-2163.

BOATWRIGHT, J. \& FLETCHER, J.B. - 1984 - The partition of radiated seismic energy between P and S waves, Bull. Seismol. Soc. Am., 74, 361-376. 
BORMANN, P., BAUMBACH, M., BOCK, G., GROSSER, H., CHOY, G.L \& BOATWRIGHT, J. - 2002 - Seismic Source and Source Parameters. In : IASPEI - New Manual of Seismological Observatory Practice. Vol 1. (ed) Peter Bormann.

BRUNE, J. - 1970 - Tectonic stress and the spectra of seismic shear waves from earthquakes, Journal of Geophysical Research., 75, 4,997-5009.

BRUNE, J. - 1971 - Correction, Journal of Geophysical Research.,76, 5002.

CAVALCANTE, A.S.A. - 2006 - Evolução termocronológica do sistema de falhas Senador Pompeu - CE. Dissertação de Mestrado, PPGG/UFRN, 70 pp.

COSTA, J.M., FERREIRA, J.M., OLIVEIRA, R.T., ASSUMPCAO, M., ANJOS, C.A., MENEZES, E.A., AIRES, A. - O sismo de João Câmara de 10 de Março de 1989. In: I Congresso Brasileiro de Geofísica, 1989, Rio de Janeiro. Simpósio; Sismicidade Intraplaca na América do Sul. São Paulo: Anais do I Congresso Brasileiro de Geofísica, 1989. v. 1. p. 371-375.

CPRM (Companhia de Pesquisa de Recursos Minerais) - 2006 - Mapeamento Geológico, Integrações Geológicas Regionais, escala 1:500.000.

DIAS, A.P. \& SOUZA, J.L. - 2004 - Estimates of coda Q attenuation in the João Câmara area (Northeastern Brazil) Journal of Seismology. 00: 1-2, 2004, 12pp.

DNPM (Departamento Nacional de Produção Mineral) - 1984 - Carta Metalogenética. Folha Aracati. 1:250.000.

DOMANSKI, B., GIBOWICZ, S.J., WIEJACZ, P. - 2002 - Source time function of seismic events at Rudna Copper Mine, Poland. Pure and Applied Geophysics, 159: 31144. 
DO NASCIMENTO, A.F. - 1997 - Estudo da sismicidade induzida pelo reservatório da barragem do Assu (RN) - Dissertação de Mestrado, PPGG/UFRN, 69pp.

DO NASCIMENTO, A.F., PEARCE, R.G. \& TAKEYA, M.K. - 2002 - Local shear wave observations in João Câmara, northeast Brazil. Journal Geophysical Research, 107(B10), 2232.

DO NASCIMENTO, A.F., COWIE, P.A., LUNN, R.J. \& PEARCE, R.G. - 2004 Spatio-temporal evolution of induced seismicity at Açu Resevoir, NE Brazil, Geophys. J. Int., 158: 1041-1052.

ESHELBY, J.D. - 1957 - The determination of the elastic of an ellipsoidal inclusion and related problems, Proceedings of the Royal Society of London, A, 241: 376-396.

FERREIRA, J.M., \& ASSUMPÇÃO, M. - 1983 - Sismicidade do Nordeste do Brasil. Revista Brasileira Geofísica, 1:67-68.

FERREIRA, J.M., TAKEYA, M.K., COSTA, J.M., MOREIRA, J.A.M., ASSUMPÇÃO, M., VELOSO, J.A.V. \& PEARCE, R.G. - 1987 - A continuing intraplate earthquake sequence near João Câmara - Northeastern Brazil - preliminary results, Geophys. Res Lett., 14: 1402-1405.

FERREIRA, J.M., OLIVEIRA, R.T., ASSUMPÇÃO, M., MOREIRA, J.A.M., PEARCE, R.G. \& TAKEYA, M.K. - 1995 - Correlation of seismicity and water level in Açu Resevoir - an example from Northeast Brazil. Bull. Seism. Soc. Am., 85: 1483-1489.

FERREIRA, J.M. - 1997 - Sismicidade e esforços no Nordeste do Brasil. Tese de Doutorado, IAG/USP, $126 \mathrm{pp}$. 
FERREIRA, J.M., OLIVEIRA, R.T., TAKEYA, M.K. \& ASSUMPÇÃO, M. - 1998 Superposition of local and regional stress in northeast Brazil: evidence from focal mechanisms around the Potiguar marginal basin. Geophysical Journal International. 134: 341-355.

FERREIRA, J. M., FRANÇA, G. S., VILAR, C. S., DO NASCIMENTO, A. F., BEZERRA, F. H. R., ASSUMPÇÃO, M. - 2008 - Induced seismicity in the Castanhão reservoir, NE Brasil - Preliminary results. Tectonophysics, article in press.

FRANKEL, A. - 1982 - Effects of attenuation and site response on the spectra of microearthquakes in the northeastern Caribbean, Bull. Seism. Soc. Am., 72: 1379-1402.

FRANKEL, A. \& KANAMORI, H. - 1983 - Determination of rupture duration and stress rrop for earthquakes in Southern California, Bulletin of the Seismological Society of America, 73: 1527-1551.

FRANKEL, A. \& WENNERBERG, L. - 1989 - Microearthquakes spectra from the Anza. California seismic network: Site response and source scaling. Bull. Seism. Soc. Am., 79: 581-609.

GOMES, S.G.F.A. - 2007 - Anisotropia sísmica crustal na região de Cascavel - CE. Tese de Mestrado, PPGG/UFRN, 48 pp.

GUTENBERG, B. and RICHTER, C.F. - 1956 - Earthquake magnitude, intensity, energy, and acceleration, Bull. Seism. Soc. Am. 46, 105-145.

HASKOV, J. \& ALGUACIL, G. - 2004 - Instrumentation in earthquake seismology. Netherlands. Springe.

IDA, Y. - 1972 - Cohesive force across the tip of a longitudinal-shear crack and Griffiths specific surface energy. J. Geophys. Res., 77, 3796-3805. 
IDE, S. \& BEROZA, G.C. - 2001 - Does apparent stress vary with earthquake size? Geophysics Research Letters, 28, 3349-3352.

IDE, S., BEROZA, G.C., PREJEAN, S.G. \& ELLSWORTH, W.L. - 2003 - Apparent break in earthquake scaling due to path and site effects on deep borehole recordings. $J$. Geophys. Res., 108(B5 2271).

IMANISHI, K. \& ELLSWORTH, W.L. - 2006 - Source scaling relationships of microearthquakes at parkfield, CA, determined using the SAFOD pilot hole seismic array. In Abercrombie, McGarr, Kanamori, and diToro, editors, Earthquakes: Radiated Energy and the Physics of Faulting, pages 81-90. AGU Geophys. Monograph 170.

JARDIM DE SÁ, E.F. - 1994 - A faixa seridó (Província Borborema, NE do Brasil) e seu significado geodinâmico na cadeia Brasiliana/Pan-Africana. Tese de Doutoramento, Ins. Geoc, Unb. 862 pp.

JOHNSTON, A.C. - 1989 - The seismicity of 'stable continental interiors'.In: Earthquakes at North Atlantic Passive Margins: Neotectonics and Post-Glacial Rebound. S. Gregersen \& P.W. Basham (eds.), Kluwer, Dordrecht, pp. 299-327.

KANAMORI, H. \& ANDERSON, D.L. - 1975 - Theoretical basis of some empirical relations in seismology, Bulletin of the Seismological Society of America, 65: 1073-1095.

KANAMORI, H. - 1977 - The energy release in great earthquake. J. Geophys. Res., V. 82, p. 2981-2987.

KANAMORI, H., HAUKSSON E., HUTTIN, L.K., \& JONES, L.M. - 1993 Determination of earthquake energy release and ML using TERRAscope, Bull. Seismol. Soc. Am., 83, 330-346. 
KANAMORI, H. \& HEATON, T.H. - 2000 - Microscopic and macroscopic physics of earthquakes. In J. Rundle, D. L. Turcotte, and W. Kein, editors, Geocomplexity and the Physics of Earthquakes, pages 147-155, Washington, D. C. American Geophysical Union. Monograph 120.

KANAMORI, H. \& RIVERA, L. - 2004 - Static and dynamic scaling relations for earthquake and their implications for rupture speed and stress drop, Bulletin of the Seismological Society of America, 94: 314-319.

KANAMORI, H. \& RIVERA, L. - 2006 - Energy partitioning during an earthquake. In Abercrombie, McGarr, Kanamori, and diToro, editors, Earthquakes: Radiated Energy and the Physics of Faulting, pages 3-13. AGU Geophys. Monograph 170.

LAY, T. \& WALLACE, T.C. - 1995 - Modern Global Seismology. San Diego. Academic Press.

MADARIAGA, R. - 1976 - Dynamics of an expanding circular fault, Bulletin of the Seismological Society of America, 66: 639-666.

MATOS, R.M.D. - 1992 - The Northeast Brazilian rift system. Tectonics, 11: 766-791.

MORI, J., ABERCROMBIE, R.E., KANAMORI, H. - 2003 - Stress drops and radiated seismic energies of aftershocks of 1994 Northridge, Califórnia, Earthquake, J. Geophys. Res., 108, B11, 2545.

OLIVEIRA, R.T., FERREIRA, J.M., COSTA, J.M., ASSUMPÇÃO, M., ANJOS, C.A., MENEZES, E.A. \& AIRES, A. - 1989 - O Crescimento da falha de samambaia e o sismo de 01/09/1988. Proc. I Intern. Congr. Braz. Geophys. Soc., 1: 365-370. 
OLIVEIRA, R.T., TAKEYA, M.K. FERREIRA, J.M., ASSUMPÇÃO, M. \& PEARCE, R.G. - 1994 - Eigth years of continuos seismic activity near João Câmara NE Brazil. Regional Seismological Assembly in South America, Brasília, 22-26 de agosto, abstracts: 17.

PALMER, A.C. \& RICE, J.R. - 1973 - The growth of slip surfaces in the progressive failure of overconsolidated clay. Proc. R. Soc. Lond., A, 332, 527-548.

PLICKA, V. \& ZAHRADNÍK, J. - 1998 - Inverting seismograms of weak events for empirical Green's tensor derivatives. Geophys. J. Int., 132, 471-478.

PRIETO, G.A., SHEARER, P.M., VERNON, F.L., KILB, D. - 2004 - Earthquake source scaling and self-similarity estimation from stacking $\mathrm{P}$ and $\mathrm{S}$ spectra. Journal of Geophysical Research. Vol. 109, B08310.

PRIETO, G.A., PARKER, R.L., VERNON, F.L., SHEARER, P.M. \& THOMSON, D.J. 2006 - Uncertainties in earthquake source spectrum estimation using empirical Green functions. In Abercrombie, McGarr, Kanamori, and diToro, editors, Earthquakes: Radiated Energy and the Physics of Faulting, pages 69-74. AGU Geophys. Monograph 170 .

PRIETO, G.A. - 2007 - Improving earthquake source spectrum estimation using multitaper techeniques. PhD. Thesis, University of California, $124 \mathrm{pp}$.

RBGf - Revista Brasileira de Geofísica; Boletim Sísmico.

RIVERA, L. \& KANAMORI, H. - 2005 - Representations of the radiated energy in earthquakes. Geophys. J. Int., 162, 148-155.

SCHOLZ, C.H. - 1990 - The mechanics of earthquakes and faulting. Cambridge University Press, New York, 1-438. 
SHEARER, P.M. - 1999 - Introduction to seismology. Cambridge University Press, Cambridge.

SONLEY, E. \& ABERCROMBIE, R.E. - 2006 - Variability introduced by methods of attenuation correction: the effect on source parameter determination. In Abercrombie, Mc-Garr, Kanamori, and diToro, editors, Earthquakes: Radiated Energy and the Physics of Faulting. AGU Geophys. Monograph 170.

SYKES. L.R., \& SBAR, M.L. - 1973 - Intraplate earthquakes, lithosphere stresses, and the driving mechanism of plate tectonics: Nature, v. 245, p. 298-302.

SYKES, L.R. - 1978 - Intraplate seismicity, reactivation of preexisting zones of weakness, alkaline magmatism, and other tectonism posdating continental fragmentation. Ver. Geophys. Space Phys., 16: 621-688.

TEXEIRA, W., TOLEDO, M.C.M., FAIRCHILD, T.R. \& TAIOLI, F. - 2008 Decifrando a Terra, $3^{\mathrm{a}}$ edição, São Paulo.

TAKEYA, M.K., FERREIRA, J.M., PEARCE, R.P., ASSUMPÇÃO, M., COSTA, J.M. \& SOPHIA, C.M. - 1989 - The 1986-1987 intraplate earthquakes sequence near João Câmara, northeast Brazil- evolution of seismicity. Tectonophysics, 167: 117-131.

TAKEYA, M.K. - 1992 - High precision studies of an intraplate earthquake sequence in Northeast Brazil. Ph D. Thesis, University of Edinburgh, 228 pp.

TOMIC, J. - 2004 - Source parameters of resevoir induced earthquake, Açu Dam, NE Brasil, Thesis, Boston University, 82 pp.

TOMIC, J., R.E. Abercrombie, \& Do Nascimento, A.F. - 2008 - Source parameters and rupture velocity of small $\mathrm{M} \leq 2.2$ reservoir induced earthquakes, Geophys. Res. Lett., submitido. 
VILAR, C.S. - 2000 - Estudo da atividade sísmica em Cascavel - CE com estações sismográficas digitais, Tese de Mestrado, PPGG/UFRN, 73 pp.

VILAR, C.S., FERREIRA, J.M., FRANÇA, G.S. - 2005 - Monitoramento da atividade sísmica no Estado do Rio Grande do Norte. Revista Fapern, Brasil, v. 1, n. 2, p. 24-25.

WALTER, W.R., MAYEDA, K. \& GOK, R. - 2006 -The scaling of seismic with moment: simple models compared with observations. In Abercrombie, Mc-Garr, Kanamori, and diToro, editors, Earthquakes: Radiated Energy and the Physics of Faulting, pages 25-41. AGU Geophys. Monograph 170.

WYSS, M. \& BRUNE, J.N. - 1968 - Seismic moment, stress, and source dimensions for earthquakes in the california- nevada region. J. Geophys. Res., 73, 4681-4694. 


\section{APÊNDICE A}

\section{PARÂMETROS LIVRES OBTIDOS PELO AJUSTE DOS ESPECTROS DE DESLOCAMENTOS DOS 21 SISMOS UTILIZADOS, EM CADA ESTAÇÃO.}




\begin{tabular}{|c|c|c|c|c|}
\hline \multicolumn{5}{|c|}{ Estação CH06 } \\
\hline & \multicolumn{2}{|c|}{ Componente Norte } & \multicolumn{2}{|c|}{ Componente Leste } \\
\hline Sismo & $\Omega_{0}(m \cdot s)$ & $f_{c}(H z)$ & $\Omega_{0}(m \cdot s)$ & $f(H z)_{c}$ \\
\hline 1 & $1,51 \mathrm{E}-11 \pm 9,19 \mathrm{E}-13$ & $18,9 \pm 2,5$ & - & - \\
\hline 5 & $4,77 \mathrm{E}-13 \pm 4,21 \mathrm{E}-14$ & $29,3 \pm 6,6$ & - & - \\
\hline 15 & - & - & - & - \\
\hline 17 & $1,03 \mathrm{E}-12 \pm 1,10 \mathrm{E}-13$ & $40,3 \pm 13,4$ & $8,69 \mathrm{E}-13 \pm 6,78 \mathrm{E}-14$ & $41,9 \pm 10,4$ \\
\hline 20 & $1,27 \mathrm{E}-12 \pm 9,88 \mathrm{E}-14$ & $39,0 \pm 8,7$ & $1,25 \mathrm{E}-12 \pm 9,72 \mathrm{E}-14$ & $46,5 \pm 11,5$ \\
\hline 21 & $2,33 \mathrm{E}-12 \pm 1,50 \mathrm{E}-13$ & $13,0 \pm 1,7$ & - & - \\
\hline 24 & $9,17 \mathrm{E}-12 \pm 5,41 \mathrm{E}-13$ & $36,4 \pm 6,0$ & $8,02 \mathrm{E}-12 \pm 7,57 \mathrm{E}-13$ & $46,9 \pm 14,3$ \\
\hline 30 & - & - & - & - \\
\hline 36 & $2,32 \mathrm{E}-12 \pm 1,25 \mathrm{E}-13$ & $19,2 \pm 2,2$ & - & - \\
\hline 54 & $6,75 \mathrm{E}-13 \pm 1,64 \mathrm{E}-14$ & $85,3 \pm 79,1$ & - & - \\
\hline 59 & $2,32 \mathrm{E}-12 \pm 1,41 \mathrm{E}-13$ & $51,0 \pm 10,1$ & - & - \\
\hline 62 & $2,95 \mathrm{E}-12 \pm 1,86 \mathrm{E}-13$ & $20,9 \pm 2,8$ & $9,27 \mathrm{E}-13 \pm 4,95 \mathrm{E}-13$ & $23,5 \pm 27,9$ \\
\hline 65 & $1,40 \mathrm{E}-11 \pm 1,21 \mathrm{E}-12$ & $29,9 \pm 6,7$ & $7,24 \mathrm{E}-12 \pm 1,44 \mathrm{E}-12$ & $64,8 \pm 54,3$ \\
\hline 66 & $1,62 \mathrm{E}-12 \pm 9,92 \mathrm{E}-14$ & $26,4 \pm 3,9$ & - & - \\
\hline 69 & $1,20 \mathrm{E}-11 \pm 4,44 \mathrm{E}-13$ & $12,2 \pm 0,9$ & $4,57 \mathrm{E}-12 \pm 3,80 \mathrm{E}-13$ & $38,8 \pm 9,4$ \\
\hline 71 & $9,16 \mathrm{E}-13 \pm 1,07 \mathrm{E}-13$ & $41,0 \pm 13,5$ & - & - \\
\hline 76 & $1,65 \mathrm{E}-12 \pm 1,38 \mathrm{E}-13$ & $48,2 \pm 14,2$ & $1,15 \mathrm{E}-12 \pm 7,81 \mathrm{E}-14$ & $44,9 \pm 10,2$ \\
\hline 83 & $1,19 \mathrm{E}-11 \pm 4,05 \mathrm{E}-13$ & $14,7 \pm 0,9$ & $5,25 \mathrm{E}-12 \pm 4,66 \mathrm{E}-13$ & $46,3 \pm 12,6$ \\
\hline 85 & $2,84 \mathrm{E}-12 \pm 1,37 \mathrm{E}-13$ & $22,4 \pm 2,4$ & $1,93 \mathrm{E}-12 \pm 1,47 \mathrm{E}-13$ & $71,6 \pm 22,8$ \\
\hline 86 & $3,65 \mathrm{E}-12 \pm 1,56 \mathrm{E}-13$ & $28,5 \pm 2,9$ & $2,82 \mathrm{E}-12 \pm 2,57 \mathrm{E}-13$ & $33,3 \pm 7,8$ \\
\hline 92 & $1,11 \mathrm{E}-11 \pm 6,64 \mathrm{E}-13$ & $27,9 \pm 4,0$ & $1,14 \mathrm{E}-11 \pm 9,24 \mathrm{E}-13$ & $24,4 \pm 4,8$ \\
\hline
\end{tabular}

Tabela A.1: Parâmetros obtidos após ajustar a equação (3.3) com os valores do erro. Nos sismos em que foram obtidos valores em apenas uma componente, não foi possível determinar os seus parâmetros de fonte. 


\begin{tabular}{|c|c|c|c|c|}
\hline \multicolumn{5}{|c|}{ Estação CH08 } \\
\hline & \multicolumn{2}{|c|}{ Componente Norte } & \multicolumn{2}{|c|}{ Componente Leste } \\
\hline Sismo & $\Omega_{0}(m \cdot s)$ & $f_{c}(H z)$ & $\Omega_{0}(m \cdot s)$ & $f(H z)_{c}$ \\
\hline 1 & - & - & $5,67 \mathrm{E}-12 \pm 4,69 \mathrm{E}-13$ & $47,9 \pm 12,6$ \\
\hline 5 & $1,74 \mathrm{E}-13 \pm 2,04 \mathrm{E}-14$ & $37,6 \pm 12,6$ & - & - \\
\hline 15 & $2,73 \mathrm{E}-12 \pm 1,25 \mathrm{E}-13$ & $23,3 \pm 2,4$ & $1,26 \mathrm{E}-12 \pm 8,15 \mathrm{E}-14$ & $83,1 \pm 26,2$ \\
\hline 17 & $1,13 \mathrm{E}-12 \pm 5,87 \mathrm{E}-13$ & $37,9 \pm 5,8$ & $8,49 \mathrm{E}-13 \pm 7,8 \mathrm{E}-14$ & $92,1 \pm 50,4$ \\
\hline 20 & - & - & - & - \\
\hline 21 & - & - & - & - \\
\hline 24 & $9,44 \mathrm{E}-12 \pm 7,63 \mathrm{E}-13$ & $26,5 \pm 5,1$ & $1,08 \mathrm{E}-11 \pm 4,20 \mathrm{E}-13$ & $34,7 \pm 3,6$ \\
\hline 30 & $8,09 \mathrm{E}-13 \pm 4,24 \mathrm{E}-14$ & $28,8 \pm 3,7$ & $2,33 \mathrm{E}-13 \pm 6,58 \mathrm{E}-14$ & $48,3 \pm 44,1$ \\
\hline 36 & $6,09 \mathrm{E}-13 \pm 5,31 \mathrm{E}-14$ & $66,8 \pm 24,8$ & $1,08 \mathrm{E}-12 \pm 5,61 \mathrm{E}-14$ & $39,0 \pm 5,9$ \\
\hline 54 & $1,09 \mathrm{E}-12 \pm 4,72 \mathrm{E}-14$ & $24,0 \pm 4,2$ & $6,89 \mathrm{E}-13 \pm 4,82 \mathrm{E}-14$ & $82,6 \pm 91,6$ \\
\hline 59 & $3,06 \mathrm{E}-12 \pm 1,86 \mathrm{E}-13$ & $39,2 \pm 6,7$ & - & - \\
\hline 62 & $3,96 \mathrm{E}-12 \pm 1,92 \mathrm{E}-13$ & $24,7 \pm 6,7$ & $1,43 \mathrm{E}-12 \pm 1,97 \mathrm{E}-13$ & $59,9 \pm 29,4$ \\
\hline 65 & $2,88 \mathrm{E}-11 \pm 1,69 \mathrm{E}-12$ & $23,5 \pm 3,2$ & $2,17 \mathrm{E}-11 \pm 1,38 \mathrm{E}-12$ & $32,6 \pm 5,5$ \\
\hline 66 & $1,78 \mathrm{E}-12 \pm 7,68 \mathrm{E}-14$ & $19,8 \pm 1,9$ & $9,45 \mathrm{E}-13 \pm 6,61 \mathrm{E}-14$ & $41,8 \pm 8,8$ \\
\hline 69 & $6,79 \mathrm{E}-12 \pm 3,30 \mathrm{E}-13$ & $14,7 \pm 1,4$ & $5,03 \mathrm{E}-12 \pm 4,41 \mathrm{E}-13$ & $14,4 \pm 2,5$ \\
\hline 71 & $3,91 \mathrm{E}-12 \pm 1,98 \mathrm{E}-13$ & $19,9 \pm 2,2$ & $1,75 \mathrm{E}-12 \pm 1,53 \mathrm{E}-13$ & $70,6 \pm 26,0$ \\
\hline 76 & $8,24 \mathrm{E}-13 \pm 6,73 \mathrm{E}-14$ & $57,0 \pm 18,1$ & $1,16 \mathrm{E}-12 \pm 8,23 \mathrm{E}-14$ & $58,3 \pm 16,4$ \\
\hline 83 & $4,15 \mathrm{E}-12 \pm 3,52 \mathrm{E}-13$ & $31,1 \pm 6,4$ & $1,24 \mathrm{E}-11 \pm 3,45 \mathrm{E}-13$ & $20,1 \pm 1,2$ \\
\hline 85 & $2,03 \mathrm{E}-12 \pm 1,15 \mathrm{E}-13$ & $46,3 \pm 7,7$ & $3,29 \mathrm{E}-12 \pm 1,29 \mathrm{E}-13$ & $28,6 \pm 2,6$ \\
\hline 86 & $2,89 \mathrm{E}-12 \pm 1,64 \mathrm{E}-13$ & $48,7 \pm 8,3$ & $5,00 \mathrm{E}-12 \pm 1,82 \mathrm{E}-13$ & $29,3 \pm 2,6$ \\
\hline 92 & $9,04 \mathrm{E}-12 \pm 5,00 \mathrm{E}-13$ & $33,0 \pm 4,5$ & $1,35 \mathrm{E}-11 \pm 6,25 \mathrm{E}-13$ & $23,8 \pm 2,4$ \\
\hline
\end{tabular}

Tabela A.2: Parâmetros obtidos após ajustar a equação (3.3) com os valores do erro. Nos sismos em que foram obtidos valores em apenas uma componente, não foi possível determinar os seus parâmetros de fonte. 


\begin{tabular}{|c|c|c|c|c|}
\hline \multicolumn{5}{|c|}{ Estação CH10 } \\
\hline & \multicolumn{2}{|c|}{ Componente Norte } & \multicolumn{2}{|c|}{ Componente Leste } \\
\hline Sismo & $\Omega_{0}(m \cdot s)$ & $f_{c}(H z)$ & $\Omega_{0}(m \cdot s)$ & $f(H z)_{c}$ \\
\hline 1 & $9,14 \mathrm{E}-12 \pm 8,72 \mathrm{E}-13$ & $38,9 \pm 10,7$ & - & - \\
\hline 5 & $8,68 \mathrm{E}-14 \pm 2,41 \mathrm{E}-14$ & $28,5 \pm 20,4$ & $1,43 \mathrm{E}-13 \pm 2,55 \mathrm{E}-14$ & $35,7 \pm 18,2$ \\
\hline 15 & - & - & $1,34 \mathrm{E}-12 \pm 1,22 \mathrm{E}-13$ & $37,5 \pm 9,8$ \\
\hline 17 & $6,96 \mathrm{E}-13 \pm 7,23 \mathrm{E}-14$ & $51,2 \pm 20,2$ & - & - \\
\hline 20 & - & - & - & - \\
\hline 21 & $9,10 \mathrm{E}-13 \pm 7,60 \mathrm{E}-14$ & $38,8 \pm 9,8$ & $6,84 \mathrm{E}-13 \pm 5,57 \mathrm{E}-14$ & $46,1 \pm 12,6$ \\
\hline 24 & $3,16 \mathrm{E}-12 \pm 2,58 \mathrm{E}-13$ & $45,0 \pm 11,8$ & $2,31 \mathrm{E}-12 \pm 2,72 \mathrm{E}-13$ & $47,1 \pm 18,3$ \\
\hline 30 & $7,98 \mathrm{E}-14 \pm 3,20 \mathrm{E}-14$ & $75,9 \pm 150,9$ & $2,30 \mathrm{E}-13 \pm 1,64 \mathrm{E}-14$ & $74,8 \pm 20,0$ \\
\hline 36 & $6,15 \mathrm{E}-13 \pm 9,07 \mathrm{E}-14$ & $39,6 \pm 17,8$ & $1,31 \mathrm{E}-12 \pm 6,76 \mathrm{E}-14$ & $36,2 \pm 5,4$ \\
\hline 54 & $4,09 \mathrm{E}-13 \pm 3,10 \mathrm{E}-14$ & $6,1 \pm 1,0$ & - & - \\
\hline 59 & $1,01 \mathrm{E}-12 \pm 1,94 \mathrm{E}-13$ & $33,3 \pm 17,4$ & $1,19 \mathrm{E}-12 \pm 9,43 \mathrm{E}-14$ & $52,2 \pm 14,7$ \\
\hline 62 & - & - & $2,27 \mathrm{E}-12 \pm 1,56 \mathrm{E}-13$ & $33,6 \pm 6,2$ \\
\hline 65 & $3,56 \mathrm{E}-12 \pm 1,88 \mathrm{E}-12$ & $67,3 \pm 163,0$ & $1,30 \mathrm{E}-11 \pm 9,18 \mathrm{E}-13$ & $61,1 \pm 18,1$ \\
\hline 66 & - & - & $1,01 \mathrm{E}-12 \pm 5,98 \mathrm{E}-14$ & $58,6 \pm 14,0$ \\
\hline 69 & $5,29 \mathrm{E}-12 \pm 1,53 \mathrm{E}-13$ & $15,2 \pm 0,9$ & $5,29 \mathrm{E}-12 \pm 1,53 \mathrm{E}-13$ & $15,2 \pm 0,9$ \\
\hline 71 & - & - & $1,21 \mathrm{E}-12 \pm 8,50 \mathrm{E}-14$ & $33,0 \pm 6,3$ \\
\hline 76 & - & - & - & - \\
\hline 83 & - & - & $2,64 \mathrm{E}-12 \pm 2,09 \mathrm{E}-13$ & $46,5 \pm 11,1$ \\
\hline 85 & - & - & $2,29 \mathrm{E}-13 \pm 5,44 \mathrm{E}-14$ & $49,6 \pm 36,9$ \\
\hline 86 & - & - & $4,10 \mathrm{E}-13 \pm 6,92 \mathrm{E}-14$ & $77,6 \pm 58,6$ \\
\hline 92 & - & - & - & - \\
\hline
\end{tabular}

Tabela A.3: Parâmetros obtidos após ajustar a equação (3.3) com os valores do erro. Nos sismos em que foram obtidos valores em apenas uma componente, não foi possível determinar os seus parâmetros de fonte. 


\begin{tabular}{|c|c|c|c|c|}
\hline \multicolumn{5}{|c|}{ Estação CH11 } \\
\hline & \multicolumn{2}{|c|}{ Componente Norte } & \multicolumn{2}{|c|}{ Componente Leste } \\
\hline Sismo & $\Omega_{0}(m \cdot s)$ & $f_{c}(\mathrm{~Hz})$ & $\Omega_{0}(m \cdot s)$ & $f(H z)_{c}$ \\
\hline 1 & $1,74 \mathrm{E}-11 \pm 2,31 \mathrm{E}-12$ & $56,6 \pm 27,2$ & - & - \\
\hline 5 & $4,64 \mathrm{E}-13 \pm 7,07 \mathrm{E}-14$ & $38,8 \pm 16,8$ & $4,81 \mathrm{E}-13 \pm 5,68 \mathrm{E}-14$ & $39,5 \pm 13,5$ \\
\hline 15 & - & - & - & - \\
\hline 17 & - & - & - & - \\
\hline 20 & $2,31 \mathrm{E}-12 \pm 3,32 \mathrm{E}-13$ & $65,7 \pm 36,7$ & $3,29 \mathrm{E}-12 \pm 2,65 \mathrm{E}-13$ & $74,5 \pm 25,8$ \\
\hline 21 & - & - & $1,44 \mathrm{E}-12 \pm 2,80 \mathrm{E}-13$ & $49,1 \pm 32,4$ \\
\hline 24 & $1,79 \mathrm{E}-11 \pm 2,13 \mathrm{E}-12$ & & $2,24 \mathrm{E}-11 \pm 1,96 \mathrm{E}-12$ & $45,6 \pm 12,3$ \\
\hline 30 & - & - & - & - \\
\hline 36 & - & - & - & - \\
\hline 54 & $3,81 \mathrm{E}-12 \pm 3,19 \mathrm{E}-13$ & $7,9 \pm 1,5$ & - & - \\
\hline 59 & - & - & $2,26 \mathrm{E}-12 \pm 8,24 \mathrm{E}-13$ & $38,7 \pm 37,9$ \\
\hline 62 & - & - & $3,71 \mathrm{E}-12 \pm 3,06 \mathrm{E}-13$ & $41,9 \pm 9,5$ \\
\hline 65 & $4,10 \mathrm{E}-11 \pm 3,15 \mathrm{E}-12$ & $27,4 \pm 5,1$ & $2,90 \mathrm{E}-11 \pm 2,46 \mathrm{E}-12$ & $32,0 \pm 7,1$ \\
\hline 66 & $8,32 \mathrm{E}-13 \pm 3,44 \mathrm{E}-13$ & $19,2 \pm 16,9$ & $3,68 \mathrm{E}-12 \pm 3,35 \mathrm{E}-13$ & $13,7 \pm 2,4$ \\
\hline 69 & $8,54 \mathrm{E}-12 \pm 9,12 \mathrm{E}-13$ & $41,1 \pm 12,9$ & $1,80 \mathrm{E}-11 \pm 1,73 \mathrm{E}-12$ & $16,3 \pm 3,2$ \\
\hline 71 & $2,29 \mathrm{E}-12 \pm 1,01 \mathrm{E}-12$ & $21,1 \pm 20,1$ & $4,00 \mathrm{E}-05 \pm 3,33 \mathrm{E}-12$ & $46,6 \pm 12,4$ \\
\hline 76 & $2,00 \mathrm{E}-12 \pm 1,59 \mathrm{E}-13$ & $47,0 \pm 14,5$ & $1,21 \mathrm{E}-12 \pm 3,24 \mathrm{E}-13$ & $62,0 \pm 67,9$ \\
\hline 83 & $1,82 \mathrm{E}-11 \pm 1,83 \mathrm{E}-12$ & $43,5 \pm 12,6$ & $2,64 \mathrm{E}-11 \pm 2,09 \mathrm{E}-12$ & $18,8 \pm 3,1$ \\
\hline 85 & $4,74 \mathrm{E}-12 \pm 5,95 \mathrm{E}-13$ & $43,0 \pm 15,3$ & $8,31 \mathrm{E}-12 \pm 7,79 \mathrm{E}-13$ & $31,1 \pm 7,1$ \\
\hline 86 & $6,56 \mathrm{E}-12 \pm 6,74 \mathrm{E}-13$ & $76,1 \pm 33,1$ & $8,36 \mathrm{E}-12 \pm 8,63 \mathrm{E}-13$ & $32,3 \pm 8,3$ \\
\hline 92 & $1,87 \mathrm{E}-11 \pm 2,27 \mathrm{E}-12$ & $57,9 \pm 23,7$ & $2,50 \mathrm{E}-11 \pm 2,96 \mathrm{E}-12$ & $27,5 \pm 7,5$ \\
\hline
\end{tabular}

Tabela A.4: Parâmetros obtidos após ajustar a equação (3.3) com os valores do erro. Nos sismos em que foram obtidos valores em apenas uma componente, não foi possível determinar os seus parâmetros de fonte. 


\begin{tabular}{|c|c|c|c|c|}
\hline \multicolumn{5}{|c|}{ Estação CH13 } \\
\hline & \multicolumn{2}{|c|}{ Componente Norte } & \multicolumn{2}{|c|}{ Componente Leste } \\
\hline Sismo & $\Omega_{0}(m \cdot s)$ & $f_{c}(H z)$ & $\Omega_{0}(m \cdot s)$ & $f(H z)_{c}$ \\
\hline 1 & $1,80 \mathrm{E}-11 \pm 2,24 \mathrm{E}-12$ & $25,3 \pm 7,3$ & $8,45 \mathrm{E}-12 \pm 8,27 \mathrm{E}-13$ & $45,3 \pm 13,5$ \\
\hline 5 & $5,74 \mathrm{E}-13 \pm 5,68 \mathrm{E}-14$ & $48,8 \pm 16,5$ & $5,43 \mathrm{E}-13 \pm 3,39 \mathrm{E}-14$ & $55,8 \pm 13,0$ \\
\hline 15 & $6,15 \mathrm{E}-12 \pm 6,46 \mathrm{E}-13$ & $20,4 \pm 4,7$ & $3,48 \mathrm{E}-12 \pm 2,74 \mathrm{E}-13$ & $21,4 \pm 3,8$ \\
\hline 17 & $3,49 \mathrm{E}-12 \pm 3,18 \mathrm{E}-13$ & $28,6 \pm 6,9$ & $3,59 \mathrm{E}-12 \pm 2,19 \mathrm{E}-13$ & $16,9 \pm 2,2$ \\
\hline 20 & $6,50 \mathrm{E}-12 \pm 4,75 \mathrm{E}-13$ & $16,8 \pm 2,5$ & $2,16 \mathrm{E}-12 \pm 3,11 \mathrm{E}-13$ & $28,0 \pm 9,7$ \\
\hline 21 & $1,87 \mathrm{E}-12 \pm 1,47 \mathrm{E}-13$ & $43,1 \pm 10,6$ & $1,03 \mathrm{E}-12 \pm 1,90 \mathrm{E}-13$ & $40,6 \pm 22,5$ \\
\hline 24 & $1,94 \mathrm{E}-11 \pm 1,49 \mathrm{E}-12$ & $18,1 \pm 2,9$ & $1,37 \mathrm{E}-11 \pm 1,20 \mathrm{E}-12$ & $21,5 \pm 4,2$ \\
\hline 30 & - & - & $4,89 \mathrm{E}-13 \pm 2,79 \mathrm{E}-14$ & $50,4 \pm 10,0$ \\
\hline 36 & - & - & $8,63 \mathrm{E}-12 \pm 6,83 \mathrm{E}-13$ & $12,4 \pm 1,9$ \\
\hline 54 & - & - & - & - \\
\hline 59 & $5,32 \mathrm{E}-12 \pm 4,82 \mathrm{E}-13$ & $50,0 \pm 15,4$ & $3,62 \mathrm{E}-12 \pm 3,58 \mathrm{E}-13$ & $45,5 \pm 14,4$ \\
\hline 62 & $5,85 \mathrm{E}-12 \pm 9,72 \mathrm{E}-13$ & $23,0 \pm 8,6$ & $1,14 \mathrm{E}-11 \pm 8,72 \mathrm{E}-13$ & $15,6 \pm 2,4$ \\
\hline 65 & $4,62 \mathrm{E}-11 \pm 4,59 \mathrm{E}-12$ & $25,3 \pm 6,1$ & - & - \\
\hline 66 & $2,44 \mathrm{E}-12 \pm 2,29 \mathrm{E}-13$ & $30,4 \pm 7,5$ & $6,30 \mathrm{E}-12 \pm 8,10 \mathrm{E}-13$ & $35,1 \pm 12,8$ \\
\hline 69 & $1,24 \mathrm{E}-11 \pm 1,17 \mathrm{E}-12$ & $14,2 \pm 2,7$ & $6,31 \mathrm{E}-12 \pm 1,37 \mathrm{E}-12$ & $14,3 \pm 6,3$ \\
\hline 71 & $4,68 \mathrm{E}-12 \pm 6,94 \mathrm{E}-13$ & $25,6 \pm 9,1$ & $4,68 \mathrm{E}-12 \pm 5,29 \mathrm{E}-13$ & $26,1 \pm 7,1$ \\
\hline 76 & $3,31 \mathrm{E}-12 \pm 2,73 \mathrm{E}-13$ & $48,6 \pm 14,3$ & - & - \\
\hline 83 & - & - & $1,98 \mathrm{E}-11 \pm 1,66 \mathrm{E}-12$ & $19,5 \pm 3,4$ \\
\hline 85 & $3,74 \mathrm{E}-12 \pm 4,50 \mathrm{E}-13$ & $33,0 \pm 9,7$ & $1,08 \mathrm{E}-11 \pm 9,21 \mathrm{E}-13$ & $18,3 \pm 3,2$ \\
\hline 86 & $5,45 \mathrm{E}-12 \pm 6,76 \mathrm{E}-13$ & $31,3 \pm 9,4$ & $1,41 \mathrm{E}-11 \pm 8,09 \mathrm{E}-13$ & $21,4 \pm 2,6$ \\
\hline 92 & $1,47 \mathrm{E}-11 \pm 1,45 \mathrm{E}-12$ & $25,8 \pm 5,7$ & - & - \\
\hline
\end{tabular}

Tabela A.5: Parâmetros obtidos após ajustar a equação (3.3) com os valores do erro. Nos sismos em que foram obtidos valores em apenas uma componente, não foi possível determinar os seus parâmetros de fonte. 


\section{APÊNDICE B}

\section{GRÁFICOS DO INTERVALO DA ONDA S DO SISMO 65, NAS COMPONENTES NORTE E LESTE PARA CADA UMA DAS SEIS ESTAÇÕES, BEM COMO OS ESPECTROS DE DESLOCAMENTO AJUSTADOS.}



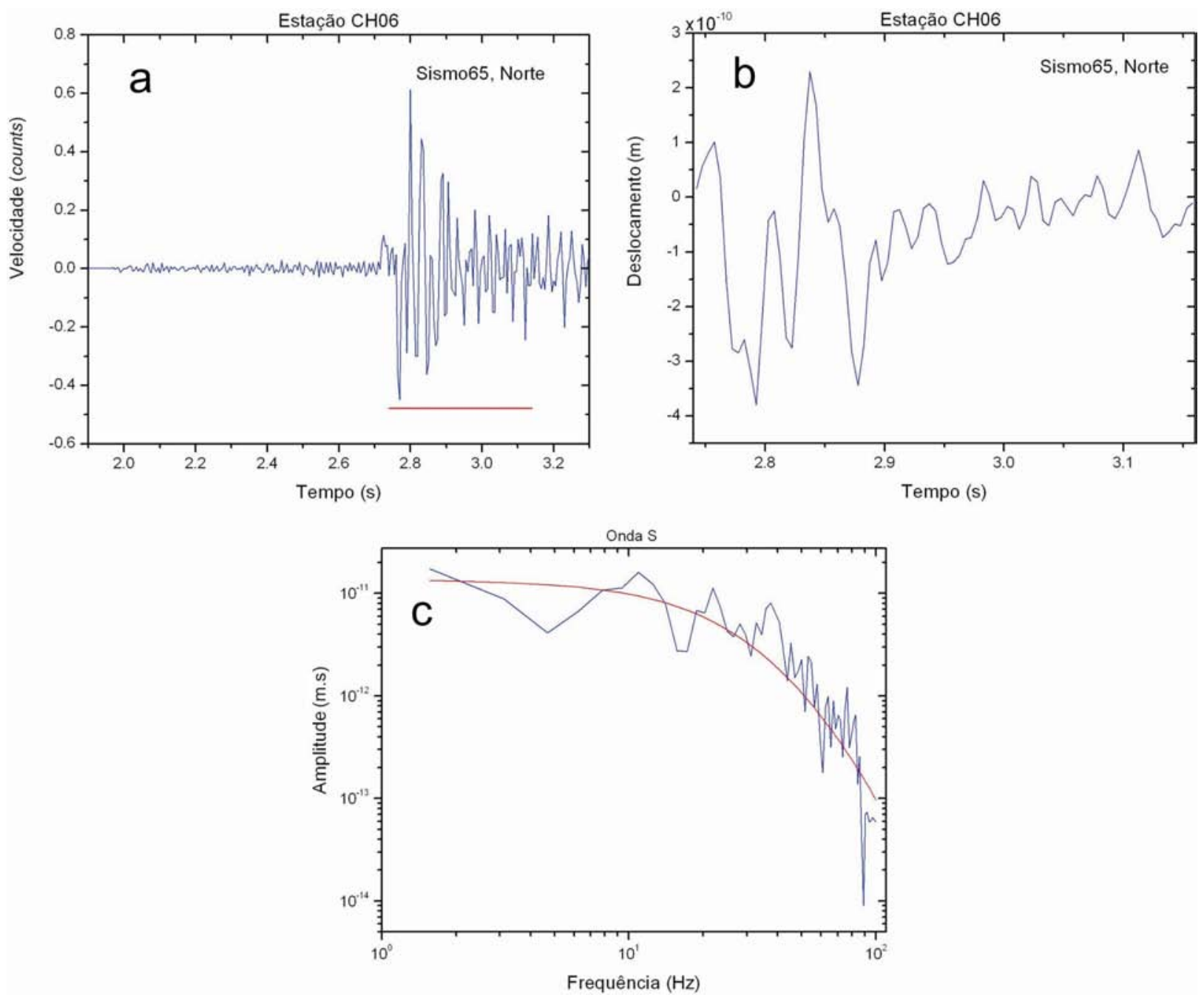

Figura B. 1: a) $\mathrm{O}$ intervalo da onda $\mathrm{S}$ utilizado para determinar os parâmetros de fonte está representado pela linha vermelha. b) Intervalo anterior após ter a resposta do equipamento removida e ser integrado no tempo. c) Espectro de deslocamento do intervalo da onda S (linha azul) após aplicar a Transformada de Fourier e ajustar o espectro (linha vermelha) através da equação (3.3). 

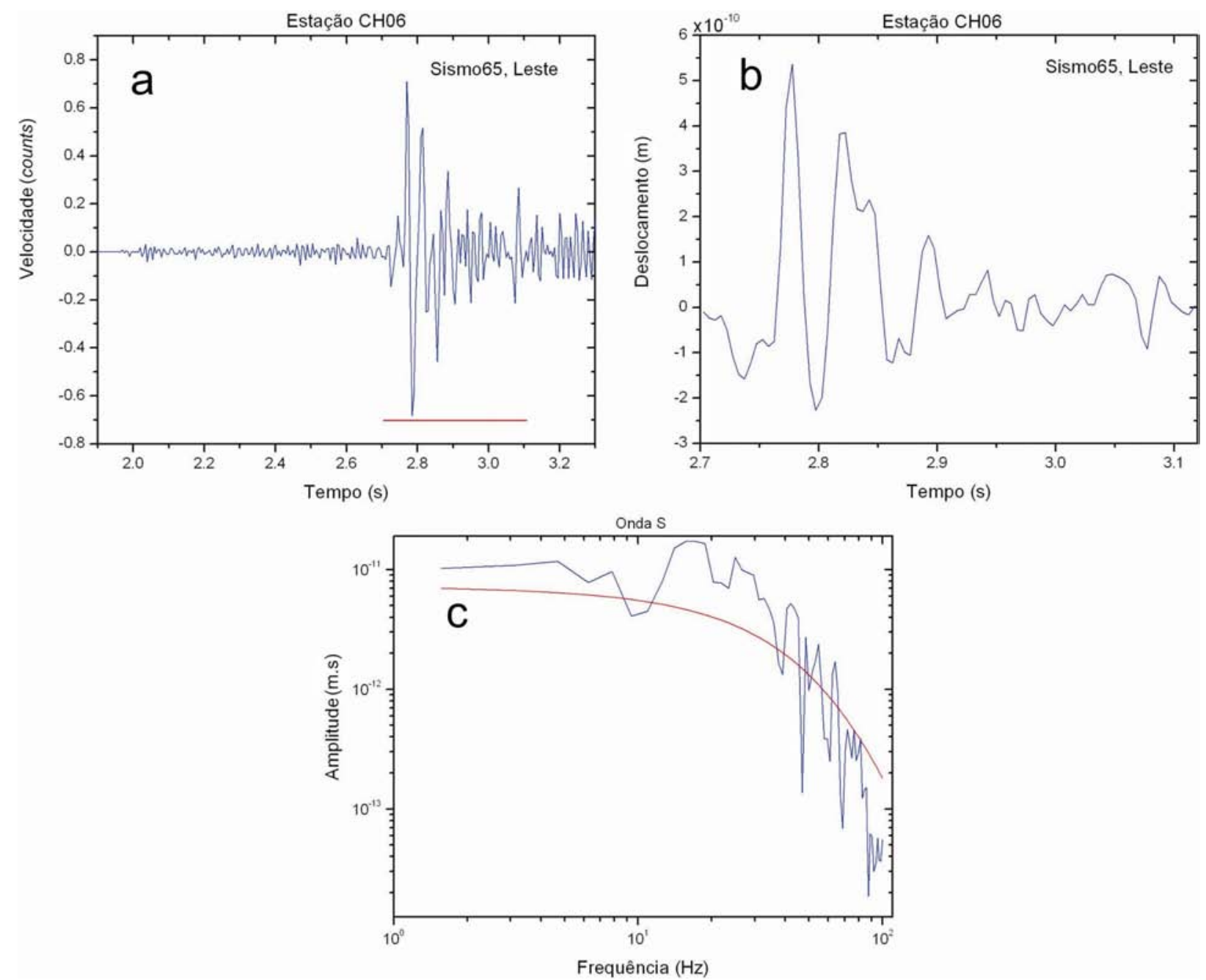

Figura B. 2: a) $\mathrm{O}$ intervalo da onda $\mathrm{S}$ utilizado para determinar os parâmetros de fonte está representado pela linha vermelha. b) Intervalo anterior após ter a resposta do equipamento removida e ser integrado no tempo. c) Espectro de deslocamento do intervalo da onda $\mathrm{S}$ (linha azul) após aplicar a Transformada de Fourier e ajustar o espectro (linha vermelha) através da equação (3.3). 

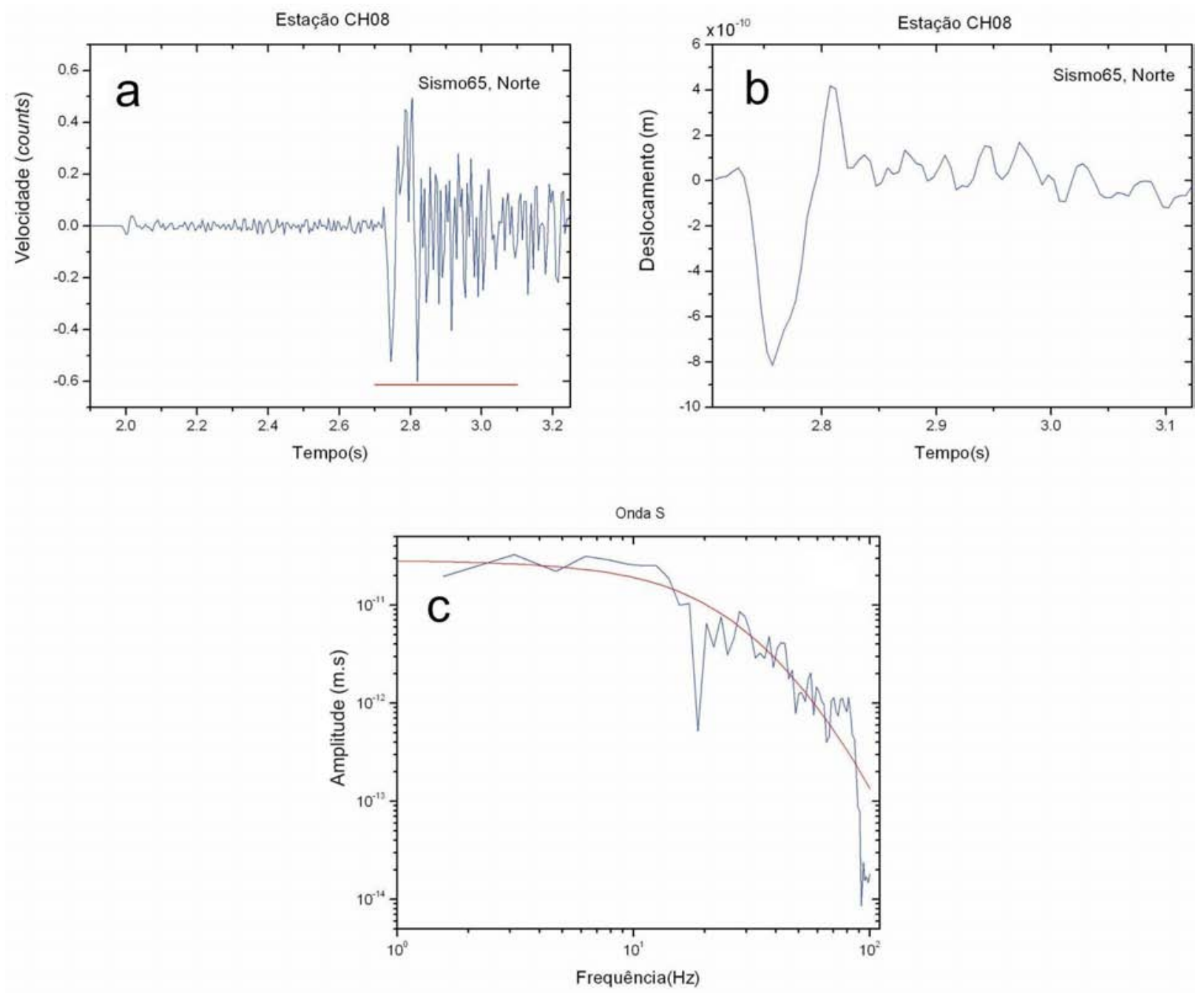

Figura B. 3: a) O intervalo da onda S utilizado para determinar os parâmetros de fonte está representado pela linha vermelha. b) Intervalo anterior após ter a resposta do equipamento removida e ser integrado no tempo. c) Espectro de deslocamento do intervalo da onda $\mathrm{S}$ (linha azul) após aplicar a Transformada de Fourier e ajustar o espectro (linha vermelha) através da equação (3.3). 

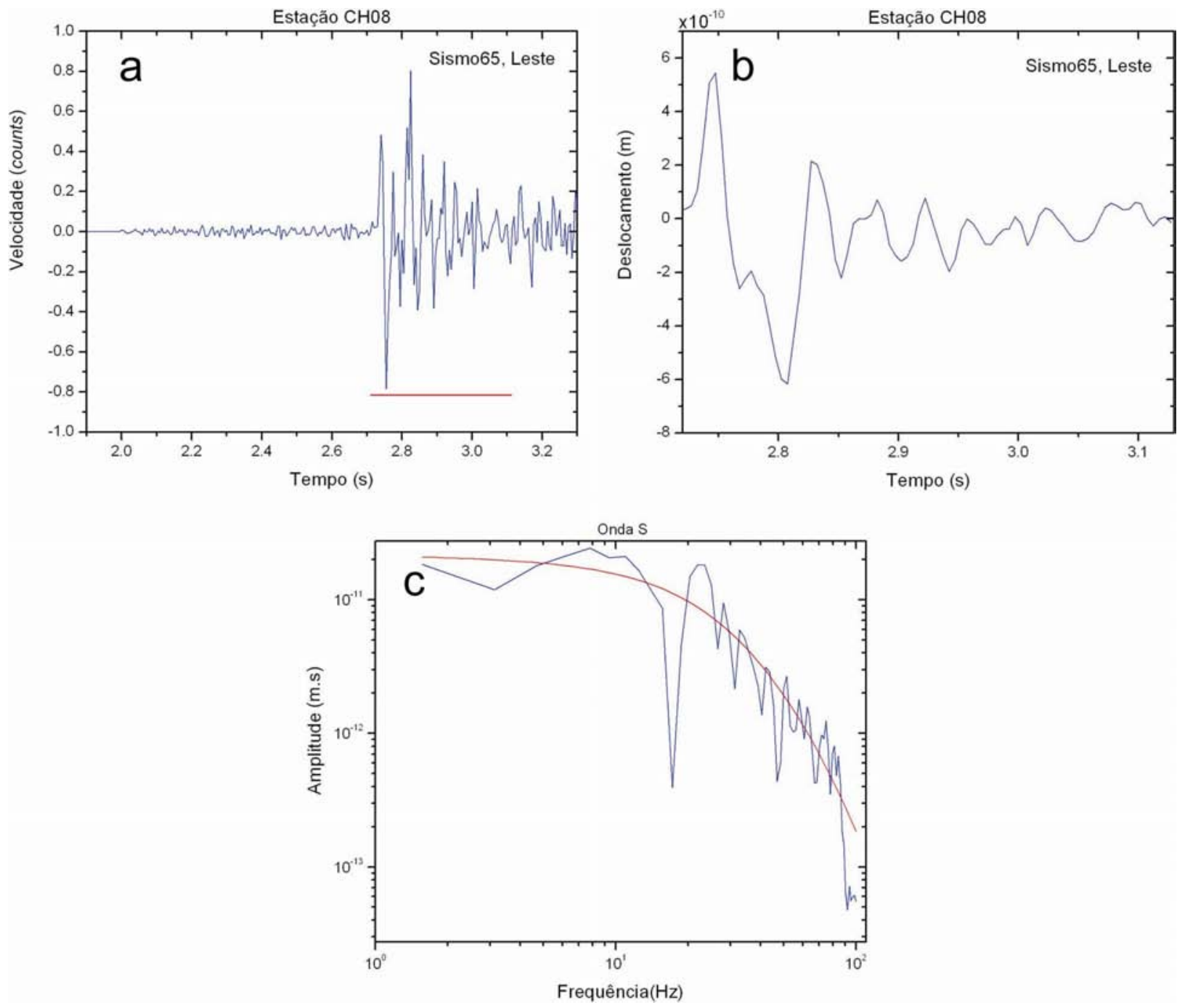

Figura B. 4: a) $\mathrm{O}$ intervalo da onda $\mathrm{S}$ utilizado para determinar os parâmetros de fonte está representado pela linha vermelha. b) Intervalo anterior após ter a resposta do equipamento removida e ser integrado no tempo. c) Espectro de deslocamento do intervalo da onda $\mathrm{S}$ (linha azul) após aplicar a Transformada de Fourier e ajustar o espectro (linha vermelha) através da equação (3.3). 

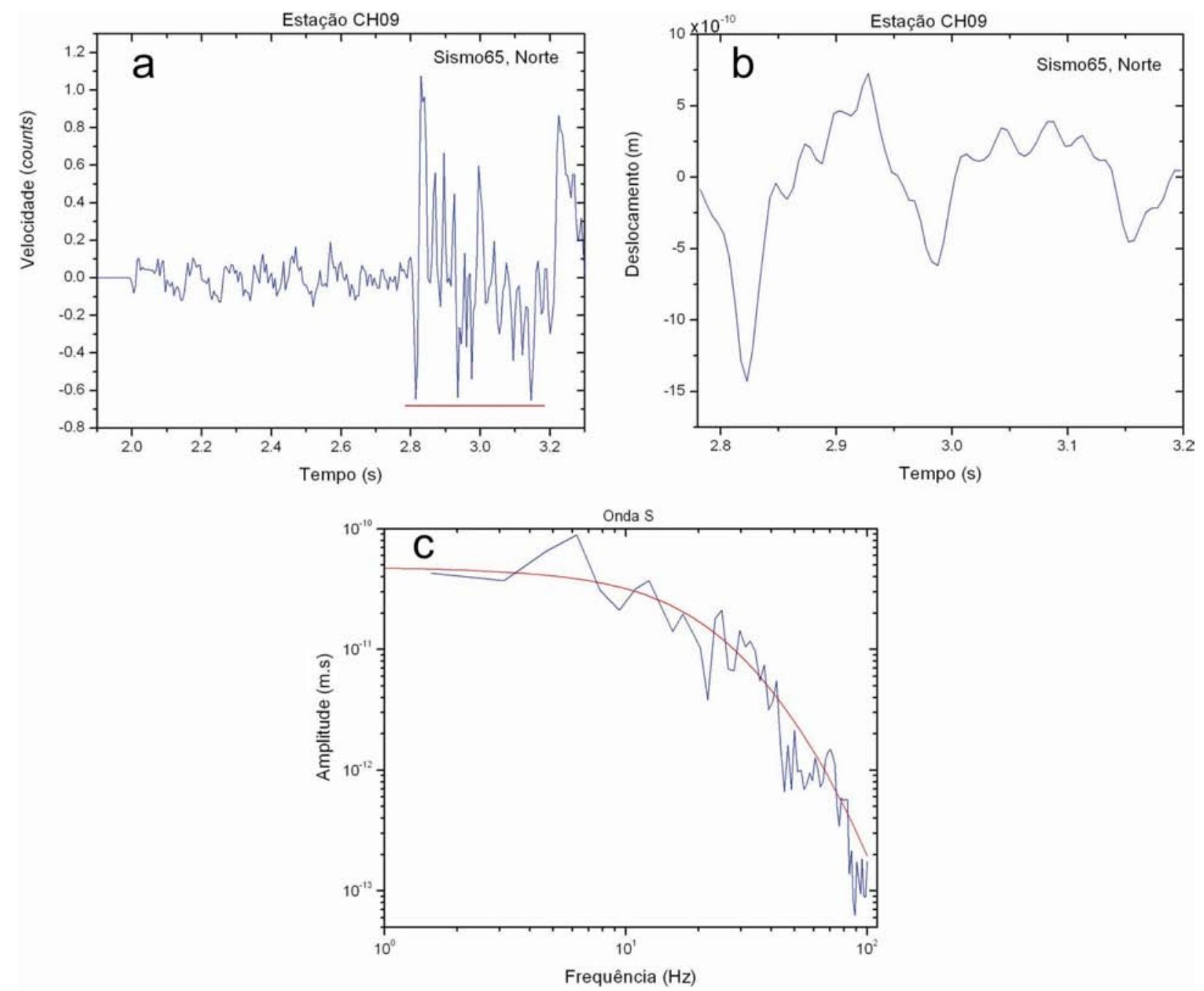

Figura B. 5: a) $\mathrm{O}$ intervalo da onda $\mathrm{S}$ utilizado para determinar os parâmetros de fonte está representado pela linha vermelha. b) Intervalo anterior após ter a resposta do equipamento removida e ser integrado no tempo. c) Espectro de deslocamento do intervalo da onda S (linha azul) após aplicar a Transformada de Fourier e ajustar o espectro (linha vermelha) através da equação (3.3). 

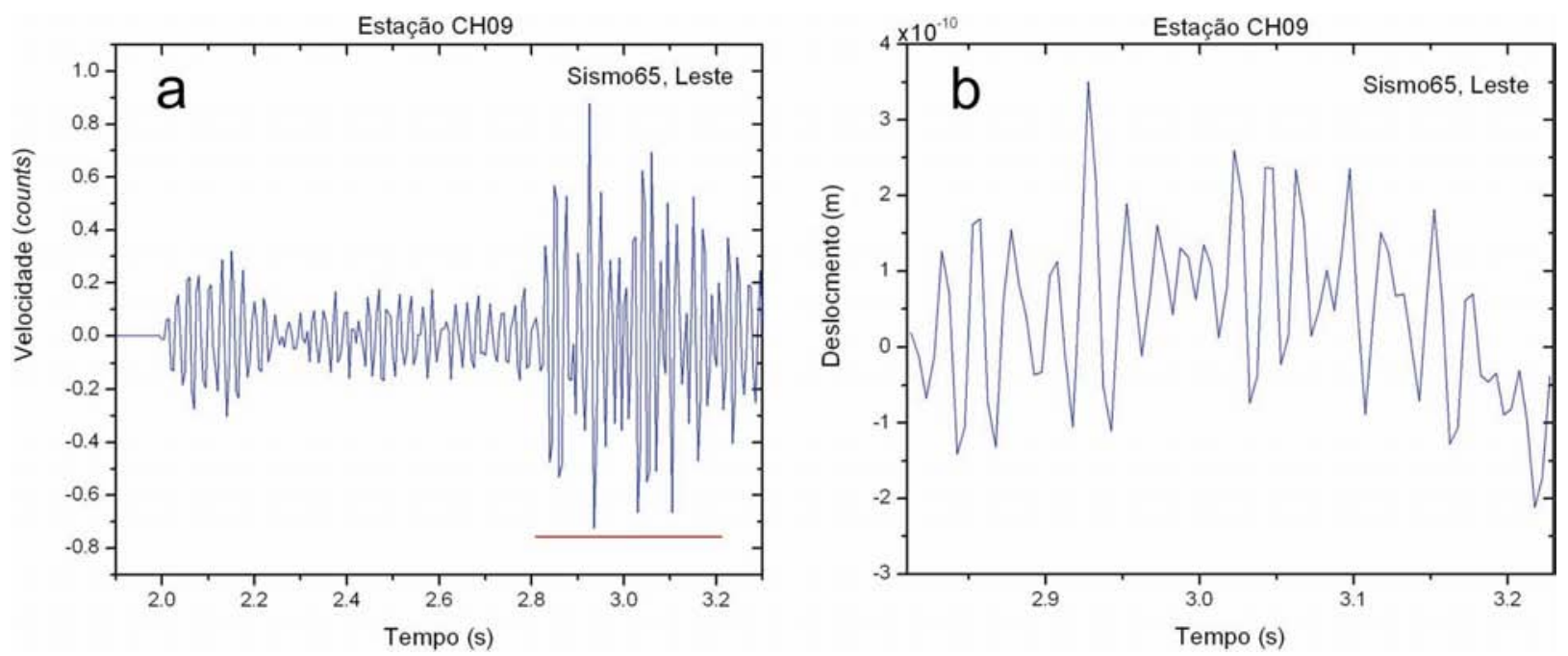

Figura B. 6: a) O intervalo da onda S utilizado para determinar os parâmetros de fonte está representado pela linha vermelha. b) Intervalo anterior após ter a resposta do equipamento removida e ser integrado no tempo. 

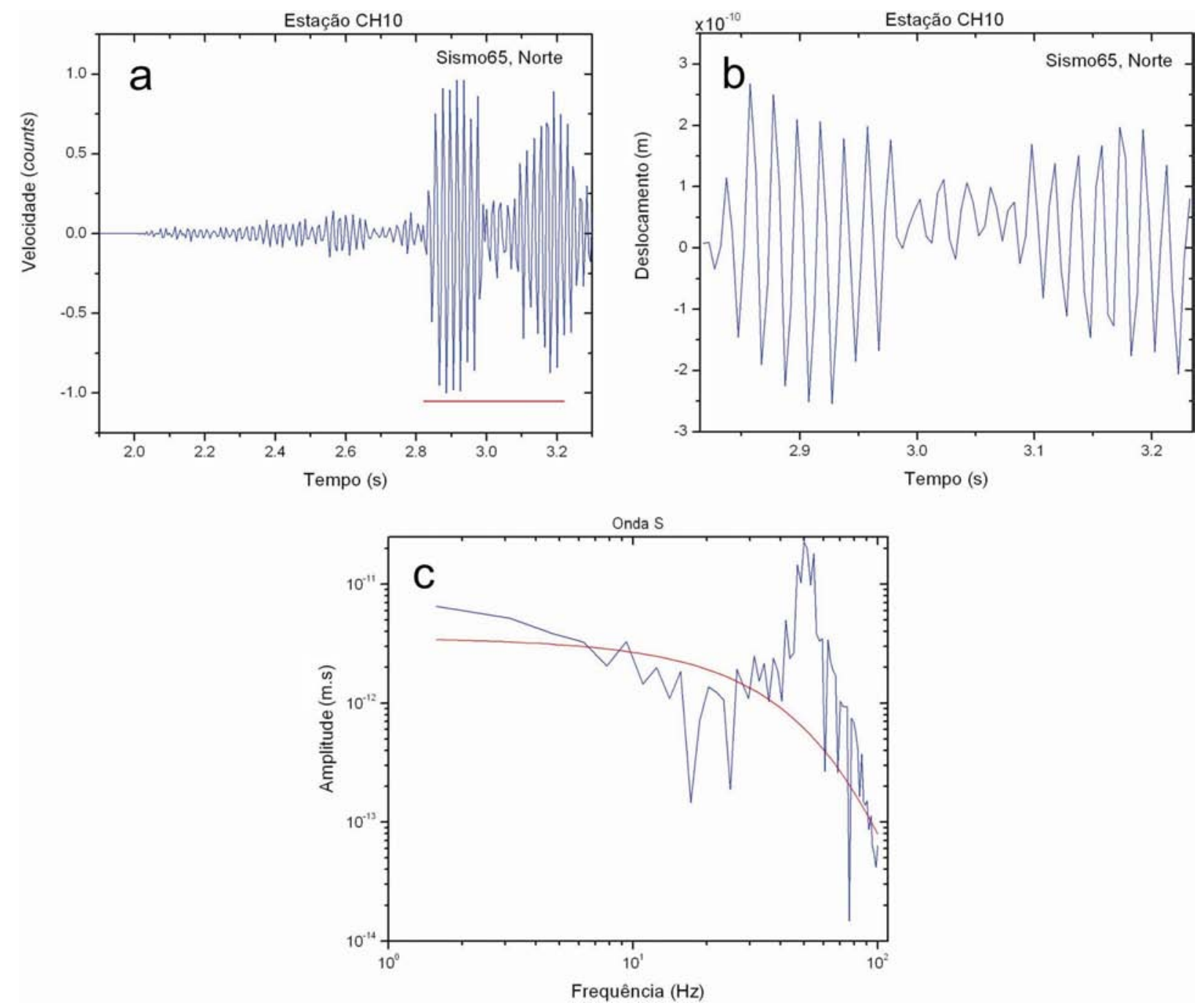

Figura B. 7: a) $\mathrm{O}$ intervalo da onda $\mathrm{S}$ utilizado para determinar os parâmetros de fonte está representado pela linha vermelha. b) Intervalo anterior após ter a resposta do equipamento removida e ser integrado no tempo. c) Espectro de deslocamento do intervalo da onda S (linha azul) após aplicar a Transformada de Fourier e ajustar o espectro (linha vermelha) através da equação (3.3). 

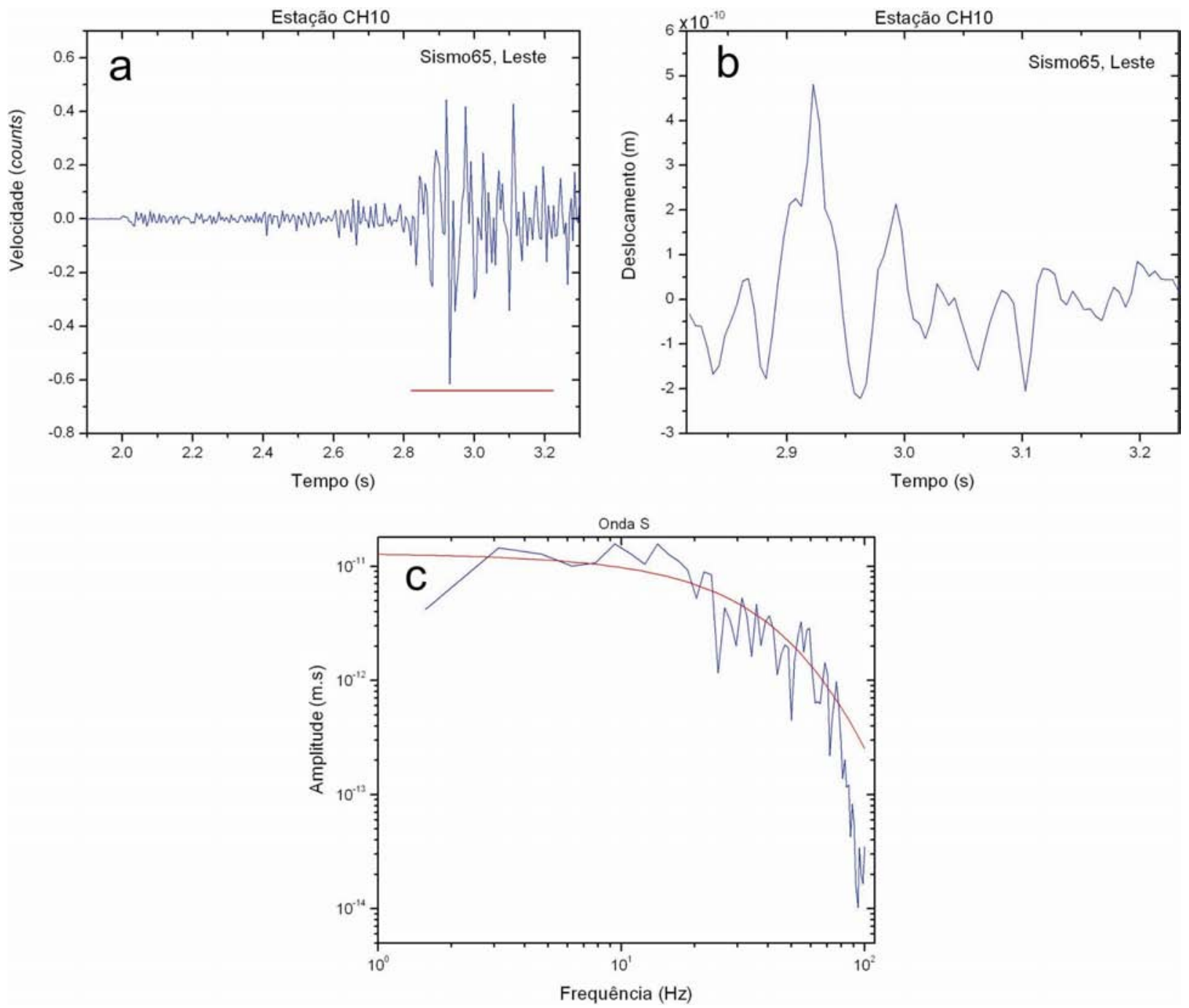

Figura B. 8: a) $\mathrm{O}$ intervalo da onda $\mathrm{S}$ utilizado para determinar os parâmetros de fonte está representado pela linha vermelha. b) Intervalo anterior após ter a resposta do equipamento removida e ser integrado no tempo. c) Espectro de deslocamento do intervalo da onda S (linha azul) após aplicar a Transformada de Fourier e ajustar o espectro (linha vermelha) através da equação (3.3). 

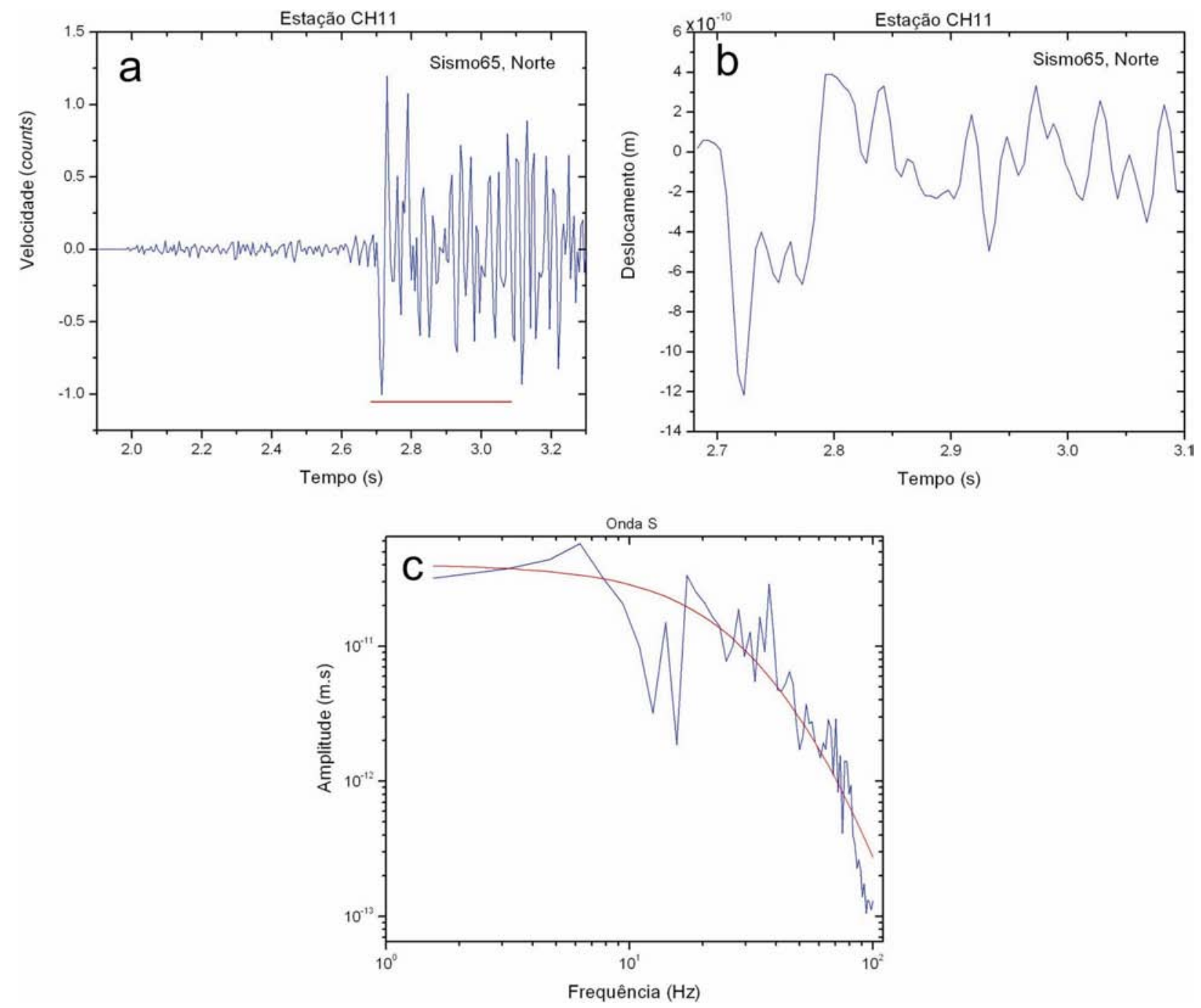

Figura B. 9: a) O intervalo da onda S utilizado para determinar os parâmetros de fonte está representado pela linha vermelha. b) Intervalo anterior após ter a resposta do equipamento removida e ser integrado no tempo. c) Espectro de deslocamento do intervalo da onda $\mathrm{S}$ (linha azul) após aplicar a Transformada de Fourier e ajustar o espectro (linha vermelha) através da equação (3.3). 

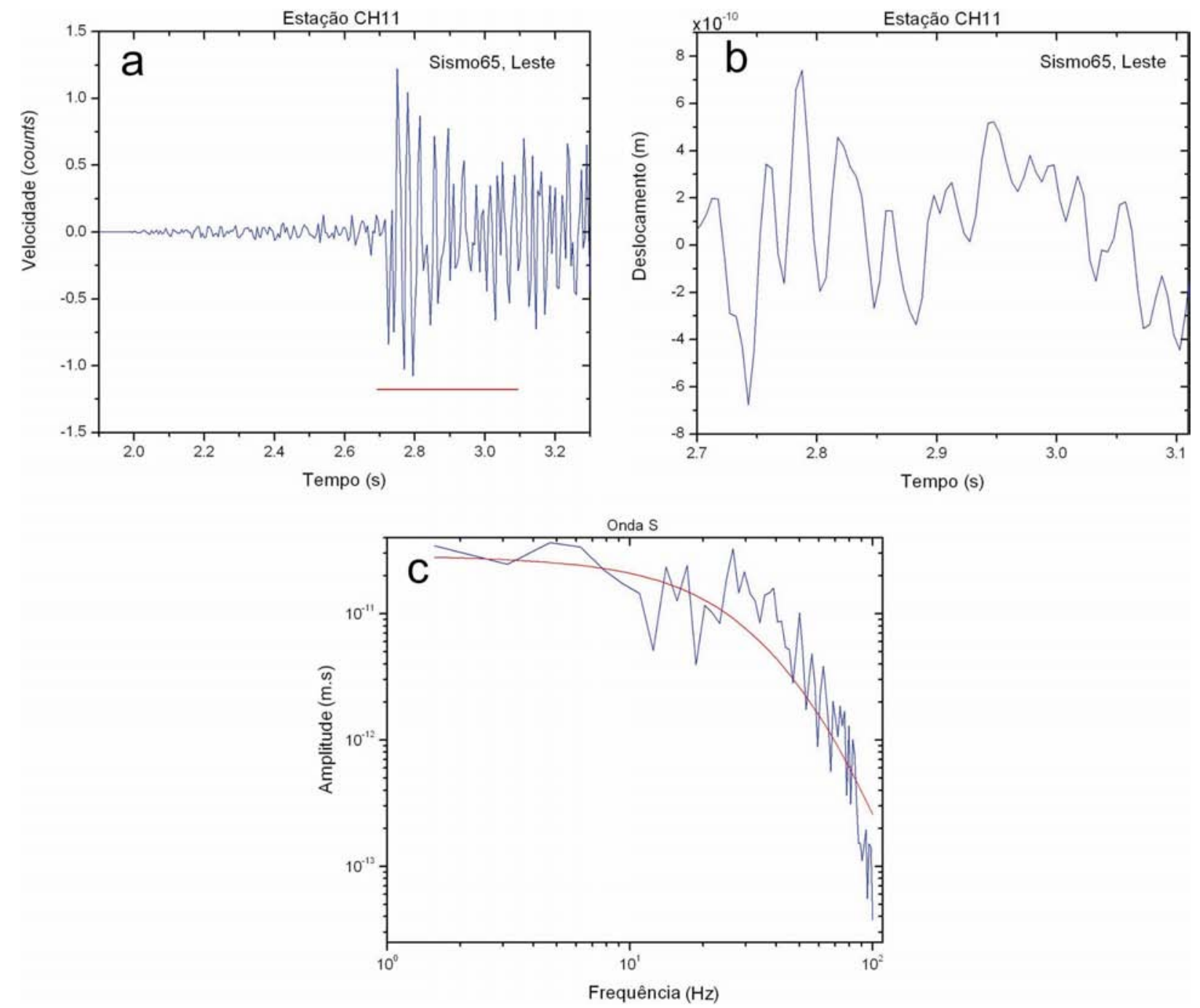

Figura B. 10: a) O intervalo da onda $\mathrm{S}$ utilizado para determinar os parâmetros de fonte está representado pela linha vermelha. b) Intervalo anterior após ter a resposta do equipamento removida e ser integrado no tempo. c) Espectro de deslocamento do intervalo da onda S (linha azul) após aplicar a Transformada de Fourier e ajustar o espectro (linha vermelha) através da equação (3.3). 

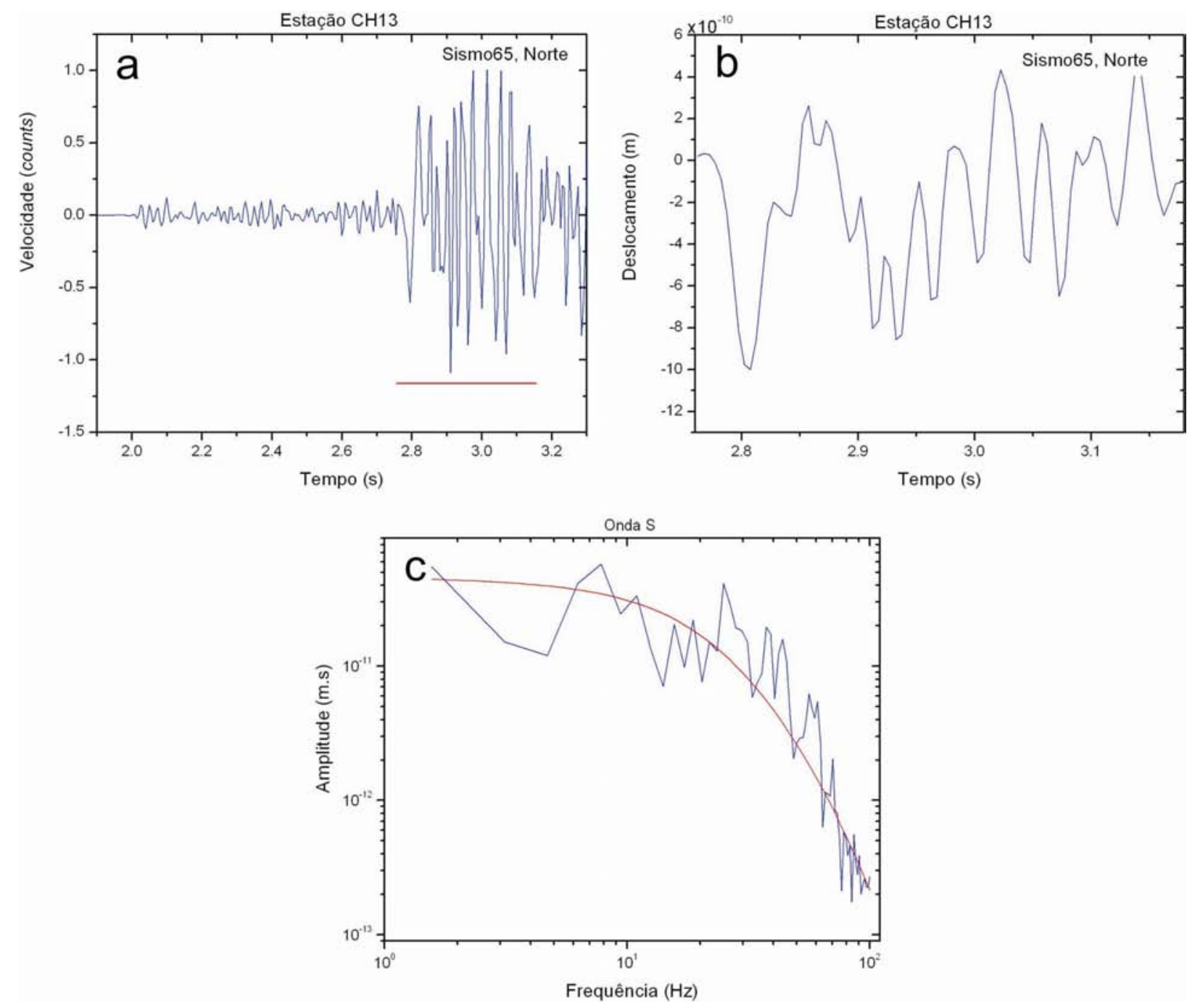

Figura B. 11: a) O intervalo da onda $\mathrm{S}$ utilizado para determinar os parâmetros de fonte está representado pela linha vermelha. b) Intervalo anterior após ter a resposta do equipamento removida e ser integrado no tempo. c) Espectro de deslocamento do intervalo da onda S (linha azul) após aplicar a Transformada de Fourier e ajustar o espectro (linha vermelha) através da equação (3.3). 

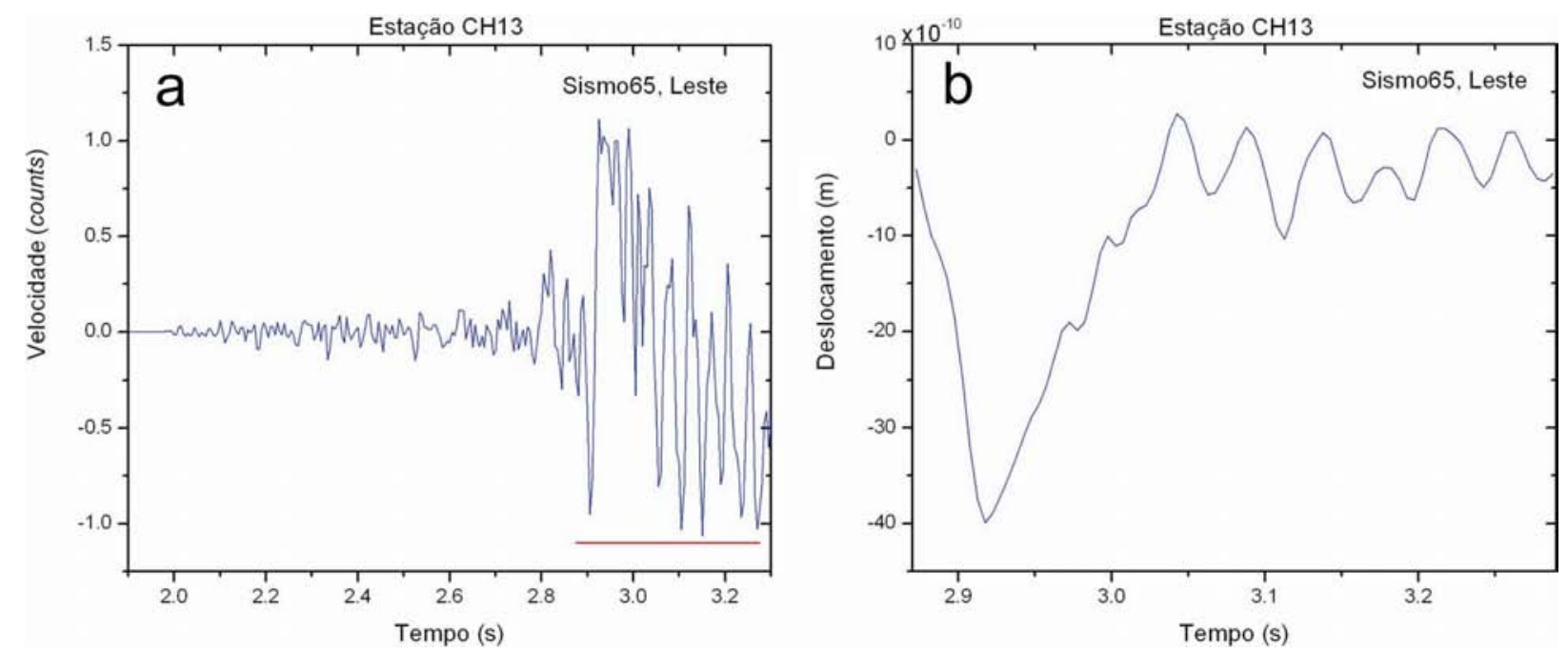

Figura B. 12: a) O intervalo da onda $\mathrm{S}$ utilizado para determinar os parâmetros de fonte está representado pela linha vermelha. b) Intervalo anterior após ter a resposta do equipamento removida e ser integrado no tempo. 


\section{APÊNDICE C}

\section{RESULTADO FINAL DOS PARÂMETROS DE FONTE DOS 21 SISMOS UTILIZADOS NESTE TRABALHO}




\begin{tabular}{|c|c|c|c|c|c|c|c|c|c|}
\hline & & \multicolumn{2}{|c|}{ Modelo de Brune } & \multicolumn{2}{|c|}{ Modelo de Madariaga } & & \\
\hline Sismo & $M_{0}\left(x 10^{12} N \cdot m\right)$ & $r(m)$ & $\Delta \sigma_{\mathrm{e}}(\mathrm{MPa})$ & $r(m)$ & $\Delta \sigma_{\mathrm{e}}(\mathrm{MPa})$ & $\mathrm{E}_{\mathrm{S}}(\mathrm{J})$ & $\Delta \sigma_{\mathrm{a}}(\mathrm{MPa})$ & $M_{W}$ & $m_{b}$ \\
\hline 1 & $2,8 \mathrm{E}+12$ & 37 & 24,9 & 21 & 138,5 & $4,6 \mathrm{E}+07$ & 0,54 & 2,3 & 1,6 \\
\hline 5 & $8,3 \mathrm{E}+10$ & 33 & 1,6 & 19 & 9,1 & $1,1 \mathrm{E}+06$ & 1,15 & 1,2 & 0,7 \\
\hline 15 & $7,5 \mathrm{E}+11$ & 43 & 7,5 & 24 & 41,7 & $2,3 \mathrm{E}+06$ & 0,09 & 1,9 & 1,2 \\
\hline 17 & $4,3 \mathrm{E}+11$ & 36 & 5,9 & 20 & 49,0 & $1,4 \mathrm{E}+06$ & 0,11 & 1,7 & 0,9 \\
\hline 20 & $6,0 \mathrm{E}+11$ & 36 & 15,0 & 20 & 83,2 & $4,8 \mathrm{E}+06$ & 0,28 & 1,8 & 1,2 \\
\hline 21 & $2,6 \mathrm{E}+11$ & 31 & 3,9 & 17 & 21,5 & $1,1 \mathrm{E}+06$ & 0,13 & 1,6 & 1,1 \\
\hline 24 & $2,4 \mathrm{E}+12$ & 39 & 28,9 & 22 & 160,8 & $5,6 \mathrm{E}+07$ & 0,63 & 2,2 & 1,5 \\
\hline 30 & $8,1 \mathrm{E}+10$ & 25 & 2,4 & 14 & 13,3 & $1,8 \mathrm{E}+05$ & 0,08 & 1,2 & 0,8 \\
\hline 36 & $2,1 \mathrm{E}+11$ & 29 & 4,1 & 17 & 22,9 & $6,4 \mathrm{E}+05$ & 0,10 & 1,5 & 1,2 \\
\hline 54 & $5,0 \mathrm{E}+11$ & 24 & 15,1 & 14 & 84,2 & $2,7 \mathrm{E}+05$ & 0,02 & 1,8 & 1,3 \\
\hline 59 & $6,1 \mathrm{E}+11$ & 29 & 12,7 & 16 & 70,4 & $6,0 \mathrm{E}+06$ & 0,37 & 1,8 & 1,5 \\
\hline 62 & $9,6 \mathrm{E}+11$ & 52 & 4,1 & 29 & 22,9 & $4,2 \mathrm{E}+06$ & 0,13 & 1,9 & 1,3 \\
\hline 65 & $4,4 \mathrm{E}+12$ & 34 & 58,8 & 19 & 326,8 & $2,5 \mathrm{E}+08$ & 2,27 & 2,4 & 2,1 \\
\hline
\end{tabular}

Tabela C.1: Resultado final dos parâmetros de fonte dos 21 sismos utilizados. 


\begin{tabular}{|c|c|c|c|c|c|c|c|c|c|}
\hline & & \multicolumn{2}{|c|}{ Modelo de Brune } & \multicolumn{2}{|c|}{ Modelo de Madariaga } & & \\
\hline Sismo & $M_{0}\left(x 10^{12} N \cdot m\right)$ & $r(m)$ & $\Delta \sigma_{\mathrm{e}}(\mathrm{MPa})$ & $r(m)$ & $\Delta \sigma_{\mathrm{e}}(\mathrm{MPa})$ & $\mathrm{E}_{\mathrm{S}}(\mathrm{J})$ & $\Delta \sigma_{\mathrm{a}}(\mathrm{MPa})$ & $M_{W}$ & $m_{b}$ \\
\hline 66 & $6,5 \mathrm{E}+11$ & 40 & 3,3 & 30 & 18,4 & $2,8 \mathrm{E}+06$ & 0,12 & 1,8 & 1,2 \\
\hline 69 & $1,9 \mathrm{E}+12$ & 72 & 4,7 & 41 & 26,1 & $7,9 \mathrm{E}+06$ & 0,12 & 2,1 & 1,6 \\
\hline 71 & $6,8 \mathrm{E}+11$ & 39 & 9,1 & 22 & 33,7 & $8,0 \mathrm{E}+06$ & 0,55 & 1,8 & 1,3 \\
\hline 76 & $3,1 \mathrm{E}+11$ & 25 & 9,2 & 14 & 51,2 & $2,0 \mathrm{E}+06$ & 0,20 & 1,6 & 1,0 \\
\hline 83 & $2,6 \mathrm{E}+12$ & 45 & 14,1 & 25 & 78,2 & $3,7 \mathrm{E}+07$ & 0,35 & 2,2 & 1,4 \\
\hline 85 & $9,3 \mathrm{E}+11$ & 37 & 8,3 & 21 & 46,2 & $5,4 \mathrm{E}+06$ & 0,17 & 1,9 & 1,3 \\
\hline 86 & $1,2 \mathrm{E}+12$ & 38 & 15,8 & 21 & 87,6 & $1,3 \mathrm{E}+07$ & 0,33 & 2,0 & 1,3 \\
\hline 92 & $2,8 \mathrm{E}+12$ & 42 & 27,1 & 24 & 150,6 & $1,1 \mathrm{E}+08$ & 0,98 & 2,2 & 1,6 \\
\hline
\end{tabular}

Tabela C.2: Continuação da Tabela C.1. 
